\title{
ESTUDO SOBRE A EXPOSIÇÃO COMBINADA ENTRE RUÍDO E VIBRAÇÃO DE CORPO INTEIRO E OS EFEITOS NA AUDIÇÃO DE TRABALHADORES
}

\section{LUIZ FELIPE SILVA}

Tese de Doutorado apresentada ao Departamento de Saúde Ambiental da Faculdade de Saúde Pública da Universidade de São Paulo para a obtenção do Grau de Doutor.

Área de concentração:

Saúde Ocupacional

ORIENTADOR: PROF. DR. RENÉ MENDES

São Paulo

2002 
Autorizo, exclusivamente para fins acadêmicos e científicos, a reprodução total ou parcial desta tese, por processos fotocopiadores. Assinatura:

Data: 
Aos meus pais, Lydia Carletti Silva e Adelmo Silva. (in memoriam) 
"So depois de haver conhecido a superficle cas coisas é que se pode proceder à busca daquilo que está embaixo. Mas a superficie das corsas é inexaurivel." (CALVINO 1994, p.52) 


\section{AGRADECIMENTOS}

Ao Prof. Dr. RENE MENDES, por acreditar, estimular e pelo imenso apoio.

AOs professores ANTONIO REGGIANI e IOLE PINTO pela solidariedade manifesta no esforço para contribuir para a realização da avaliação de exposição à vibração e ao Prof. MASSIMO BOVENZI pelo gentil auxilio, com valiosas sugestões, na análise de regressão.

A Prof.a. Dra. MARIA REGINA ALVES CARDOSO por indicar rumos seguros na análise de regressão.

As fonoaudiólogas CAROLINA MOURA DE SOUZA, DEOLINDA DO CARMO DE JESUS, ELLEN REGINA SOLA, PAULA ASCENCIO FERRAZ, SIMONE ALVES DOS SANTOS por conduzirem com segurança e profissionalismo as avaliaçōes audiológicas e, em especial, à MÁRCIA TIVERON DE SOUZA.

Aos promotores de justiça JORGE LUIZ USSIER e CARLOS ALBERTO SALLES pelo sustentáculo para a execução do trabalho.

Ao CEREST-SP, representado pela coordenadora MARIA MAENO, pela cessão de sua estrutura para o desenvolvimento da pesquisa.

À minha esposa ANA e à minha filha BEATRICE pela tolerância e compreensão.

À colega TERESA CRISTINA MACHADO pelos comentários e sugestões pertinentes. 


\section{INDICE}

1. INTRODUÇÃO

1.1 Aspectos sobre vibração de corpo inteiro 1

1.1.1 Magnitude 2

1.1.2 Freqüência 3

1.1.3 Direção 5

1.1.4 Normalização 7

1.2 Avaliação de vibração 10

1.2.1 Critérios 12

1.3 Exemplos de avaliação de vibração de corpo inteiro 15

1.3.1 A importância do assento

1.4 Revisão da literatura - Estudos epidemiológicos 20

1.4.1 Lombalgia e distúrbios na coluna 20

1.5 Aspectos sobre exposição ao ruido 30

1.5.1 Fontes de ruido em um veículo a diesel 33

1.6 Influência do ruido sobre as condições de trabalho entre 34 motoristas

1.7 Pesquisas em nivel nacional 37

1.8 Estudos que se utilizam de regressão logistica para 39 estudar as causas de perda auditiva

1.9 Estudos sobre exposições combinadas 41

1.10 Estudos sobre vibração de corpo inteiro em nivel 49 nacional

2. OBJETIVOS 50

3. MATERIAL EMÉTODOS 51

3.1 População do estudo 51

3.2 Avaliação da exposição ao ruido 54

3.2.1 Grandezas empregadas 55

3.2.2 Exemplo de cálculo do nivel de exposição - Lex: 57

3.2.3 Avaliação do erro estatístico 60

3.2.4 Dimensionamento da amostra de medidas para a 62 avaliação de exposição ao ruido 
3.2.5 Cálculo do nivel de imissão sonora 64

3. 3 Avaliação da exposição à vibração de corpo inteiro 65

3.4 Questionário $\quad 68$

3.5 Questōes éticas $\quad 70$

3.6 Avaliação audiológica $\quad 71$

3. 7 Análise dos dados 81

4. RESULTADOS 83

4.1 Característica da frota 83

4.2 Avaliação de exposição ao ruido 87

4.3 Avaliação da vibração de corpo inteiro 97

4.4 Avaliação audiológica 101

4.5 Caracteristicas fundamentais da população de 105 condutores analisada

4.6 Análise por regressāo logística 109

5. DISCUSSĀO 135

5.1 Aspectos sobre a exposição ao ruido 135

5.2 Aspectos sobre a exposição à vibração 139

5.3 Meios de prevenção 142

5.3.1 Contribuição da normalização 144

5.4 Aspectos sobre a avaliação audiológica 148

5.5 Discussões finais $\quad 150$

6. CONCLUSÃO 155

7. REFERÊNCIAS BIBLIOGRÁFICAS 158

Anexos - Questionário aplicado, listas de simbolos e abreviaturas e resultados dos exames audiométricos 


\section{Resumo}

Silva LF. Estudo sobre a exposição combinada entre ruido e vibração de corpo inteiro e os efeitos na audição de trabalhadores. São Paulo; 2001. [Tese de Doutorado - Faculdade de Saúde Pública da USP].

Objetivos. Este estudo, de caracteristica transversal, se propôs a quantificar a exposição de motoristas de ônibus à vibração de corpo - inteiro (VCI) e ao ruído, a analisar a possivel associação entre estes dois agentes para 0 desenvolvimento de perda auditiva induzida por ruido (PAIR) e a discutir meios possiveis de prevenção. Métodos. Uma população constituida por 141 motoristas de ônibus de uma empresa da cidade de São Paulo foi analisada. A taxa de prevalência de PAIR foi obtida através de avaliação audiológica empregando-se o critério de MERLUZZI e col. (1979). Os grupos, exposto e de referência, foram determinados internamente por meio de estratificação em relação ao tempo de trabalho acumulado na empresa como motorista. Um questionário foi aplicado com o fim de recuperar 0 histórico ocupacional e obter informações de interesse do estudo. A metodologia de avaliação de exposição ao ruido fundamentou-se nas diretrizes estabelecidas pela ISO - 1999 (1990) e pela Diretiva da Comunidade Econômica Européia (1986). A avaliação de exposição à VCl obedeceu os principios definidos pela ISO - 2631(1985). Empregou-se a técnica de regressão logística multivariada não condicional para descrever a associação entre a variável dependente e 0 conjunto de variáveis explanatórias. Resultados. Foi registrado um nivel de exposição semanal de $83,6 \pm 1,9 \mathrm{~dB}(\mathrm{~A})$ para os motoristas condutores de ônibus com motor localizado na seção dianteira e de $77,0 \pm 1,1 \mathrm{~dB}(\mathrm{~A})$ para os que operam os veículos com motor na seção traseira. $O$ valor médio do niveł equivalente (Leq) no posto de trabalho dos motoristas de ônibus com motor na seção dianteira foi de $83,1 \pm 1,9 \mathrm{~dB}(\mathrm{~A})$, enquanto que para os modelos com motor na traseira, este valor foi de $76,2 \pm 1,7 \mathrm{~dB}(\mathrm{~A})$, indicando uma diferença 
estatisticamente significante. O valor médio da aceleração da vibração, obtida nos cinco modelos de ônibus, ponderado por número e tempo de uso dos veículos, foi de $0,85 \mathrm{~m} / \mathrm{s}^{2}$. As taxas de prevalência de PAIR foram de $46 \%$ e de $24 \%$ para os grupos exposto e de referência respectivamente. $\mathrm{Na}$ análise univariada, a Razão de Chances (RC) de prevalência de PAIR foi de 2,68 , com intervalo de confiança de $95 \%=1,31-5,48$, para o grupo exposto comparando-se com o de referência. O modelo mais ajustado, resultante da análise multivariada, apontou a idade superior ou igual a 44 anos $(\mathrm{RC}=$ $2,54 ; \mathrm{IC} 95 \%=1,15-5,62) ;$ o histórico de diabetes $(\mathrm{RC}=5,46 ; \mathrm{IC} 95 \%=$ $0,95-31,4)$ e o nível de imissão sonora igual ou acima de $86,8 \mathrm{~dB}(\mathrm{~A})(\mathrm{RC}=$ $2,76 ; 1 C 95 \%=1,24-6,15)$ como os fatores de risco mais relevantes para 0 desenvolvimento de PAIR. Exposição à VCl, representada como dose, não apresentou significância. Conclusões. Os motoristas de ônibus da população analisada estão expostos a niveis de $\mathrm{VCl}$ relevantes, que superam os limites de exposição definidos pela ISO-2631(1985). Os veículos dotados de motor na seção dianteira apresentaram niveis de ruido mais importantes do que aqueles com motor na traseira. Não foi observada associação entre exposição à VCl e PAIR, nem interação com a exposição ao ruído. No entanto, outros modelos de regressão logística analisados sugerem a possibilidade de associação de PAIR com $\mathrm{VCl}$, recomendando a necessidade de estudos posteriores.

Descritores: Vibração de corpo inteiro. Ruido. Exposições combinadas. Motoristas. Ónibus. 


\section{SUMMARY}

SILVA LF Estudo sobre a exposição combinada entre ruído e vibração de corpo inteiro e os efeitos na audição de trabalhadores. [Study on combined exposure to noise and whole-body vibration and its effects on workers' hearing]. São Paulo; 2001. [Tese de Doutorado - Faculdade de Saúde Pública da USP].

Objectives. The purposes of this study, a cross-sectional one, were defined as a quantitative assessment of occupational exposure to noise and wholebody vibration (WBV); an analysis on the possibility of an association between these two hazards in the production of noise-induced hearing loss (NIHL); and, a discussion on feasible means of prevention.

Methods. This cross-sectional study was carried out in a population of 141 bus drivers of the City of São Paulo. The prevalence of noise-induced hearing loss (NIHL) was established through an audiometric examination of all workers. The audiograms were classified according to audiometric criteria formulated by Merluzzi and cols. (1979). The whole group of bus drivers was classified and stratified internally in sub-groups of "exposed" and "controls", according to the cumulated length of working time as bus driver. A questionnaire was designed and applied in order to retrieve the occupational history and other relevant information. The methodology for noise exposure evaluation was based on the procedures established in the international standard ISO 1999 (1990), as well as in the European Economic Community (EEC) Directive (1986). The methodology for whole-body vibration (WBV) exposure evaluation was based on the principles established in the international standard ISO 2631 (1985). The association between the dependent variable and the set of explanatory variables was analyzed through the technique of non-conditional multivariable logistic regression.

Outcomes. It was found that these bus drivers were exposed to noise levels of $83.6 \pm 1.9 \mathrm{~dB}(\mathrm{~A})$ (week average) in buses with front engines; bus drivers that work in buses with rear engines were exposed to noise levels of $77.0 \pm$ $1.1 \mathrm{~dB}(\mathrm{~A})$. Also, the average of noise exposure equivalents $\left(L_{\mathrm{Aeq}}\right)$ for bus 
drivers in front-engines buses was $83.1 \pm 1.9 \mathrm{~dB}(\mathrm{~A})$, whereas the average $L_{A e q}$ for drivers of rear-engine buses was $76.2 \pm 1.7 \mathrm{~dB}(\mathrm{~A})$. This difference was statistically significant. The average of the vibration acceleration found in the five different bus types analyzed, weighted according to the number and length of use of vehicles, was $0.85 / \mathrm{m}^{2}$. The NIHL prevalence rates were $46 \%$ and $24 \%$ for the "exposed" group and the "reference" group, respectively. It was found that the odds ratio (OR) for NIHL prevalence, according to the univariable analysis, was 2.68 (1,31-5.48, for a $95 \%$ confidence interval) for the "exposed" group, when compared with the referrals. For the best adjusted model, the multivariable analysis has shown that age (44 years old or more), reference to diabetes, and level of noise exposure (above $86.8 \mathrm{~dB}(\mathrm{~A})$ ) were risk factors, relevant for the development of NIHL. Exposure to WBV, when represented by doses, was not significant for NIHL development.

Conclusions. The bus drivers analyzed in this cross-sectional study were exposed to relevant WBV levels, higher than the permissible exposure levels established by the international standard ISO 2631 (1985). Also, the noise exposure levels found at the drivers' work-posts in front-engine buses were higher than the noise exposure levels observed at the drivers' work-posts in rearengine buses. No association between WBV exposure and NIHL prevalence was observed in this study. Also, this study could not found any interaction between WBV exposure and noise exposure. However, further studies are required, because other logistic regresion models were analyzed, showing that an association between WBV and NIHL could occur, thus aggravating the potential risk of adverse health effects to workers.

Descriptors: whole-body vibration; noise; combined exposures; noiseinduced hearing loss; buses; drivers. 


\section{INTRODUÇÃO}

\subsection{Aspectos sobre vibração de corpo inteiro}

Vibração de corpo inteiro (VCI) é um estímulo freqüentemente presente em muitas realidades de trabalho, expondo trabalhadores $\mathrm{em}$ diversas operações e situações: indủstria da construção civil (máquinas de movimentação de terra em geral como motoniveladoras, pá carregadeiras, tratores de esteira); indústria do transporte (caminhões, ônibus, motocicletas, veículos em geral); transporte ferroviário (trens, metrô); equipamentos industriais (ponte-rolante, empilhadeira); máquinas agricolas (tratores, colheitadeiras); helicópteros; embarcações e veículos fora-de-estrada usados em mineração.

Há, aproximadamente, sete milhões de trabalhadores nos Estados Unidos expostos à vibração de corpo inteiro, envolvidos na operação dos veiculos e máquinas referidos acima. (WASSERMAN e col. 1997). Portanto, constitui-se como um fator de risco ocupacional de importância, uma vez que atinge diversas categorias de trabalhadores. Conforme estimativas elaboradas em alguns paises europeus, aproximadamente 4 a $7 \%$ da força de trabalho estão expostos potencialmente à $\mathrm{VCl}$ em niveis considerados de risco à saúde (CEN 1996).

Uma ampla estimativa de prevalência de exposição foi conduzida na Grã-Bretanha, utilizando como instrumento de coleta de dados um questionário enviado pelo correio. Cerca de 7,2 milhōes de homens e 1,8 milhōes de mulheres são expostas à $\mathrm{VCl}$ no trabalho em um periodo de uma semana (PALMER e col. 2000a).

A discussão a respeito dos conceitos fundamentais sobre a vibração do corpo inteiro é também conduzida por GRIFFIN (1990b), que acrescenta 
às definições particulares, uma abordagem sobre os efeitos causados pela exposição, bem como os métodos de medida.

Desse modo, como no caso da localizada, há quatro variáveis fundamentais que caracterizam ou estão envolvidas na avaliação da vibração, a saber: magnitude da vibração; freqüência; direção e duração.

\subsubsection{Magnitude:}

Iniciou-se a discussão sobre o primeiro tópico que se refere à magnitude da vibração que pode ser expressa em $\mathrm{m} / \mathrm{s}^{2}$.

A magnitude do deslocamento provocado pela vibração e visualmente perceptivel não se configura como um indicador de gravidade da vibração (GRIFFIN 1990a).

A faixa de magnitudes de aceleração concernente à vibração de corpo inteiro oscila entre 0,01 a $10 \mathrm{~m} / \mathrm{s}^{2}$ (valor de pico). Para determinadas situações a aceleração [root mean square - r.m.s.] ponderada em freqüência comporta-se como um indicador adequado para estimar-se a gravidade da exposição. Valor da dose de vibração [vibration dose value - VDV] é definido por GRIFFIN (1990a) como o método mais consistente para se estimar a gravidade da exposição à vibração com diversas características (estacionária, aleatória, com choques). A forma de cálculo de VDV será abordada mais adiante, no tópico sobre normalização.

Conforme GRIFFIN (1990a), vibração de corpo inteiro com aceleração de $10 \mathrm{~m} / \mathrm{s}^{2}$ r.m.s. pode ser classificada como de risco, e uma magnitude da ordem de $1 \mathrm{~m} / \mathrm{s}^{2}$ r.m.s. é capaz de assumir a mesma característica dependendo da direcão. duracão e freqüência. 


\subsubsection{Freqüência:}

BENEDETTO e col. (1986) para mais bem elucidar a importância da variável freqüência, dividem-na em três zonas:

Abaixo de dois $\mathrm{Hz}$ : nesta faixa o corpo humano responde como uma massa homogênea, e os efeitos relacionados ao "mal de transporte" são proporcionais à energia recebida;

Entre dois e $80 \mathrm{~Hz}$ : a musculatura voluntária não consegue mais controlar os movimentos oscilatórios das várias partes do corpo, que não se comporta mais como uma estrutura única, mas sim como um conjunto de massas suscetiveis de movimento relativo, associadas entre elas por estruturas elásticas viscosas. Além disso cada componente reage de modo diferente de acordo com sua característica de massa, freqüência, etc.

Acima de $80 \mathrm{~Hz}$ : o movimento vibratório nesta faixa é amortecido facilmente pelo corpo.

Cada órgão e tecido possui uma freqüência natural, que quando se submete a um estímulo provocado pela vibração de frequeência equivalente, gera o fenômeno denominado de ressonância. $O$ autor classifica o campo de freqüência compreendido entre um e $100 \mathrm{~Hz}$, como o sendo de mais elevado risco ao trabalhador (BENEDETTO e col. 1986). Checcacci, citado por BENEDETTO e col. (1986, p. 235), fornece as freqüências de ressonância para alguns órgãos do corpo humano.

\footnotetext{
1 Vômito, náusea ou mal-estar provocado por sensação ou por movimento real do corpo ou de seu contorno (GRIFFIN 1990a).
} 
Tabela 1.1 Freqüências de ressonância para alguns órgãos do corpo humano.

\begin{tabular}{|c|c|}
\hline $\begin{array}{l}\text { Freqüência } \\
(\mathrm{Hz})\end{array}$ & Efeitos \\
\hline 2 & $\begin{array}{l}\text { Ressonância da cabeça por vibração longitudinal, } \\
\text { posição sentada. }\end{array}$ \\
\hline $1-3$ & Todas as ressonâncias por vibração vertical. \\
\hline $2-3$ & $\begin{array}{l}\text { Ressonância ombro - cabeça por vibração longitudinal, } \\
\text { posição em pé. }\end{array}$ \\
\hline $2-6$ & Ressonância do corpo sentado. \\
\hline $3-3,5$ & $\begin{array}{l}\text { Ressonância máxima dos órgãos do tórax e } \\
\text { do abdome em posição em pé, com os } \\
\text { músculos relaxados. }\end{array}$ \\
\hline 4 & Máxima ressonância do corpo por vibração longitudinal. \\
\hline $4-6$ & $\begin{array}{l}\text { Ressonância do tórax e do abdome por vibração } \\
\text { vertical do corpo sentado. }\end{array}$ \\
\hline 4-12 & Ressonância do corpo em pé. \\
\hline 5 & Máxima ressonância do tórax e do abdome. \\
\hline 12 & $\begin{array}{l}\text { Pico de ressonância do corpo ereto por vibração } \\
\text { vertical. }\end{array}$ \\
\hline $13-20$ & Ressonância da cabeça. \\
\hline $20-30$ & Máxima ressonância do corpo. \\
\hline $20-30$ & $\begin{array}{l}\text { Ressonância da cabeça e ombros por vibração vertical } \\
\text { e posição sentada. }\end{array}$ \\
\hline $30-90$ & Ressonância do globo ocular. \\
\hline
\end{tabular}

A faixa de freqüência de vulnerabilidade localiza-se entre quatro e oito $\mathrm{Hz}$ na direção vertical, ou eixo z (pés - cabeça), justamente onde se concentra a maioria das freqüências da coluna vertebral. Bastam pequenos valores da magnitude da vibração para produzir respostas negativas no 
corpo humano, se as freqüências aplicadas forem de ressonância (WASSERMAN e col. 1997)

\subsubsection{Direção:}

A direção da vibração já discutida anteriormente, obedece o sistema de coordenadas biodinâmicas, definido pelos três eixos: $x$ (direção coluna peito) , y (direção lado direito - lado esquerdo) e z (direção cabeça - pé) (fig. 1.1).
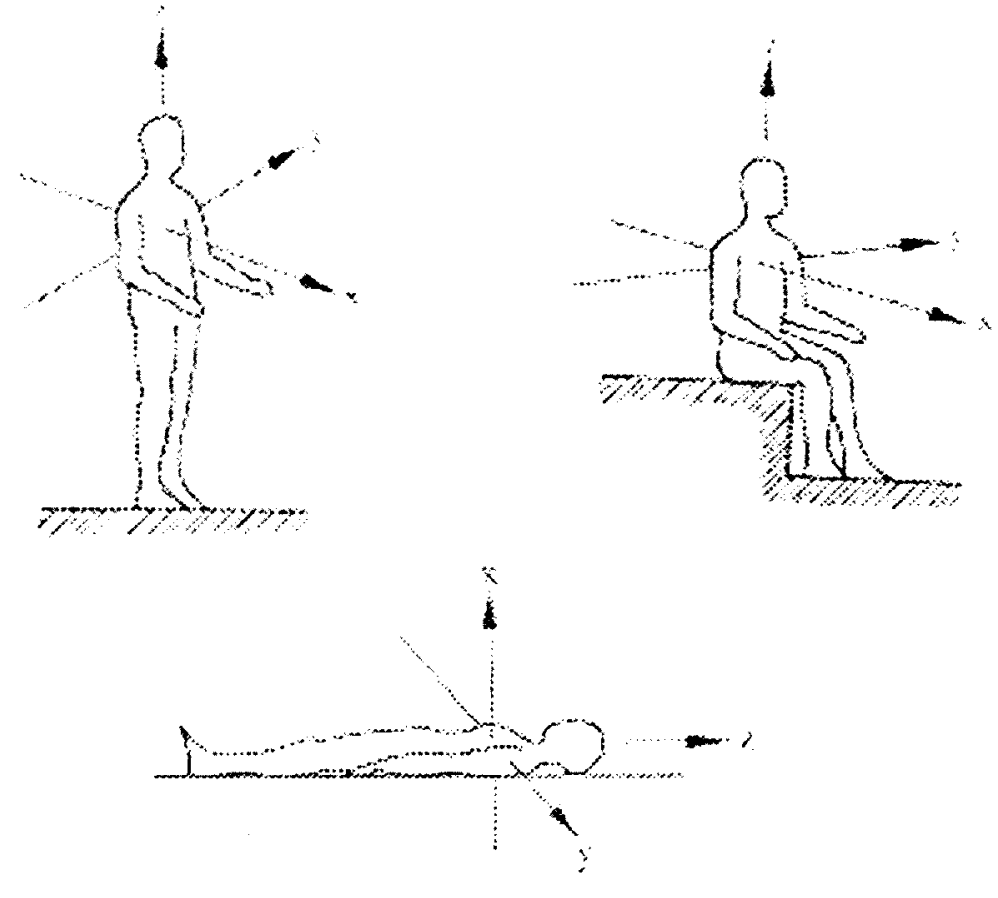

eixo $x$ : costas - peito

eixo y: lado direito - lado esquerdo

eixo z: pés ou nádegas - cabeça

Figura 1.1 Sistema de coordenadas para vibração mecânica aplicadas ao homem, conforme norma ISO-2631-1 (1985) 
A exposição à vibração, além de provocar sensações variadas como prazer, desconforto e dor e interferir com várias atividades, como a leitura e movimentos de controle da mão, pode acarretar efeitos fisiológicos e patológicos. As respostas fisiológicas, que se restringem a alterações temporárias durante a exposição, podem estar associadas aos seguintes aspectos: cardiovasculares, respiratórios, endócrinos e metabólicos, processos motores, processos sensoriais, sistema nervoso central e esquelético (GRIFFIN 1990a). Sucintamente, os possiveis efeitos, que podem ser gerados pela exposição à vibração de corpo inteiro, são os seguintes:

- Resposta subjetiva

- Desconforto

- Dor

- Perturbação da atividade:

- Visão

- Controle dos movimentos da mão

- Controle dos movimentos dos pés

- Efeitos patológicos

- Problemas da coluna ${ }^{2}$

- Mal do transporte

- Náusea

- Vômito

- Redução do desempenho

Verifica-se pelas informações acima, que os efeitos patológicos limitam-se ainda aos problemas de coluna, os quais de fato constituem-se como tema central da grande maioria dos estudos, que se preocupam com o

${ }^{2} \mathrm{O}$ efeito mais estudado na literatura è a lombalgia, como pode ser observado na seção dedicada à revisão bibliográfica. 
tema, como pode ser verificado na revisão bibliográfica neste capítulo, e de fato influi organicamente na constituição das normas sobre a questão.

As prováveis fontes associadas com agravos à saúde, são aquelas também associadas com o desconforto, tais como as citadas no início deste capítulo.

1.1.4 Normalização:

Em nível mundial, a norma que serve como referência para o tema é a ISO-2631-1 (1985), que ainda tem sido objeto de várias revisões. Esta norma cobre a faixa de freqüência compreendida entre um e $80 \mathrm{~Hz}$ e a duração da exposição de um minuto até $24 \mathrm{~h}$. Diversos limites estão presentes no texto da norma (GRIFFIN 1990b), tais como:

1. Não é responsabilidade dos comitês da ISO a definição dos limites de vibração para resposta humana.

2. Não há informação sobre dose-efeito e nenhuma forma de indicar a gravidade da vibração sem referència aos limites dependentes do tempo.

3. A dependência do tempo:

É muito complexa;

Não é fundamentada em dados cientificos;

É restrita a eventos com duração maior do que um minuto;

É dificil de aplicar com exposições variáveis e intermitentes;

Não é disponivel para definir uma medida de dose

4. As ponderaçōes por freqüência:

Não são consistentes com respostas subjetivas à vibração

5. Os eixos de vibração:

São restritos a três eixos que suportam o corpo

6. Os limites da vibração:

São surpreendentemente altos para exposições de curta duração;

São surpreendentemente baixos para exposiçōes de longa duração. 
A norma, que foi redigida inicialmente em 1974, sofreu modestas revisōes em 1985.

Os seus limites são definidos em relação à magnitude r.m.s. da vibração e o tempo de exposição variando de um min a $24 \mathrm{~h}$.

Os limites de exposição definidos pela norma são apresentados na figura 1.2, como ilustração para os tempos de exposição de 1 min e $24 \mathrm{~h}$.

Como pode ser observado, os valores limitam-se para a faixa de frequêencia de um a $80 \mathrm{~Hz}$ e não relevam tempo de exposição inferior a um minuto.

A norma è válida apenas para movimentos oscilatórios que apresentem fator de crista [Crest factor] inferior a aproximadamente seis.

A magnitude deve ser expressa preferencialmente em $\mathrm{m} / \mathrm{s}^{2}$ r.m.s.

A cadeia de aparelhos é similar à discutida para a vibração localizada, contendo os seguintes componentes básicos: transdutor (acelerômetro), amplificador e medidor ou registrador. 


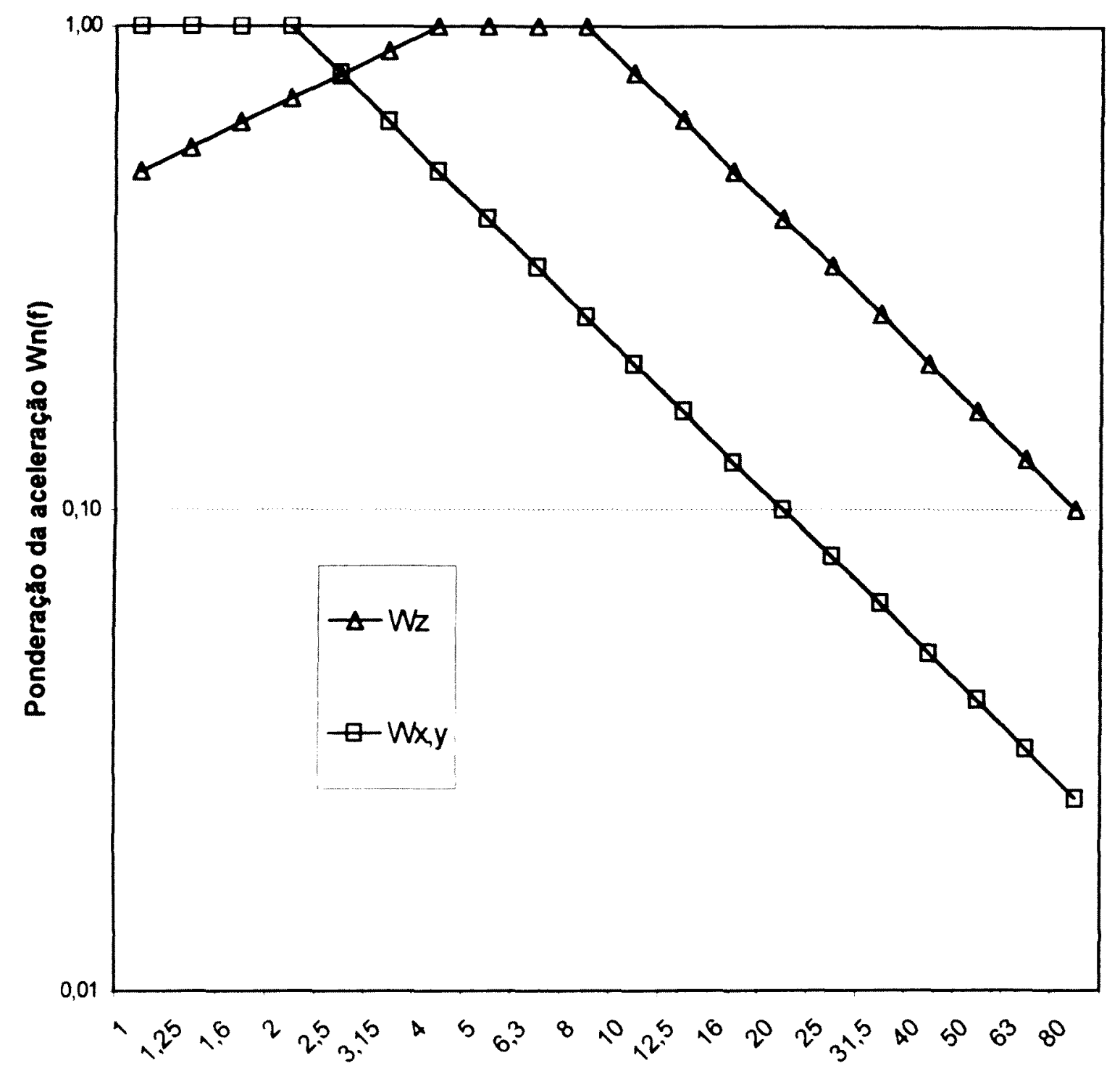

Frequência tz

Figura 1.2 Curvas de ponderação para os eixos $z(W z)$ e $x, y(W x, y)$, segundo norma ISO-2631-1 (1985). 


\subsection{Avaliação de vibraçăo:}

A medida e a análise da vibração significam a conversão de um movimento oscilatório em um conjunto de valores numéricos de acordo com algumas regras definidas.

A vibração normalmente é medida nas interfaces do assento através da utilização de acelerômetros montados em dispositivos adequados, de tal modo que não afetem a postura do trabalhador. As medidas executadas sobre assentos devem ser realizadas com uma pessoa sentada, uma vez que a impedância do corpo afeta a transmissão de vibração através do assento. O procedimento de avaliação deve ser executado em condições normais de trabalho conforme recomenda a norma (ISO-2631-1 1985).

Utiliza-se um acelerômetro de assento afixado rigidamente sobre o plano do assento do motorista. Os sinais advindos do acelerômetro das direções ortogonais $x$, y e $z$ são amplificados e registrados.

O assento pode exercer uma influência considerável sobre as pessoas expostas. Apesar de os assentos serem capazes de amortecer vibrações de altas freqüências, eles normalmente amplificam as de baixa frequêencia. Há três fatores que governam a eficiência de isolamento de vibração: espectro da vibração de entrada; a transferência do assento e a resposta humana à vibração. Tais fatores são combinados em um índice denominado S.E.A.T. [Seat Effective Amplitude Transmissibility] (GRIFFIN 1990a).

Com uso de equipamentos com esta possibilidade, como um analisador de frequêencia, os registros das magnitudes da vibração podem ser apresentados através de um espectro na faixa de freqüencias 
considerada. As magnitudes da aceleração ponderada em cada eixo do sistema de coordenadas são obtidas, a saber: $a_{x w}, a_{y w}$ e $a_{z w}$. A somatória vetorial, ou seja, a grandeza "awt", é calculada empregando estes valores através da seguinte fórmula (ISO-2631-1 1985):

$$
\left.a_{w t}=\sqrt{\left[\left(1,4 a_{x w}\right)^{2}+\left(1,4 a_{y w}\right)^{2}+a_{z w}^{2}\right.}\right] \mathrm{m} / \mathrm{s}^{2} \text { r.m.s. }
$$

$O$ fator de 1,4 é aplicado para os valores $x$ e $y$, desde que os limites para a vibração no eixo $z$, na faixa de frequeências de 4 a $8 \mathrm{~Hz}$, são 1,4 vezes mais elevados do que os limites para o eixo x e y na faixa de 1 a $2 \mathrm{~Hz}$.

Este meio è uma das alternativas para a realização da medição de espectros complexos, os quais são os encontrados nos ambientes e processos de trabalho, que é denominado método da ponderação [weighting procedure]. Esta forma é a mais utilizada por ser mais conveniente, mais lógica e mais consistente (GRIFFIN 1990a).

Pode ser utilizada a somatória vetorial, ou apenas uma grandeza se esta for a dominante em relação aos outros dois eixos. Após a obtenção do valor, seja pela somatória ou por um eixo dominante, compara-se com os limites correspondentes à magnitude da vibração e tempo de exposição, como pode ser observado nas figuras 1.3 e 1.4

Os equipamentos portáteis medidores de vibração, de leitura única, fornecem um valor de magnitude de vibração que deve seguir 0 procedimento descrito acima.

Outro método de avaliação sugerido pela ISO-2631-1 (1985) é o procedimento de classificação [rating procedure], no qual cada banda de 1/3 
de oitava do espectro analisado é comparada com os limites definidos para cada banda.

\subsubsection{Critérios:}

Os limites definidos por esta norma internacional referem-se a três critérios:

> preservação do conforto;

> prevenção da fadiga e queda da eficiência e

- preservação da saúde e da segurança - limite de exposição.

De acordo com o texto da norma o limite de exposição corresponde a duas vezes o limite da prevenção da fadiga e queda da eficiência e este, por sua vez, representa 3,15 vezes o limite referente à preservação do conforto. 


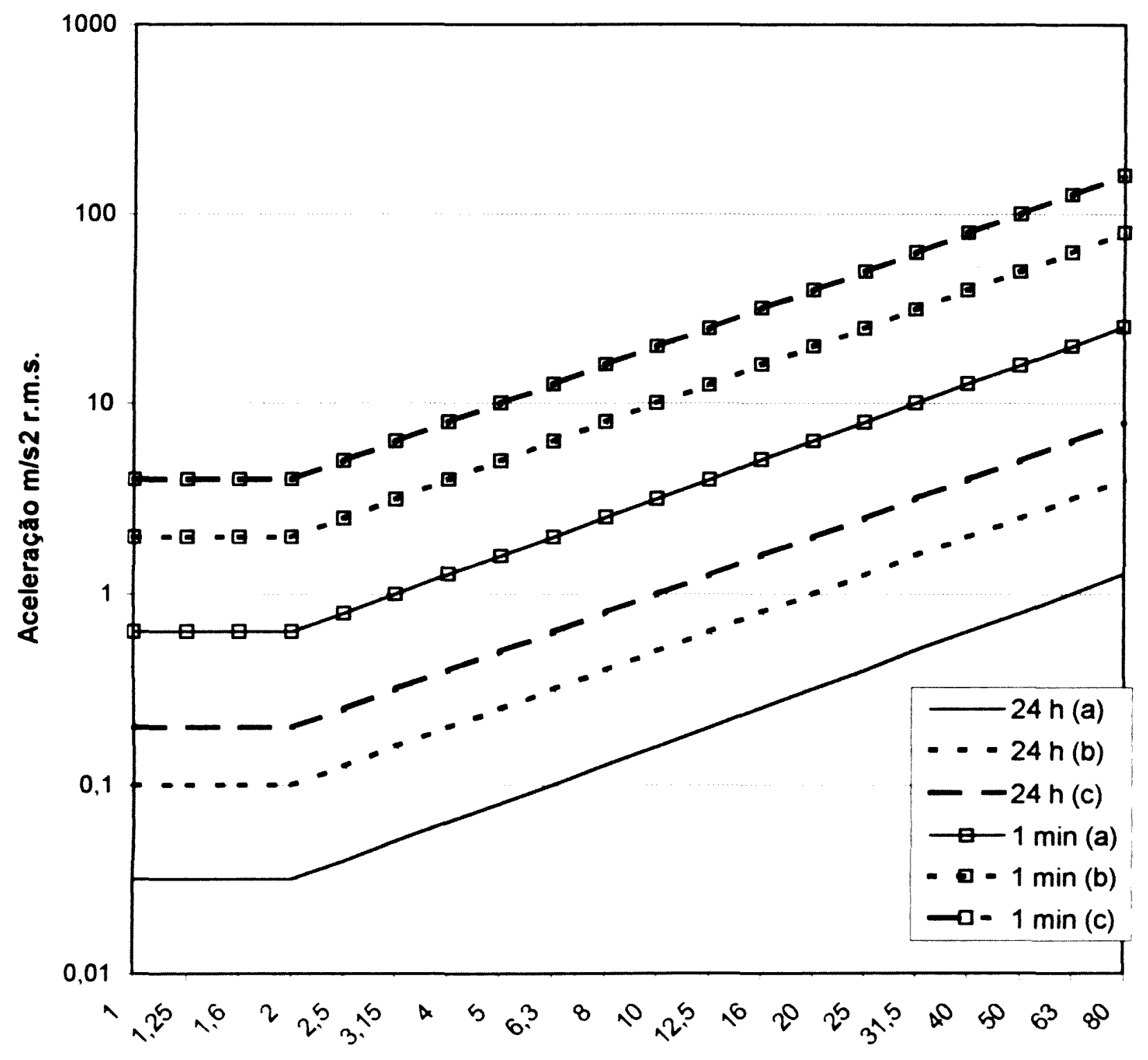

Frequência $-\mathrm{Hz}$

Figura 1.3 Limites de exposição (a), prevenção da fadiga e queda da eficiência (b) e redução do conforto (c) para 1 min e $24 \mathrm{~h}$ em relação à vibração longitudinal (eixos $x$ e y), segundo ISO-2631-1 (1985). 


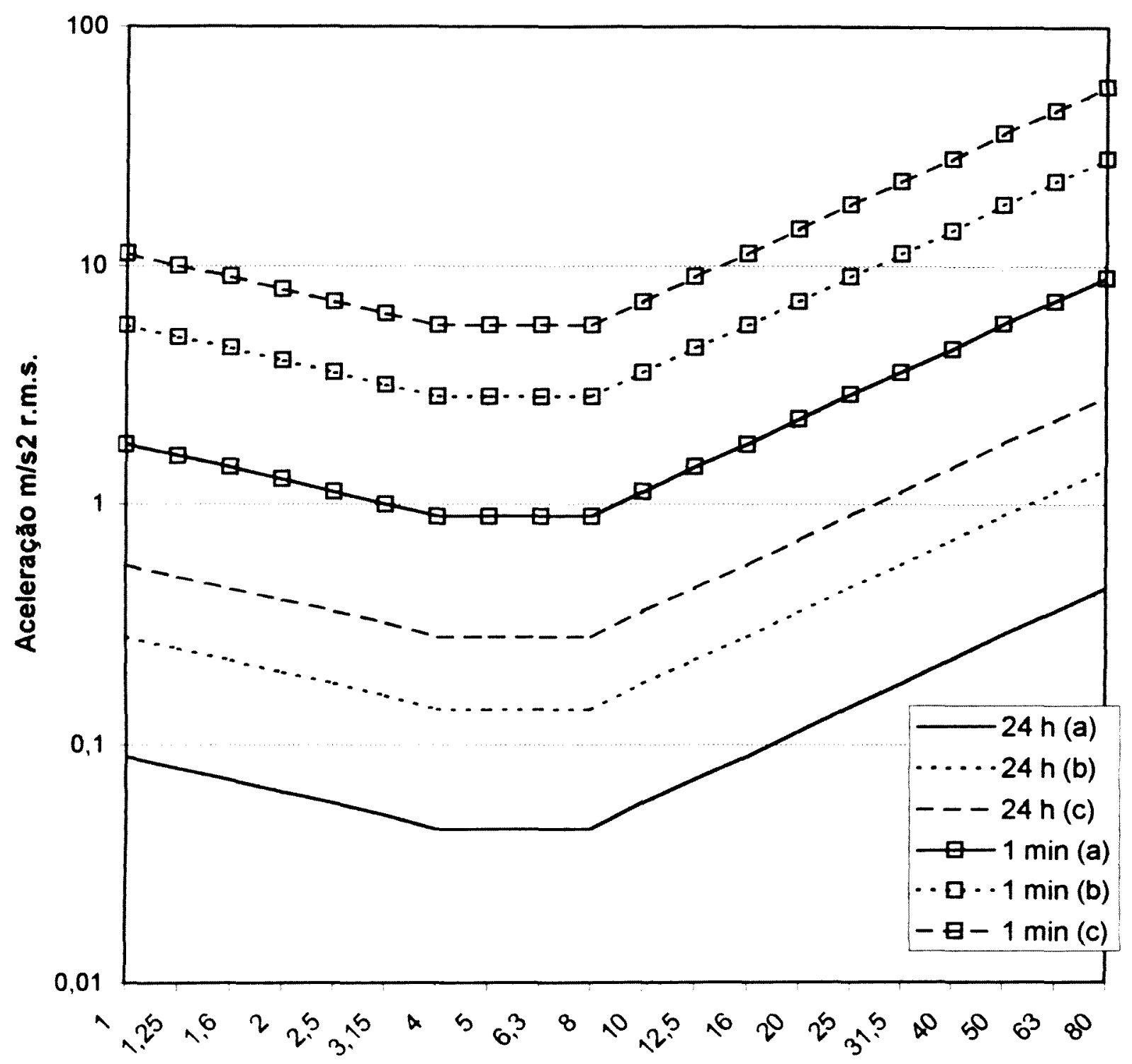

Frequência $\mathrm{Hz}$

Figura 1.4: Limites de exposição (a), prevenção da fadiga e queda da eficiência (b) e redução do conforto (c) para um min e $24 \mathrm{~h}$ em relação à vibração transversal (eixo z), segundo ISO-2631-1 (1985). 


\subsection{Estudos sobre a avaliação de vibração de corpo inteiro:}

Valores da magnitude da aceleração da vibração podem ser obtidos em um banco de dados construído pela organização sueca Instituto Nacional de Vida no Trabalho (NATIONAL INSTITUTE OF WORKING LIFE 2000). Este banco de informações encontra-se disponível na rede mundial de computadores - INTERNET e contém resultados de avaliações de exposição à $\mathrm{VCl}$ de diversos veículos importantes no âmbito do ramo de movimentação de terra. $\mathrm{Na}$ tabela seguinte, são apresentados alguns exemplos:

Tabela 1.2: Exemplos de valores de acelerações ponderadas encontradas nos três eixos ortogonais e as respectivas somatórias, em $\mathrm{m} / \mathrm{s}^{2}$, segundo a norma ISO-2631-1 (1985).

\begin{tabular}{lcccc}
\hline Veículo & a wx & awy & awz & Somatória \\
\hline Escavadeira & 0,4 & 0,2 & 0,4 & 0,70 \\
Pá carregaderia & 0,2 & 0,3 & 0,5 & 0,66 \\
trator escavadeira - pá & 0,4 & 0,3 & 0,4 & 0,83 \\
carregadeira & & & & \\
Caminhão caçamba 1 & 0,2 & 0,4 & 0,7 & 0,90 \\
Caminhão caçamba 2 & 0,3 & 0,5 & 0,9 & 1,26 \\
\hline
\end{tabular}

Fonte: NATIONAL INSTITUTE OF WORKING LIFE 2000

Para se obter a estimativa do valor da dose de vibração, em pesquisa de âmbito nacional na Grã-Bretanha, PALMER e col. (2000a), recorreram a valores representativos das magnitudes de vibração no eixo $z$ de veículos considerados relevantes para o cálculo. Alguns exemplos são citados a seguir na tabela : 
Tabela 1.3: Exemplos de valores da magnitude da aceleração ponderada no eixo $z$ (awz), segundo a norma BS - 6841 (1997), de alguns veículos

\begin{tabular}{lc}
\hline Veículo ou máquina & awz $\mathrm{m} / \mathrm{s}^{2}$ r.m.s. \\
\hline Ónibus & 0,6 \\
Trem & 0,5 \\
Trator & 0,75 \\
Motocicleta & 1,0 \\
Carregadeira & 1,2 \\
Helicóptero & 0,8 \\
Barco de alta velocidade & 1,5 \\
Empilhadeira & 0,9
\end{tabular}

Fonte: PALMER e col. (2000a)

Os aspectos ergonômicos da cabina de ônibus em uso na Holanda foram analisados por Oortman-Gerlings e col. (1985), citado por KOMPIER (1996). Os pesquisadores puderam constatar que os niveis de vibração para a maioria dos veiculos observados excederam os limites de proficiència decrescida pela fadiga propostos pela ISO-2631-1 (1985) e em alguns casos, houve até a superação do limite de exposição ocupacional para 8 horas referente à mesma norma. Os autores destacam que a vibração se constitui como o maior risco ocupacional para os motoristas de ônibus holandeses

Condiçōes de trabalho em empilhadeiras, do ponto e vista acústico e vibratório, foram objeto de estudo de DANIĖRE e col. (1992). Estes elaboraram um estudo, cujo objetivo foi o de responder às necessidades da normalização no campo das estratégias de redução de vibração e ruido no posto de trabalho do condutor destes veículos. Cotejando os resultados com a norma francesa, os autores observaram que os niveis de vibração encontrados em empilhadeiras com capacidade de carga inferior a 10 t e os utilizados em construção civil são algumas vezes incompativeis com a 
duração quotidiana de um posto de trabalho. Além disso, os pesquisadores revelaram que as suspensões empregadas nestes veículos são freqüentemente inadequadas.

Máquinas agricolas utilizadas em várias culturas no Japão foram objeto de avaliação em pesquisa conduzida por FUTATSUKA e col. (2000). Niveis acima dos limites de tolerância definidos pela ISO-2631-1 (1985) foram registrados nos assentos dos veículos em operação. Os autores também estimaram o tempo de exposição segundo os critérios da ISO-26311 (1997), referindo-se à somatória vetorial calculada para cada máquina, levando em consideração os procedimentos definidos pela ISO-2631-1 (1985). Trata-se de um método incoerente, pois as duas normas possuem ponderações diferentes por freqüência e outras diferenças, que não permitem uma comparação desta natureza.

\subsubsection{A importância do assento:}

Três tipos de assentos foram avaliados por ÖZKAYA et col. (1996) tendo como referência a transmissão da vibração. O primeiro assento, considerado o mais simples, foi classificado como o mais apropriado, comparando-se com os outros dois, os quais possuiam caracteristicas avançadas e estruturas complexas, já que estes últimos ampliaram a vibração global de 5 a $19 \%$ para operadores de trem. Os autores salientam que a despeito de os assentos mais complexos e com caracteristicas avançadas obedecerem critérios ergonômicos de ajuste e conforto, eles não foram concebidos para suportar exposição à vibração a longo prazo. De acordo com os autores, estes assentos foram configuradcs para postos de trabalho com caracteristicas estáticas, e não dinâmicas como a do operador de trem.

A eficiência em prevenir a transmissão de vibração de 11 tipos de assento utilizados em caminhões pesados, tratores e empilhadeiras foi 
avaliada por BURDORF e SWUSTE (1993). Os autores verificaram que os dados obtidos em laboratório não são adequados para predizer a eficiência no campo e que em diversas situaçōes de trabalho, a magnitude e a duração da vibração excederam os limites da curva fadiga - decréscimo de produtividade estabelecidas pela norma ISO-2631-1(1985) para o eixo vertical. Portanto, segundo os pesquisadores, em várias situaçōes de trabalho com exposição de $8 \mathrm{~h}$ diárias, os assentos não oferecem a devida proteção contra os efeitos da $\mathrm{VCl}$.

Valores de vibração superiores, particularmente na direção lateral, aos definidos pela norma ISO-2631-1 (1985) em referência à duração da exposição foram observados em postos de trabalho de condutores de máquinas de transporte de troncos de árvores em pesquisa conduzida por BOILEAU e SCORY (1988). Os pesquisadores também destacam a impropriedade dos assentos existentes nestes veículos, os quais tendem a amplificar a vibração recebida e por sua vez, transmitida ao operador. A ausência de amortecimento da máquina e as irregularidades ao longo do percurso provocam importantes solicitações, favorecendo assim a elevação dos niveis de vibração.

WIKSTROM e col. (1994) também elaboraram uma vasta revisão da literatura sobre o tema com o fim de fornecer condutas e meios de avaliar a exposição, principalmente no que se refere à ocupação de motoristas. Fundamentando-se nos estudos analisados os autores concluem, sobre os efeitos a longo-prazo, que muitos anos de exposição podem contribuir para lesões e/ou distúrbios na região lombar e o risco tende a crescer se esta exposição for combinada com posturas inadequadas e longo tempo na posição sentada sem pausas.

Uma cuidadosa revisão acerca dos efeitos do ruido e vibração sobre trabalhadores agricolas foi elaborada por CRUTCHFIELD e SPARKS (1991). Nesta revisão, os dois riscos são analisados de forma individual não 
havendo enfoque sobre a ação combinada de ambos. Desse modo, detendo-se nos aspectos referentes aos efeitos advindos da exposição à $\mathrm{VCl}$, os autores salientam pesquisas, nas quais foram revelados os efeitos a longo prazo mais evidentes, como lombalgias, degeneração precoce da coluna e hérnia de disco. Os autores declararam que estudos, cujos objetos se detiveram sobre outras regiões do corpo, não foram suficientemente conclusivos. Verifica-se por meio desta ampla revisão que existe um risco elevado para danos na coluna vertebral e no sistema nervoso periférico, enquanto que para outros locais do corpo, como sistema digestivo, órgãos do sistema reprodutivo feminino e sistema vestibular, há uma probabilidade menor de ocorrência.

Abordando além dos riscos para a coluna vertebral, uma extensa revisão crítica sobre efeitos a longo prazo produzidos pela exposição à VCl foi realizada por SEIDEL e HEIDE (1986). Os autores analisaram 185 pesquisas e discutiram os dados mais relevantes de cada uma delas de modo condensado, referente a associação entre a qualidade da exposição (intensidade, direção e duração) e efeitos patológicos, o papel dos fatores individuais, conclusões para o estabelecimento de padrões e o cuidado médico dispensado aos trabalhadores expostos. Os dados obtidos por esta análise apontaram uma elevação de risco para a coluna e para o sistema nervoso periférico. O sistema digestivo e os órgãos reprodutivos femininos são atingidos com uma menor probabilidade. Nos aspectos referentes à exposiçăo simultânea de ruido e $\mathrm{VCl}$, os pesquisadores citam 3 estudos de campo, pelos quais foi observado um efeito aditivo discreto da vibração no desenvolvimento de perda auditiva induzida por ruído e também 3 de caráter experimental que compartilham da mesma conclusão. Exposição a longoprazo à $\mathrm{VCl}$ possivelmente pode contribuir para o surgimento de distúrbios nos órgãos reprodutivos femininos (distúrbios menstruais, anomalias de posição) além de distúrbios na gravidez (abortos, parto prematuro). 


\subsection{Revisão da literatura - Estudos epidemiológicos:}

A grande maioria dos estudos sobre o tema tem se detido sobre os problemas na coluna decorrentes da exposição à $\mathrm{VCl}$. Verifica-se também que há o cuidado em referir que não é possivel estabelecer um determinado risco para $\mathrm{VCl}$, uma vez que há uma complexidade de outros agentes presentes que interferem na geração do efeito (posição sentada por tempo prolongado, postura inadequada, etc.). $\mathrm{O}$ conhecimento adquirido a respeito dos efeitos crônicos decorrentes da exposição à $\mathrm{VCl}$ foi gerado principalmente através de estudos transversais e retrospectivos (GRIFFIN 1990a). Nota-se também a referència a alguns problemas para o desenho destes estudos, principalmente os transversais que analisam os efeitos sobre a coluna, como o "fenômeno do trabalhador saudável", pois trabalhadores que apresentam problemas de coluna tendem a deixar estes postos.

\subsubsection{Lombalgia e distúrbios na coluna:}

O tema mais relevante, constatado através da revisão bibliográfica executada, foi sobre os efeitos decorrentes da exposição à $\mathrm{VCl}$ sobre a coluna, principalmente em virtude de número representativo de afastamentos do trabalho provocado por este problema.

Choque mecânico e $\mathrm{VCl}$ são consideradas causas representativas para o desenvolvimento de lombalgias em motoristas (BURTON e SANDOVER 1987). Os autores sustentam esta conclusão devido a uma redução significativa da incidência e gravidade de lombalgias entre pilotos, quando a rigidez da suspensão de veículos de competição foi reduzida.

Queixas de operadores de pontes-rolantes referentes à exposição à VCI foram levantadas por MALCHAIRE e PIETTE (1991). No estudo, observou-se que os operadores são mais sensiveis às vibrações horizontais 
(eixos $x$ e y). Além disso, os operadores apresentaram maior sensibilidade aos niveis de vibração não ponderados do que aos ponderados, e às intensidades de pico (L10 - percentil 10 ) do que às de valor r.m.s.

O desconforto provocado por $\mathrm{VCl}$ em posto de trabalho de tratoristas foi objeto de análise em uma pesquisa de campo empreendida por FAIRLEY (1995). Diversos procedimentos de análise quantitativa de vibração para predizer o desconforto foram empregados, e após comparados com as avaliaçōes subjetivas dos operadores. O autor considerou a norma ISO2631-1 (1985) como o melhor instrumento para se predizer o desconforto, utilizando-se os valores de vibração r.m.s. ponderados em freqüência $(0,5-$ $20 \mathrm{~Hz}$ ) medida no plano do assento nas três direções ortogonais.

BONGERS e col. (1998a) empreenderam uma pesquisa longitudinal com o propósito de verificar os efeitos da $\mathrm{VCl}$ sobre operadores de ponte rolante. Os autores observaram que entre os operadores com mais de cinco anos de exposição à $\mathrm{VCI}$, a ocorrência de incapacidades por problemas de coluna foi mais elevada comparando-se ao grupo controle. A razão de densidade de incidência superou o valor de dois para incapacidade, controlando as variáveis idade, nacionalidade, trabalho em turnos e ano calendário

Distúrbios na coluna foram estudados em operadores de máquinas de movimentação de terra, com pelo menos três anos de exposição, por meio de estudo seccional desenvolvido por DUPUIS e ZERLETT (1987). Os autores empregaram um grupo controle para possibilitar comparações entre os expostos. A pesquisa demonstrou que a prevalência de trabalhadores com queixa de desconforto na coluna foi muito mais alta no grupo de trabalhadores expostos à vibração.

HULSHOF e VAN ZANTEN (1987) elaboraram ampla e crítica revisão da literatura sobre $\mathrm{VCl}$, pela qual foram definidas classificaçóes, 
obedecendo determinados critérios referentes ao desenho dos estudos revisados, a fim de verificar a consistência epidemiológica dos mesmos. Pelo levantamento, revelou-se que os efeitos adversos mais comuns foram: lombalgia, degeneração precoce da região lombar e hérnia de disco. Os autores destacam que são necessárias mais pesquisas em trabalhadores de alto risco, uma vez que não é possivel estabelecer uma associação sólida entre exposição e efeito com base nas pesquisas analisadas.

WALSH e col. (1989) investigaram as causas de lombalgia relacionadas ao trabalho através de um estudo retrospectivo, utilizando-se de questionário enviado pelo correio, pelo qual observaram-se as associaçōes mais consistentes nas atividades de transporte e levantamento de cargas e na condução prolongada de veiculos.

Operadores de empilhadeira apresentam maiores problemas de coluna quando comparados com outros grupos de trabalhadores, conforme pesquisa conduzida por BRENDSTRUP e BIERING-SøRENSEN (1987). No entanto, este achado não comportou diferenças significativas entre os grupos analisados, pois, segundo os autores, o grupo controle escolhido era em número reduzido. Além disso, estes trabalhadores, não qualificados, pertencentes ao grupo controle, desenvolviam atividades classificadas de risco para geração de problemas de coluna.

Os fatores de risco para lombalgia são analisados por BURDORF e SOROCK (1997) através de uma exaustiva revisão na literatura, compreendendo 35 estudos epidemiológicos sobre o tema com os mais variados desenhos. Em relação aos aspectos de $\mathrm{VCl}$, os autores detiveramse sobre 13 textos. Associações significativamente positivas entre a exposiçāo e efeito foram encontradas praticamente na totalidade dos estudos analisados, com exceção de um com desenho longitudinal, cujos resultados não demonstraram uma associação estatisticamente significativa. 
A elevação de prevalência de lombalgias entre pilotos de helicópteros e motoristas profissionais deve-se parcialmente à exposição à $\mathrm{VCl}$, uma vez que estes grupos de trabalhadores encontram-se expostos a outros riscos que podem contribuir na geração deste agravo. Estas considerações estabelecidas por BOSHUIZEN e col. (1990a) sustentam-se em estudos epidemiológicos realizados pela Universidade de Amsterdã, instituição em que trabalham. Estes estudos compreendiam três de natureza longitudinal entre operadores de ponte rolante de uma siderúrgica e de um estaleiro e operadores de trator e três seccionais conduzidos sobre operadores de trator, operadores de empilhadeira e pilotos de helicópteros. Os objetivos dos primeiros foram o de verificar a diferença da incidência de incapacidade e afastamento do trabalho com um grupo controle pertencente à mesma empresa, enquanto que os do segundo foram a determinação de prevalência entre as ocupaçōes analisadas.

Aspectos sobre a poluição química, ruido e $\mathrm{VCl}$ em operadores de empilhadeiras elétricas e a diesel, foram avaliados por COCHEO e col. (1984). Os resultados revelaram que o tipo de motor não influencia sobre os niveis de vibração, mas sim a características dos pneus empregados no equipamento. As empilhadeiras dotadas de pneus homogêneos (sem càmara de ar) apresentaram niveis mais elevados de $\mathrm{VCl}$, comparando-se com as que utilizam pneus elásticos constituidos de câmara de ar. Os niveis encontrados não oferecem conforto nem garantem a preservação da capacidade de trabalho de acordo com os limites impostos pela norma ISO2631-1 (1985).

Um estudo epidemiológico de campo entre operadores do metrô da cidade de Nova lorque, levando em conta os efeitos combinados de $\mathrm{VCl}$ nos sentidos lateral e vertical, foi desenvolvido por JOHANNING e col. (1991a), os quais classificam este estimulo como um fator de maior contribuição para - desencadeamento de dor e doenças na coluna. Os pesquisadores realizaram avaliação sobre os diversos tipos de trens utilizados, bem comu 
respeitando as caracteristicas das linhas, referenciando-se principalmente à norma ISO-2631-1 (1985). Os niveis de vibração lateral e vertical encontrados situavam-se bem acima dos limites de fadiga- decréscimo na eficiência para $8 \mathrm{~h}$ estabelecidos pela norma ISO-2631-1 (1985). De acordo com os autores, a jornada de trabalho destes operadores submetidos a estes niveis de $\mathrm{VCl}$ não deveria ultrapassar 3 horas e 44 minutos. Além deste risco, o posto de trabalho do operador de metrô encontrava-se exposto a outros riscos importantes tais como: posto de trabalho mal dimensionado em relação aos critérios ergonômicos, elevados niveis de ruído e estresse provocado pela inadequação da organização do trabalho.

Comparando incidências de absenteismo devido a distúrbios na coluna entre operadores de ponte rolante expostos à $\mathrm{VCl}$ e um grupo controle, em um estudo retrospectivo de dez anos, BONGERS e col. (1988b) não verificaram diferenças significativas entre os dois grupos. No entanto, no grupo formado de operadores de ponte rolante, observou-se um maior e mais longo absenteismo devido a ocorrências de distúrbios no disco intervertebral. Já no grupo controle houve mais queixas e distúrbios da coluna inespecificos.

Motoristas de ônibus e de caminhões e operadores de equipamentos pesados são ocupações com mais elevadas prevalências de distúrbios causados pela exposição à $\mathrm{VCl}$, conforme mostra revisão de dados epidemiológicos produzidos pelo NIOSH [National Institute for Occupational Safety and Health] conduzida por HELMKAMP e col. (1984). Entretanto, segundo os autores da revisão, a associação causal não foi estabelecida adequadamente

Uma das primeiras revisões criticas e sistemáticas a respeito de pesquisas epidemiológicas sobre o tema foi desenvolvida por HELMKAMP e col. (1984). Em 1954, Loeb citado por HELMKAMP e col. (1984, p.162), considerado como um dos precursores na análise de efeitos combinados, 
através de um estudo experimental e dispondo ainda de um grupo controle, não verificou nenhuma alteração significativa nas médias das pressões arteriais sistólica e diastólica entre os dois grupos.

Pesquisa realizada por Gruber e Ziperman citado por HELMKAMP e col. (1984, p. 163) entre trabalhadores expostos à VCl comparou padrões de morbidade, por meio de um estudo retrospectivo, de motoristas de ônibus e de trabalhadores de escritório formando, entre outros, o grupo controle. Já Gruber citado por HELMKAMP e col. (1984, p. 164), em 1976, desenvolveu outra pesquisa com desenho similar, envolvendo motoristas de caminhões e nesta oportunidade, controladores de tráfego aéreo foram empregados como controle. Uma pertinente critica tecida por HELMKAMP e col. (1984) é o viés expressivo que pode haver na seleção de controles, os quais se submetem a uma avaliação médica mais rigorosa para o cargo. Desse modo, é de se esperar que nesta última população de trabalhadores, serão encontrados os mais saudáveis.

Diante da dificuldade em encontrar um grupo controle, cuja realidade de trabalho diferisse do grupo objeto de análise, apenas no tocante à exposição à VCI , Grzesik citado por HELMKAMP e col. (1984, p. 165) optou em desenhar um estudo longitudinal, de 1972 a 1980, entre operadores de minas de carvão e areia, dotado de dois pontos de determinação do quadro de saúde da população de estudo. O pesquisador verificou que exposição à $\mathrm{VCl}$ a longo prazo, em baixas e médias frequêencias, exerce uma influência negativa sobre a saúde destes trabalhadores, demonstrada por uma maior e significativa incidência de distúrbios da mobilidade, sistemas circulatório e digestivo e nos órgãos urogenitais. Este estudo especificamente não revelou nenhuma ação sinérgica pela presença do ruido, uma vez que não se detectou nenhum agravo à audição.

Exposição à $\mathrm{VCl}$ e ao frio pode contribuir para a ocorrência do fenômeno de Raynaud entre mineiros, de acordo com a pesquisa efetuada 
por HEDLUND (1989). Após examinar 27 trabalhadores submetidos na jornada de trabalho aos dois tipos de exposição à vibração, constatou uma maior prevalência do fenômeno nos dedos das mãos e pés, comparando-se com um grupo controle. $O$ autor afirma que há possibilidade de surgimento do fenômeno nos dedos dos pés em pessoas com exposição a longo prazo à vibração nos pés.

A dose de exposição está associada ao aumento da prevalència de dor nas costas, conforme pesquisa de BOSHUIZEN e col. (1990b). Os autores analisaram isoladamente os dois componentes da dose de vibração, duração da exposição e magnitude da vibração, e concluíram que a manifestação de dor nas costas tende a crescer com a duração, mas não com a média estimada da magnitude da vibração. Segundo os autores, este resultado provavelmente se deve à deficiencia de acurácia da última variável, e concluem que a prevalência mais elevada de dor nas costas entre tratoristas (cerca de $10 \%$ superior ao grupo não exposto) pode ser parcialmente imputado à $\mathrm{VCl}$, uma vez que há outros estressores importantes no posto de trabalho, tais como postura e posição sentada prolongada.

Com o propósito de avaliar com maior propriedade os resultados de pesquisa anterior, na qual indicou que operadores de metrô se expunham a niveis de $\mathrm{VCl}$ superiores aos definidos pela ISO-2631-1 (1985), JOHANNING (1991b) desenvolveu uma análise, através da qual foi aplicado um questionário "auto-respondivel" entre estes trabalhadores e foram executadas medidas dos níveis de vibração no posto de trabalho do operador. O pesquisador pôde observar, por intermédio de regressão logística múltipla, uma Razão de Chances de $3,5(95 \%$ IC 1,7-8,6) para dor ciática e de 1,6 para problemas gastrointestinais $(95 \%$ IC 1,1-2,5) entre os operadores de metrô, cotejando-se com o grupo controle constituido por operadores de sala de controle. $O$ autor, neste estudo, não fez referència aos niveis de ruido, sob o qual os operadores estavam expostos. 
Interessante destacar outro achado deste trabalho que foi uma Razão de Chances de 3,2 para perda auditiva induzida por ruído (PAIR) entre os operadores. No entanto este valor não foi significante quando se verifica 0 intervalo de confiança a $95 \%(0,6-17,4)$.

Em estudo transversal no qual utilizou-se a metodologia de aplicação de questionários auto-respondiveis enviados pelo correio e a medição dos niveis de exposição à VCI no posto de trabalho, BOVENZI e ZADINI (1992) investigaram a prevalência de sintomas lombares entre um grupo de motoristas de ônibus expostos à $\mathrm{VCl}$ e a estresse postural. Os dados obtidos foram analisados através de regressão logistica múltipla e foram revelados valores de Razão de Chances de prevalência para diversos tipos de sintomas (dor nas pernas, dor lombar aguda, dor lombar) significativamente superiores à unidade para motoristas de ônibus, comparando-se com o grupo controle composto por trabalhadores da manutenção. BOVENZI e ZADINI (1992) também salientam que a ocorrência de sintomas lombares tende a crescer à medida que a exposição à $\mathrm{VCl}$, traduzida pela dose recebida (anos $\mathrm{m}^{2} / \mathrm{s}^{4}$ ) cresce. Destaca-se deste estudo que os sintomas surgiram em níveis de exposição à $\mathrm{VCl}$ inferiores aos estipulados pela norma ISO-2631-1 (1985).

Após o controle das variáveis de confusão através de regressão logística, detectou-se uma associação significativa entre distúrbios lombares com dose de vibração e carga postural. Este resultado é um dos achados de estudo de prevalência empreendido por BOVENZI e BETTA (1994a) com 1155 tratoristas expostos à $\mathrm{VCl}$ e estresse postural, os quais analisaram os niveis de vibração no posto de trabalho e empregaram um questionário padronizado. Os autores demonstraram que a prevalência de lombalgia é maior do que a encontrada no grupo controle formado por 220 trabalhadores de escritório, e também afirmaram que a Diretiva Européia para agentes físicos parece ser mais apropriada para a prevenção de efeitos a longo prazo na região lombar do que a norma ISO-2631-1 (1985). 
A condução de veículos a motor pode estar associada com a elevação de risco para disco intervertebral lombar herniado agudo, conforme estudo conduzido por KELSEY e HARDY (1975) que teve o desenho do tipo caso-controle. Os autores compararam fatores de risco de 223 casos com aqueles de dois grupos controle compostos de 217 pareados com as variáveis idade e gênero e 49 não pareados. Segundo os autores, a associação encontrada entre hérnia de disco aguda e condução de veículos não pôde ser atribuída a quaisquer variáveis de confusão como levantamento de cargas, ausência de atividade física, tabagismo ou trabalho sedentário. Exposição à $\mathrm{VCl}$ não foi considerada como um fator de risco no desenho da pesquisa. A falta de um grupo controle extraído da população geral e a relativa insuficiência do tamanho da amostra foram alguns dos limites discutidos pelos pesquisadores.

Em um grupo de operadores de ponte rolante não foi encontrada uma prevalência significativamente mais elevada em relação a um grupo controle constituído de trabalhadores não expostos à $\mathrm{VCl}$, mas que assumissem a mesma posição de trabalho na jornada. Esta é uma das conclusões consolidadas por PIETTE e MALCHAIRE (1992) em pesquisa, em que um dos objetivos foi o de verificar quais os elementos do equipamento que são responsáveis pela geração de vibração. Os autores concluíram que, neste aspecto, têm importância os caminhos de rolamento, as dimensões e os sistemas de suspensão tanto da cabina como do assento.

Interferências sobre 0 aprendizado foram investigadas por SHERWOOD e GRIFFIN (1992) por meio de um estudo experimental, em que 40 sujeitos cumpriram metade de determinada tarefa de aprendizado submetidos à $\mathrm{VCl}$ senoidal com freqüência de $16 \mathrm{~Hz}$ e aceleração de 2,0 $\mathrm{m} / \mathrm{s}^{2}$ e outra metade sem exposição. Os resultados indicaram que exposição à $\mathrm{VCl}$ pode prejudicar aprendizado de modo significativo. 
Após a revisão de dezenove pesquisas, algumas das quais presentes neste texto, pesquisadores do NIOSH declararam que há uma forte evidência de associação positiva entre exposição à VCl e lombalgia (BERNARD e FINE 1997). 


\subsection{Aspectos sobre exposição ao ruído:}

De acordo com PELMEAR (1995), as primeiras pesquisas que demonstraram correlação entre exposição ao ruído e perda auditiva foram somente realizadas na década de 60 . As pesquisas conduzidas por Passchier-Vermeer, citadas por PELMEAR (1995) concluiram que o dano à audição tende a crescer à medida que os niveis de pressão sonora se elevam, dado um tempo de exposição constante. Burns e Robinson, citados por PELMEAR (1995), a partir dos resultados obtidos em suas pesquisas, elaboraram uma equação pela qual é expresso o nivel esperado do limiar na faixa de frequêencias de 500 a $6000 \mathrm{~Hz}$ para um dado nível de ruido, periodo de exposição e idade. Este estudo consiste em uma referência histórica, pois a partir dele foram construidos os conceitos de nivel de emissão e energia total de ruído (ponderada pela escala A) recebidos pela orelha, estabelecendo assim o principio de igual energia, significando que uma elevação da intensidade de ruído da ordem de $3 \mathrm{~dB}$ representa a duplicação do risco devido à exposição.

Em relação a este último aspecto que define um critério de risco para exposição ao ruído, o conceito de igual energia ou a regra dos $3 \mathrm{~dB}$ (fator de troca) apresenta maior consistência e aceitação na literatura. CLUFF (1984) afirma que a regra dos $3 \mathrm{~dB}$ é fundamentada sobre um modelo mais acurado e razoável para predizer a PAIR, enquanto que a regra dos $5 \mathrm{~dB}^{3}$, baseada em dados de mudanças temporárias de $\operatorname{limiar}^{4}$ (MTL), representa uma inferência que não foi verificada ou comprovada. Atualmente a regra dos 3

\footnotetext{
3 Regra atualmente utilizada pela legislação brasileira - Lei $N^{\circ} 6.514$, de 22 de dezembro de 1977 - Portaria 3.214 de 8 de junho de 1978.

${ }^{4}$ Segundo a ANSI S3.20-1995, citada por NIOSH (1998), é uma elevação temporária no limiar de audibilidade para uma orelha causada por um estímulo acústico de alta intensidade
} 
dB é a mais aceita, justamente em razão de ser sustentada cientificamente por estudos epidemiológicos. Instituiçōes e organismos mundialmente conhecidos e conceituadas na área de saúde e trabalho, como o NIOSH (1998), a ACGIH (1996) [American Conference of Governmental Industrial Hygienists] e a AFNOR (1985) [Association Française de Normalisation] a têm adotado e estabelecido critérios de risco partindo da referência do nivel de $85 \mathrm{~dB}(\mathrm{~A})$ para uma duração de exposição de 8 horas.

A perda auditiva induzida por ruído normalmente se inicia na frequeència de $4 \mathrm{kHz}$ e em estágios posteriores se amplia e se aprofunda para as freqüências de $3 \mathrm{kHz}$ e $6 \mathrm{kHz}$, conforme demonstram todas as pesquisas revisadas por PELMEAR (1995). Antecedendo à ocorrência da mudança permanente de limiar (MPL) tem-se observado sempre uma mudança temporária de limiar (MTL), a qual depende da intensidade e da duração do ruido. Esta mudança temporária atinge o seu máximo logo após - término da exposição. Após algumas horas há recuperação, com característica logarítmica, que é determinada usualmente no ponto referente a dois minutos $\left(M T L_{2}\right)$.

Populações de trabalhadores com pressão sistólica e concentraçōes de colesterol e de triglicérides no sangue mais elevadas são mais suscetiveis à exposição ao ruido conforme pesquisa executada por Thomas e Williams, citada por PELMEAR (1995).

A perda auditiva está associada significativamente com tabagismo, como demonstram os resultados obtidos nos estudos desenvolvidos por Chung e colaboradores, citados por PELMEAR (1995). Recentemente, por intermédio de um estudo de prevalência, a associação entre tabagismo e perda auditiva foi demonstrada em pesquisa elaborada por CRUICKSHANKS e col. (1998). O risco de desenvolver perda auditiva para 
os fumantes, controlando as demais variáveis, foi 1,69 vezes (IC $95 \% 1.31$ 2.17) o dos não fumantes.

O ruido de impacto, definido basicamente como um som de curta duração e elevada energia, representa maior risco à audição dos trabalhadores, como demonstrou SULKOWSKI e col.(1983), que encontraram uma PAIR mais acentuada entre forjadores do que em tecelōes expostos ao mesmo nivel equivalente de ruído de $101 \mathrm{~dB}(\mathrm{~A})$. Esta diferença verificada foi mais proeminente na de $6 \mathrm{kHz}$.

Monóxido de carbono, metais pesados (chumbo, arsênio e mercúrio) e solventes orgânicos (tolueno, estireno e xileno) são alguns agentes que podem interagir com a exposição ao ruído, conforme revisão de PELMEAR (1995). MORATA e col. (1993), através de um estudo de prevalência em uma indústria gráfica, verificaram que, o risco estimado de perda auditiva, referenciando-se ao grupo não exposto, era 4 vezes para o grupo de expostos somente a ruído, 11 vezes para o exposto a ruído e tolueno e 5 vezes para o exposto a mistura de solventes.

Diferenças de limiares auditivos entre gêneros foram encontradas em estudo longitudinal efetuado por PEARSON e col. (1995), os quais controlaram as variáveis correspondentes à exposição a ruidos de natureza ocupacional, militar e de lazer. Os resultados indicaram que a taxa de perda auditiva é mais do que duas vezes mais rápida em homens do que em mulheres, em muitas freqüências e idades.

O desenvolvimento de pesquisa acerca de socioacusia, termo cunhado por Glorig, citado por PHANEUF e HÉTU (1990) para descrever as possiveis influências das condiçōes de vida sobre a audição, comporta sérias limitações metodológicas, uma vez que as amostras são geralmente pequenas e as exposições ocupacionais são raramente valorizadas com a exposição em atividades de lazer. 


\subsubsection{Fontes de ruído em um veículo a diesel.}

Um abordagem, a despeito de superficial, sobre os mecanismos geradores de ruido em um veículo a diesel objetiva caracterizar a máquina ou a fonte de importância ao trabalhador e servir de subsidio ao procedimento de avaliação de exposição dos motoristas do ônibus.

Conforme pesquisa realizada por SESHAGIRI (1998) há 7 principais fontes de ruido em veículos movidos a diesel, como caminhões pesados e ônibus: motor, exaustão, ventilador, entrada de ar, transmissão, pneus e outros. O ruido do motor pode ser dividido em duas categorias: ruído proveniente da combustão e o mecánico. O primeiro representa o ruido radiado pelas superfícies externas do motor, referentes às forças induzidas sobre o pistão e nas paredes do cilindro. Por sua vez, o ruido de origem mecânica vem de muitas fontes internas que contribuem para vibração da caixa, como: virabrequins, vibração flexível do bloco, válvulas, bombas de combustivel e injetoras.

Em relação à velocidade e sua associação com a emissão de ruido, o autor destaca a interação entre o pneu e a superfície do pavimento, que pode se tornar a fonte dominante quando a velocidade supera $70 \mathrm{~km} / \mathrm{h}$.

Ruido aerodinàmico produzido pela turbulência do fluxo de ar sobre a carroçaria do veículo e a irradiação da cabina e da estrutura de toda a carroçaria são consideradas as outras fontes que contribuem para o nivel global no posto de trabalho do motorista.

Assinala-se ainda que as características do pavimento das ruas desempenham papel expressivo na geração do ruído. Irregularidades existentes no pavimento podem elevar o nivel de ruido em até $10 \mathrm{~dB}(\mathrm{~A})$. conforme CRÉPEAU (1978). 


\subsection{Influência do ruído sobre as condições de trabalho entre motoristas:}

Motoristas de ônibus foram submetidos a avaliações ambiental e biológica em pesquisa com característica transversal de PATWARDHAN e col. (1991). Niveis de ruído no posto de trabalho do motorista variaram entre 89 e $106 \mathrm{~dB}(\mathrm{~A})$, enquanto que para o grupo controle, oscilaram de 50 a 62 $\mathrm{dB}(\mathrm{A})$. A prevalência de PAIR no grupo exposto, extremamente elevado, foi de $89 \%$ e de $19 \%$ para o não exposto.

VAN DEN HEEVER e ROETS (1996) examinaram a exposição ao ruído entre motoristas de caminhão, através da realização de dosimetrias, empregando nível critério de $85 \mathrm{~dB}(\mathrm{~A})$ e fator de troca igual a 3 , estudando dois tipos de cabina. Os resultados revelaram que estes trabalhadores encontram-se expostos acima dos limites estabelecidos, oferecendo assim um risco de ocorrência de perda auditiva.

Uma prevalência de PAIR de $17 \%$ foi encontrada em motoristas de ónibus na cidade do México, conforme um estudo epidemiológico conduzido por AHUMADA e col. (1991), cujo objetivo foi o de verificar as condições de trabalho destes trabalhadores.

Após a consulta nas bases de dados disponíveis sobre o tema, observou-se que a exposição de motoristas de ônibus ao ruído não tem sido considerada como um fator de risco relevante para a audição destes trabalhadores em paises industrializados, os quais detêm uma maior tradição e expressividade no campo de publicações sobre o tema saúde e trabalho; pois não foi encontrada uma referência especifica sequer. Possivelmente a concepção e o desenho dos ônibus empregados naqueles paises oferecem maior propriedade e adequação ao posto de trabalho do motorista em relação a este ponto. A exposição ao ruído é mencionada em pesquisa conduzida por Helmers e col. (1983), citado por EVANS (1994), na 
qual foram verificadas as condições ergonômicas da cabina do motorista em ônibus em uso na Suécia, país que apresenta padrões elevados de ergonomia. No entanto, o efeito discutido é sobre a performance e conforto do motorista, afetados sobretudo pelos componentes infra-sônicos do ruído existentes na cabina. Segundo o estudo, a exposição ao ruído com esta característica pode prejudicar a precisão no manuseio do volante, manutenção de uma determinada velocidade e tempo de reação.

A predominância dos estudos sobre as repercussões das condições de trabalho sobre a saúde de motoristas de ônibus urbanos, realizados principalmente em paises desenvolvidos, tem se detido sobretudo na relação entre saúde mental e trabalho. A ocorrência de estresse entre estes trabalhadores e as formas possiveis de prevenção tem sido a preocupação das pesquisas nesta realidade. A razão pela qual este agravo ter sido o eleito para análise deve-se às peculiaridades do processo e do ambiente de trabalho do motorista, determinadas por: baixa autonomia na função, pressão imposta pelo tempo para o cumprimento das viagens, congestão do tráfego, eventuais relaçōes conflituosas com passageiros e outros motoristas no trânsito, longas jornadas de trabalho, responsabilidade elevada e risco de ser vitima de um crime (EVANS 1994; DUFFY e McGOLDRICK 1990; KOMPIER 1996; EVANS e CARRĖRE 1991; KÜHLMANN 1990; CARRĖRE e col. 1991; CHAUDRON e col. 1997).

Conforme a maioria das publicaçōes consultadas, o eixo de prevenção para estes fatores de risco elencados para o desenvolvimento de estresse se fundamenta em um modelo de intervenção social, por meio de provimento de maior autonomia aos condutores, no que se refere ao planejamento e organização do trabalho. Este seria o instrumento para promover a democratização no local de trabalho, oferecendo maior participação dos motoristas na tomada de decisões, para prevenir a deterioração da saúde provocada por uma estrutura de relação saúde trabalho danosa. 
Em nivel nacional, as pesquisas desenvolvidas por SOUZA E SILVA (1998) e por SATO (1991) ilustram de modo nitido e contundente quão desgastante e estressante é o exercicio do trabalho de condução de ônibus na cidade de São Paulo. O primeiro estudo se dedicou a verificar a ocorrência de distúrbios psiquiátricos menores entre esta população, destacando a função de cobrador; enquanto que o segundo demonstrou claramente a penosidade que envolve a tarefa de condutor.

Cabe ainda acrescentar que os agravos à saúde de motoristas de ônibus urbanos relacionados ao sistema músculo-esquelético, como os já citados anteriormente, os quais se detiveram sobretudo no estudo da ocorrência de distúrbios da coluna, ao sistema digestivo e ao cardiovascular constituem-se como outros temas relevantes, com os quais as pesquisas têm se dedicado (CHAUDRON e col. 1997; ROSENGREN e col. 1991; RAGLAND e col. 1987; BELKIC e col. 1994). 


\subsection{Pesquisas em nivel nacional:}

É possivel verificar na literatura revisada, que o número de pesquisas inclinadas para investigar o risco da exposição ao ruído entre motoristas é modesto. A tese de doutorado de CAMPANA (1973), pioneira nesta área, analisou os riscos mais significativos na condução de ônibus, como ruído e vibração. O autor pôde verificar que há exposição ao ruído além dos limites, definidos pela norma brasileira, na grande maioria dos ônibus avaliados, categorizando a função de motorista, como de risco para o desenvolvimento de PAIR.

A avaliação das condições de trabalho de motoristas de ónibus na cidade do Rio de Janeiro foi efetuada por BRITTO (1975). Além de discutir sobre aspectos de conforto e outros riscos relacionados à atividade, Britto assinala que o ruido se configura como risco para o condutor. Interessante salientar que a vibração é tratada como trepidação, e que segundo o autor "não pode ser evitada". O autor se refere a Wittmarck, citado por SIMONI (1956), o qual argumenta que os trabalhadores mais atingidos pela PAIR são aqueles expostos à vibração transmitida pela estrutura óssea, citando o exemplo dos agentes ferroviários, cuja exposição ao ruido é relativamente modesta. No texto original de SIMONI (1956), verificou-se que a referència a esta constatação não apresenta elucidações muito consistentes.

Motoristas e cobradores de ônibus da cidade de Campinas foram objeto de estudo seccional desenvolvido por CORDEIRO e col. (1994), através do qual foi examinada a associação entre PAIR e as seguintes variáveis: tempo de trabalho total acumulado, pressão arterial e idade. Os autores encontraram uma prevalência de PAIR de $45,2 \%$ e, por meio de análise de regressão linear, uma associação positiva entre PAIR e tempo total acumulado de trabalho e também com a interação desta variável com idade. 
A pedido do sindicato de condutores da cidade de São Paulo, FONSECA e col. (1993) examinaram os niveis de exposição ao ruído, aos quais estão expostos motoristas e cobradores de ônibus. Os pesquisadores constataram que, para os motoristas de ônibus, cujos motores localizam-se em sua parte dianteira, as doses obtidas superaram a unidade ou se aproximaram muito desta

FERNANDES (1991) quantificou os riscos ocupacionais no posto de trabalho do tratorista, particularmente quanto à questão do ruído. Os resultados demonstraram que durante o trabalho de campo nenhum dos tratores apresentou padrões aceitáveis, uma vez valores entre 90 e 110 $\mathrm{dB}(\mathrm{A})$ foram registrados. Uma elevada prevalência de PAIR $(59,8 \%)$ entre os tratoristas constituiu-se como outro resultado relevante deste estudo.

Niveis de pressão arterial elevados durante a atividade, doenças do sistema músculo-esquelético como a causa principal de afastamentos do trabalho e frota obsoleta foram os achados mais significativos obtidos pelo estudo de SANTOS e MENDES (1999), os quais analisaram as condiçōes de trabalho e saúde de motoristas de ônibus em Belo Horizonte.

Em pesquisa de natureza seccional, MARQUES (1998) analisou uma população de 92 motoristas, condutores de ônibus com motor dianteiro, do município de São Paulo. A autora observou ma taxa de prevalência importante de $55,4 \%$ de traçados audiométricos sugestivos de PAIR, sendo que a idade e o tempo de serviço desempenharam influência na geração deste agravo. 


\subsection{Estudos que se utllizam de regressão logística para estudar as causas de perda auditiva.}

BARONE e col. (1987), em um estudo do tipo caso-controle verificaram que o tabagismo está associado com o risco elevado de perda auditiva em uma populaçăo exposta ao ruído. Com o propósito de controlar as possiveis variáveis de confusão (idade, tabagismo, lazer ruidoso, anos trabalhados na atual empresa, uso de protetor auricular e trabalhos anteriores expostos ao ruído), os pesquisadores empregaram o método de regressăo logística năo-condicional. Embora os níveis de ruído tenham sido avaliados, estes não foram usados no modelo como variável, possivelmente porque não houve diferenças significativas entre as médias registradas nos dois grupos de estudo.

SANTANA e BARBERINO (1995) analisaram a possivel associação existente entre exposiçăo ocupacional ao ruído e hipertensăo arterial. Definindo a exposição ao ruído como uma variável dicotômica (sim ou năo), cuja informação foi extraída dos prontuários, elegendo a hipertensão arterial como a variável de efeito e considerando os limites por serem utilizados dados secundários, os pesquisadores não encontraram associaçăo significativa entre ambas.

A exposição ao ruído foi utilizada como variável categórica dividida em quatro faixas de niveis de exposição ao ruído de trabalhadoras de uma indústria têxtil em estudo de prevalência desenvolvido por YIMING e col. (1991), cujos resultados mostraram que a exposição ao ruído comporta-se como um importante determinante de hipertensão arterial, atrás de ingestão de sal e história familiar.

Elegendo como variável dependente a perda auditiva grave induzida por ruído, ISHII e col. (1992) exploraram a associação entre diabetes mellitus não dependente de insulina (DMNDI) e a exposiçăo ao ruído em 
uma população de metalúrgicos. O estudo de natureza retrospectiva considerou a exposição ao ruido como variável independente contínua, além de idade (contínua), consumo de álcool (contínua), hipertensão (dicotômica), DMNDI (dicotômica), atividades de lazer ruidosas (dicotômica) e tabagismo (continua). Particularmente no que toca à caracterização da energia total de ruido recebida, os pesquisadores recorreram à exposição acumulada, representada pelo valor do nivel de imissão de ruido $\left(E_{A}\right)$ ponderado na escala $A^{5}$. Os resultados demonstraram que diabetes, exposição acumulada ao ruído e idade se comportaram como importantes preditores para a perda auditiva grave.

${ }^{5}$ O valor do nivel de imissão de ruido é calculado através da seguinte fórmula:

$E_{a}=L_{\text {teq }}+10 \log \left(\frac{1}{t_{i j}}\right) \mathrm{dB}(\mathrm{A})$

onde $\mathrm{Ea}=$ Nivel de imissão de Ruido ponderado na escala $\mathrm{A}$;

$L_{\text {Aeq }}=$ nivel sonoro equivalente;

$\mathrm{t}=$ duração em anos $\mathrm{e}$

to $=1$ ano 


\subsection{Estudos sobre exposições combinadas}

Um das primeiras publicações sobre a influência da vibração sobre a audição foi elaborada por Temkim, citado por HAMERNIK e col. (1981), em 1933, na qual o pesquisador já reportava que a exposição a este agente pode elevar a suscetibilidade individual à PAIR.

Condições ambientais complexas têm sido objeto constante de análise por parte de MANNINEN (1988), que conduziu uma pesquisa experimental, cujo principal objetivo foi o de obter informaçōes mais detalhadas sobre os efeitos combinados e isolados de ruido, vibração e temperatura sobre o corpo humano. Entre outros resultados, MANNINEN (1988) pôde observar uma elevação na mudança temporária de limiar de 4 e $6 \mathrm{kHz}$ em pessoas simultaneamente expostas a ruido e à $\mathrm{VCl}$.

Considerando que no ambiente de trabalho o homem está exposto a uma diversidade de fatores de risco, YOKOYAMA e col. (1974) empreenderam uma pesquisa experimental para verificar as possiveis consequeencias produzidas pela exposição à $\mathrm{VCl}$, ruído e a combinação de ambos os fatores de risco. A pesquisa encontrou mudanças temporárias de limiar mais expressivas e um tempo de recuperação mais longo em pessoas que se expuseram simultaneamente a ruido e à vibração, quando comparouse ao grupo somente exposto ao ruído. Apenas a exposição à $\mathrm{VCl}$ não provocou nenhuma alteração importante no traçado audiométrico.

SEIDEL e col. (1988) elaboraram uma interessante pesquisa cuja finalidade foi a de investigar os efeitos combinados entre ruído e vibração. $O$ estudo teve uma caracteristica experimental pelo qual foram estabelecidas três situações de exposição: ruído isolado com energia de $92 \mathrm{~dB}(\mathrm{~A}) ; \mathrm{VCl}$ no eixo $z$ na freqüência de $4 \mathrm{~Hz}$, aceleração de $1,0 \mathrm{~m} / \mathrm{s}^{2}$ e nivel de pressão sonora de $65 \mathrm{~dB}(\mathrm{~A})$; exposição combinada com nivel de pressão sonora de $92 \mathrm{~dB}(\mathrm{~A}), \mathrm{VCl}$ no eixo $\mathrm{z}$, com freqüência de $4 \mathrm{~Hz}$ e aceleração de $1 \mathrm{~m} / \mathrm{s}^{-}$. Os 
autores selecionaram arbitrariamente as freqüências de 10 e $12 \mathrm{kHz}$ para analisar eventuais mudanças temporárias de limiar, fundamentando-se em estudos anteriores, como os de Sataloff e o de Fausti e col. citado por SEIDEL e col. (1988, p.96), pelos quais já se afirmava que a orelha humana é mais sensivel a efeitos adversos na faixa de frequência acima de $8 \mathrm{kHz}$. Conforme os resultados obtidos pelos pesquisadores, a exposição combinada entre ruído e vibração induziu uma clara tendência de elevação da mudança temporária de limiar (MTL). As diferenças, consideradas significativas, se apresentaram de forma mais acentuada na freqüência de $10 \mathrm{kHz}$. Interessante destacar que na situação de exposição combinada, ou seja, $\mathrm{VCl}$ e ruído, este último estímulo apresentava um nivel bem abaixo dos limites estabelecidos pela higiene ocupacional (65 $\mathrm{dB}(\mathrm{A})$ ), e produziu mudanças temporárias de limiar consideráveis também nas freqüências de 4 e $6 \mathrm{kHz}$.

As exposições combinadas de ruído, vibração, temperatura e atividades de trabalho e seus eventuais efeitos sobre a saúde de trabalhadores, particularmente em relação ao estresse, foram analisadas através de pesquisa experimental conduzida por MANNINEN (1990). Os resultados encontrados pelo pesquisador revelaram que a exposição combinada entre $\mathrm{VCl}\left(2,12 \mathrm{~m} / \mathrm{s}^{2}, 2,44 \mathrm{~m} / \mathrm{s}^{2}\right)$ e ruído $(85,90,95 \mathrm{~dB}(\mathrm{~A}))$ é considerada mais estressante do que os dois fatores de risco atuando de modo isolado.

Estudos de natureza experimental foram conduzidos por LANDSTROMM e col. (1993) com o propósito de verificar os efeitos combinados da exposição a ruído e à $\mathrm{VCl}$. Operadores de helicópteros, caminhões-caçamba e veículos ferroviários foram avaliados aos dois estímulos de modo combinado $e$ isoladamente. Considerando as três situações de análise, os resultados mostraram que os niveis mais baixos de alerta e a maior referência de sonolência foram registrados durante a exposição combinada dos dois estimulos. Os autores também salientam que 
o ruído apresenta um efeito menor quando adicionado à exposição à VCI no que se refere aos aspectos de fadiga e irritação.

A qualidade do conforto da viagem também tem sido objeto de pesquisas no contexto da interação entre ruido e VCI. KIRBY e col. (1977), através de estudos experimentais, examinaram os efeitos da vibração simultânea nos eixos vertical e lateral em uma simulação de aeronaves de passageiros, e as conseqüências advindas da exposição simultânea entre vibração no eixo vertical e ruído. Os autores verificaram que em ambas as situações os estímulos se interagem a baixos niveis, mas atuam de modo isolado em valores mais elevados.

Experimentos de laboratório foram empreendidos por MANNINEN (1983b) para verificar os efeitos da exposição combinada entre ruido e VCI. Nestes estudos, voluntários foram submetidos à vibração senoidal de corpo inteiro $\left(5 \mathrm{~Hz}-2,12 \mathrm{~m} / \mathrm{s}^{2}\right.$ e $\left.10 \mathrm{~Hz}-2,65 \mathrm{~m} / \mathrm{s}^{2}\right)$ ao longo do eixo $\mathrm{z}$ com oito niveis de ruido e largura de banda diferentes de $85 \mathrm{~dB}(\mathrm{~A}), 90 \mathrm{~dB}(\mathrm{~A})$ e 98 $\mathrm{dB}(\mathrm{A})$. Os resultados revelados por esta pesquisa indicam que a presença de vibração eleva a mudança temporária de limiar após 2 minutos $\left(\mathrm{MTL}_{2}\right)$ provocada pelo ruido, notadamente nas freqüências de $4 \mathrm{kHz}$ e $6 \mathrm{kHz}$. Ainda de acordo com os dados obtidos pelo experimento, a exposição simultânea a ruído de banda larga $(0,2-16 \mathrm{kHz})$ e vibração apresentou valores de $\mathrm{MTL}_{2}$ 1,2 a 1,5 vezes o valor encontrado na freqüência de $4 \mathrm{kHz}$ para a exposição isolada ao ruído da mesma característica.

Em revisão da literatura confeccionada por SEIDEL (1993), o objeto de maior interesse é sobre a questão da exposição combinada com o ruído. Trabalho desenvolvido por Pinter em 1975, citado por SEIDEL (1993, p.594), comparou a mudança permanente de limiar de audição de tratoristas (exposição combinada) com um grupo formado por marceneiros (somente ruido). Pinter encontrou uma perda maior induzida por vibração na freqüência de $6 \mathrm{kHz}$ de $6 \mathrm{~dB}$ após uma exposição de 5 a 14 anos. 
Motoristas e técnicos de agricultura foram objeto de estudo interessante empreendido por Schimidt, em 1987, citado por SEIDEL (1993, p.594). O autor, comparando os referidos grupos, concluiu que o efeito adicional relevante da $\mathrm{VCI}$ pode ser prognosticada para o desenvolvimento de uma mudança permanente de limiar nas freqüências de 3, 4, 6 e $8 \mathrm{kHz}$ após uma exposição de 3 a 24 anos no trabalho, se os níveis de aceleração excederem $1,2 \mathrm{~m} / \mathrm{s}^{2}$ r.m.s. e o nivel equivalente de ruido for maior do que 80 $\mathrm{dB}(\mathrm{A})$.

Após examinar os estudos correspondentes a este tipo de exposição simultânea, tanto nos aspectos relativos aos efeitos a longo como a curto prazo, SEIDEL (1993) argumenta que a VCI parece ter uma contribuição modesta. A despeito desta afirmação, recomenda que o limite máximo permitido para ruido seja reduzido em $3 \mathrm{~dB}$ se houver exposição à $\mathrm{VCl}$ que exceda os limites definidos pela norma ISO-2631-1 (1985).

A respeito da exposição combinada entre ruido e vibração, os autores também citam o estudo desenvolvido por Pinter, argumentando que não é possivel excluir a afirmação de que pode ter havido uma diferença entre os niveis de exposição ao ruído entre os dois grupos eleitos para se efetuar a comparação. Verificou-se pelas conclusões obtidas na revisão, que os artigos estudados sugerem que há a possibilidade da $\mathrm{VCl}$ ampliar os efeitos do ruido, avaliados pela mudança temporária de limiar (MTL) com 2 a 5 dB.

Segundo os pesquisadores responsáveis pela revisão, os estudos experimentais permitem conclusōes mais seguras sobre os efeitos combinados e isolados de $\mathrm{VCl}$ do que os realizados no campo. Em virtude de que em muitos casos há a dificuldade para se encontrar grupo para comparação (não exposto à vibração e exposto aos outros mesmos riscos), os autores sugerem o estudo de diferentes grupos de motoristas, os quais estão expostos a diferentes niveis de vibração. 
De acordo com os autores, a fragilidade para descrever a associação exposição-resposta impossibilita uma conclusão consistente acerca dos resultados alcançados e salientam que apenas a presença de $\mathrm{VCl}$ não representa um risco para a audição.

Ruído de impacto e vibração de corpo inteiro em niveis habitualmente encontrados na indústria podem concorrer para incrementar a suscetibilidade da cóclea à PAIR. Este resultado de interação entre os dois agentes foi alcançado por HAMERNIK e col. (1981) após a execução de um estudo experimental, no qual chinchilas foram submetidas a três condições de exposição: ruído, vibração de corpo inteiro e a combinação de ambos.

Os efeitos na audição provocados pela associação entre exposição ao ruido e à vibração são avaliados por HAMERNIK e col. (1989). Neste estudo são discutidos inicialmente pesquisas já realizadas sobre o tema, as quais sugerem que a exposição à vibração pode potencializar o efeito do ruído, crescendo assim o risco de perda auditiva induzida por ruído. Revisando estudos de laboratório, os pesquisadores observaram que estes parecem indicar que os efeitos sobre a perda auditiva induzida por ruído eventualmente provocados pela presença concomitante da vibração localizar-se-iam nas freqüências mais afetadas, com a quantidade aproximada de $5 \mathrm{~dB}$. Relativamente pequenos são classificados os efeitos em experimentos humanos, uma vez que os niveis de exposição são naturalmente baixos. Por este motivo, os pesquisadores optaram em realizar um estudo experimental com chinchilas expostas à vibração a $30 \mathrm{~Hz}$, $3 \mathrm{~g}$ r.m.s. e a $20 \mathrm{~Hz}, 1,3 \mathrm{~g} \mathrm{r.m}$.s. de modo separado e conjuntamente a ruído contínuo $(95 \mathrm{~dB}, 500 \mathrm{~Hz})$ e a ruído de impacto $(113,119$ ou $125 \mathrm{~dB}$ de pico $\mathrm{SPL}$ ). Os autores verificaram que tais exposiçōes combinadas podem alterar determinadas medidas de audição, mas foram somente significativas em situações de exposição à vibração mais acentuada. 
BOVENZI (1990) analisou os efeitos agudos provocados pela exposição à $\mathrm{VCl}$, bem como discute aspectos conceituais sobre o tema, como as relações biodinâmicas do corpo humano e suas reações fisiopatológicas. BOVENZI (1990) revisou a literatura destacando os possiveis efeitos aos aparelhos neuromuscular, respiratório, cardiovascular e otovestibular. $O$ autor manifesta que, em virtude da variedade de desenhos de pesquisa e dos diferentes meios de aquisição de dados audiométricos, não é possivel delinear conclusões definitivas sobre a exposição combinada.

OKADA e col. (1971) encontraram uma mudança temporária de limiar $5 \mathrm{~dB}$ superior nas freqüências de 1 e $4 \mathrm{kHz}$, após expor cinco voluntários a ruido de banda larga de $110 \mathrm{~dB}$ e a VCl de $5 \mathrm{~m} / \mathrm{s}^{2}$.

Nas frequêencias de 4 e $6 \mathrm{kHz}$ foram constatadas as maiores e mais rápidas elevações dos valores da mudança temporária de limiar $\left(\mathrm{MTL}_{2}\right)$ quando voluntários foram submetidos simultaneamente a vibração senoidal de corpo inteiro (frequềncia de $5 \mathrm{~Hz}$, na direção do eixo $z$ e aceleraçōes de 2,12 ou $2,44 \mathrm{~m} / \mathrm{s}^{2}$ ) e a ruído (estável, de banda larga e $90 \mathrm{~dB}(\mathrm{~A})$ ). comparando-se com o grupo apenas exposto a este último estimulo. Estes achados foram descritos por MANNINEN e EKBLOM (1984) em pesquisa de laboratório, cuja finalidade foi a de registrar as conseqüências isoladas e conjugadas destes dois estimulos sobre a audição

Pesquisa de natureza experimental empreendida por MANNINEN (1983a), pela qual um dos objetivos foi o de verificar os efeitos simultâneos de $\mathrm{VCl}$ senoidal e ruido de banda larga sobre a mudança temporária de limiar $\left(\mathrm{MTL}_{2}\right)$ em homens a duas diferentes temperaturas de bulbo seco, revelou que os valores médios de $\mathrm{MTL}_{2}$ foram normalmente mais elevados na temperatura de bulbo seco a $30^{\circ} \mathrm{C}$ do que a $20^{\circ} \mathrm{C}$. As alteraçōes de limiar foram mais acentuadas nas freqüèncias de 4 e $6 \mathrm{kHz}$ e mais modestas na de $8 \mathrm{kHz}$. 
KÖHL (1975) examinou de modo abrangente os riscos à saúde que envolvem a condução de tratores, considerando a exposição à $\mathrm{VCl}$. A autora constatou, por intermédio de um questionário, que os tratoristas apresentaram altas taxas de prevalência de dor nas costas e problemas no sistema digestivo. Um interessante achado desta pesquisa, após uma avaliação clínica, foi uma perda especifica a $6 \mathrm{kHz}$ significativamente maior do que as registradas nas freqüências de 4 e $8 \mathrm{kHz}$. A autora não discute mais profundamente as possiveis causas desta perda especifica, não aludindo à exposição concomitante entre ruído e vibração.

HUMES (1984) investigou, por meio de revisão sobre o assunto, a interação do ruido com outros fatores, bem como com algumas características físicas do individuo no desencadeamento de perda auditiva induzida por ruído. Drogas ototóxicas, ruído de impacto e $\mathrm{VCl}$ compuseram a relação dos outros agentes, enquanto que idade, presença de perda auditiva anterior à exposição ao ruído, cor dos olhos e etnia foram as variáveis concernentes às características individuais. Revisando a literatura desde 1970, o autor assinala que pode haver interaçōes entre ruido contínuo e diversas drogas ototóxicas (canamicina, neomicina, salicilato de sódio) e entre ruido contínuo e de impacto.

Quatro estudos, que abordaram os efeitos da exposição combinada entre ruido e vibração de corpo inteiro, foram objeto de revisão por HUMES (1984). Segundo o autor, as pesquisas analisadas demonstram evidência de interação entre os dois agentes, e por não considerá-las suficientemente expressivas, recomenda trabalhos posteriores visando a elucidação. Em relação às características físicas, somente a idade demonstrou interação com o ruido. É salientado neste trabalho que animais mais jovens apresentam maior suscetibilidade ao ruido.

Alterações temporárias de limiar mais elevadas na faixa de frequêencias compreendidas entre 6 e $10 \mathrm{kHz}$ têm sido registradas devido à 
exposição simultânea a ruido e à vibração, comparando-se com a exposição isolada ao ruído, como atesta o guia sobre efeitos de vibração do corpo inteiro do Comitê Europeu de Normalização (CEN 1996). Portanto, de acordo com este documento, a exposição a longo prazo à $\mathrm{VCl}$ pode potencializar a PAIR, a despeito de os mecanismos patogènicos não terem ainda sido desvendados.

Nota-se através da leitura desta revisão que a expressiva maioria das pesquisas descritas se fundamentou em estudos experimentais que avaliaram mudanças temporárias de limiar (MTL). LAWTON e ROBINSON (1989), autores de um revisão extensa e critica sobre a combinação de exposição de vários agentes com o ruído, ressaltam a inexistência de evidència na literatura que a mudança permanente de limiar (MPL) em humanos obedeça o mesmo padrão para a MTL, no tocante aos estudos devotados à conjunção de ruido e vibração de corpo inteiro.

Contrariando os achados das pesquisas aqui relatadas, há estudos em que se conclui que a exposição à vibração de corpo inteiro pode exercer uma proteção contra a PAIR, pois os resultados indicaram uma melhoria no limiar na freqüència de $2 \mathrm{kHz}$ e além disso pode prevenir a MTL provocada pelo ruido. Estes efeitos protetores paradoxais foram revelados nas pesquisas conduzidas por Guignard e Coles, citado por e LAWTON e ROBINSON (1989, p. 54-55), em 1965; JAUHIAINEN e col. (1969) e KAIMIO e col. (1970). As explicaçōes acerca dos mecanismos geradores deste efeito estão além do escopo deste trabalho. 


\subsection{Estudos sobre vibração de corpo inteiro em nível nacional}

A publicação de pesquisas nacionais sobre o tema tem sido bastante timida. Na revisão bibliográfica, especialmente na base de dados LILACS, foram encontrados dois estudos sobre o assunto.

A incidência de queixas gastrintestinais e lombares foi explorada por BUSCHINELLI e MORO (1985) por intermédio de uma pesquisa, pela qual foram examinados os registros de prontuários médicos de trabalhadores de uma empresa produtora de açúcar e álcool. Os autores consideraram somente os sintomas mais representativos, os quais conduziram o trabalhador a procurar atendimento médico. O grupo classificado como exposto era constituido por operadores de trator, colheitadeiras, caminhão, enquanto que o não exposto era formado por outros trabalhadores não expostos à VCI. Os autores utilizaram a medida de associação "risco relativo RR" para efetuar a comparação entre os dois grupos. Encontraram valores elevados de RR de queixas de lombalgia e gastrintestinais na análise entre o grupo exposto e não exposto.

Uma revisão das principais normas atinentes à avaliação de exposição à $\mathrm{VCl}$ em tratoristas foi desenvolvida por ROBIN (1987), dando destaque à relevância do assento do trator. $O$ autor apontava a necessidade da montagem de laboratório para a realização de ensaios de assentos de tratores produzidos no Brasil. 


\section{OBJETIVOS}

- Geral:

- Examinar a associação entre a exposição à vibração de corpo inteiro ( $\mathrm{VCI}$ ) e ao ruido e a perda auditiva induzida por ruido (PAIR) em motoristas de ônibus.

- Específicos:

- Avaliar a exposição de motoristas de ônibus à $\mathrm{VCl}$ e ao ruído;

- Estimar a prevalência de Perda Auditiva Induzida por Ruído (PAIR) na população de estudo;

- Analisar as condições do posto de trabalho do motorista de ônibus para subsidiar as ações de intervenção que objetivem a redução ou eliminação dos riscos à saúde provenientes da exposição à $\mathrm{VCl}$ e ao ruido. 


\section{MATERIAL E MÉTODOS:}

\subsection{População do estudo:}

A população selecionada para compor o estudo foi constituida por motoristas de uma empresa de transporte coletivo urbano por ônibus na cidade de São Paulo. As condições de trabalho desta empresa foram objeto de investigação pelo serviço de vigilància do Centro de Referência em Saúde do Trabalhador - CEREST-SP, um serviço público vinculado à Secretaria de Estado da Saúde. Este tipo de procedimento de análise do processo e do ambiente de trabalho visa atender solicitação do Ministério Público do Estado de São Paulo - Promotoria de justiça de Acidentes do Trabalho da Capital, o qual designa técnicos do CEREST-SP para empreender a análise. Avaliaçōes biológicas, como audiológicas, são invariavelmente realizadas com 0 fim de subsidiar 0 processo de investigação.

A empresa, objeto desta investigação, atua na região norte da cidade de São Paulo, possuía, em setembro de 1999, uma frota de 360 ônibus e contava com 1397 funcionários envolvidos em sua operação (motoristas, cobradores e fiscais de linha), dos quais 694 (49,7\%) eram motoristas. Desta população de motoristas foram relacionados $322(46,4 \%)$, cuja jornada de trabalho era no periodo vespertino, para permitir a viabilização do necessário repouso acústico para a realização do exame audiométrico.

Assim, a população de motoristas do período vespertino foi dividida em dois grupos em relação ao tempo de trabalho na empresa como motorista. O grupo classificado como exposto foi constituido por 85 motoristas com tempo de empresa superior ou igual a 5 anos, enquanto que a população definida como referência foi definida por 105 motoristas com tempo acumulado de empresa inferior a 3 anos, totalizando 190 motoristas. 
Elaborada a relação dos motoristas selecionados, solicitou-se à empresa que estes fossem encaminhados ao CEREST-SP para serem submetidos à avaliação, com as devidas informações sobre a necessidade de repouso acústico.

A metodologia para selecionar a população de estudo encontra-se fundamentada no processo denominado restrição (KLEINBAUM e col. 1982). Os autores, para elucidar o processo, mencionam um exemplo de aplicação em saúde ocupacional, asseverando que a população de estudo pode se restringir a um grupo com exposição importante a um fator de risco e outro sem exposição. Desta forma, eleva-se a possibilidade de se detectar uma associação, independente da dimensão da amostra, caso haja uma relação monotônica ${ }^{6}$. Esta relação se manifesta de forma nítida no caso de exposição ao ruído e desenvolvimento de PAIR.

A determinação destes cortes, com o propósito de delimitar os grupos para efetivar a comparação, foi influenciada por informações acerca do tempo necessário estimado para a instalação da lesão. De acordo com SILVA e COSTA (1998), a PAIR apresenta-se normalmente após três anos de exposição tendendo a se estabilizar depois de um período de 15 anos de evolução. MORIOKA e col. (1997) afirmam que o agravo se instala gradualmente em um periodo aproximado de 1 a 5 anos.

Além disso, a delimitação da população nestes dois grupos buscou confrontar exposições acumuladas em niveis distintos. O grupo com tempo de exposição menor representa, portanto, o controle.

\footnotetext{
${ }^{6}$ Há uma relação monotônica quando o risco da doença cresce ou decresce com o aumento da exposição.
} 
A escolha por um grupo interno para comparação, se deu em razão de dificuldades enfrentadas para localizar um grupo externo que servisse como referência.

Optar por grupos internos, para se proceder a comparação, é classificado por CHECKOWAY e col. (1989), como mais apropriado, pois tende a diminuir a influência de alguns vieses importantes como o Efeito do Trabalhador Sadio. 


\subsection{Avaliação da exposição ao ruído:}

Uma vez que a posição do trabalhador é fixa e o ruido com caracteristica flutuante, optou-se pelo procedimento da medição indireta com o emprego de medidores de nivel sonoro integradores, pois havia a possibilidade de identificação dos ciclos de trabalho e sua distribuição no tempo (COMUNIDADE ECONÔMICA EUROPĖIA 1986). Desse maneira, houve a possibilidade de reconstituir a exposição.

Foram empregados um medidor de nivel sonoro integrador e um calibrador $(250 \mathrm{~Hz}, 94 \mathrm{~dB}$ ), ambos da marca Bruel\&Kjaer e de classe I, modelos 2236 e 4231 respectivamente. $O$ erro de equipamentos inseridos nesta classe de precisão situa-se entre $\pm 1 \mathrm{~dB}(\mathrm{~A})$ (BENEDETTO e col. 1986; GERGES 1992, COWAN 1994).

A metodologia seguiu os principios e grandezas estabelecidos pela ISO-1999 (1990).

As medidas foram realizadas, em condições normais de operação, com o microfone posicionado a cerca de $10 \mathrm{~cm}$ da orelha mais exposta do operador, conforme recomenda diretiva da Comunidade Econômica Européia (1986), com o equipamento posicionado sobre tripé. 


\subsubsection{Grandezas empregadas:}

A grandeza empregada na avaliação foi o nivel equivalente ( $\left.L_{\text {Aeq }}\right)$ ponderado na escala $A$, cujo significado é o valor de um ruído constante hipotético com a mesma energia do ruído eventualmente flutuante avaliado. Se o ruído avaliado for de natureza constante, os dois valores encontrados são semelhantes. $O$ valores do $L_{\text {Aeq, }}$ para os trajetos de ida e volta do veículo, foram obtidos em uma viagem realizada, considerada como ciclo de trabalho do motorista.

O nivel equivalente ponderado na escala " $A$ " é representado, segundo a ISO-1999 (1990), pela seguinte equação:

$$
L_{\text {Aeq }}=10 \log \left[\frac{1}{T_{0}} \sum_{i=1}^{N}\left(10^{L_{A i / 10}} t_{i}\right)\right] \mathrm{dB}(\mathrm{A})
$$

onde $T_{0}$ representa o período total da medição, "i" é determinado intervalo, "N" é o número total de intervalos, "ti" é duração de determinada observação e "LAi" é o nível sonoro ponderado " $A$ " durante o tempo "ti".

O valor da exposição final, correspondente à jornada de trabalho de 8 $h$, é representado pelo nivel de exposição $L_{E X}$, o qual considera tanto o valor do LAeq em cada ciclo, ou no caso, viagem, bem como o respectivo tempo de exposição. $O L_{E x}$ foi calculado de acordo com o tempo fornecido pelo aparelho em cada ciclo ou trajeto (ida e volta) de viagem, bem como pelo número de viagens realizadas por dia, de acordo com declarações prestadas pelo motorista.

Para o cálculo do nível de exposição $L_{E X}$, verifica-se a seguinte equação, conforme a ISO-1999(1990): 


$$
L_{E X}=L_{A e q}+10 \log \left(\frac{T}{T_{0}}\right) \mathrm{dB}(\mathrm{A})
$$

Onde T representa o periodo de exposição a determinado nível equivalente e $T_{0}$ o tempo critério de $8 \mathrm{~h}$.

Como a jornada semanal dos motoristas compreende 6 dias de trabalho, configurando portanto uma distribuição irregular no período, optou-

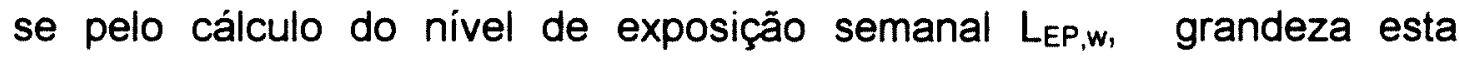
estabelecia pela diretiva da Comunidade Econômica Européia (1986) e definido pela seguinte fórmula:

$$
L_{E P, w}=10 \times \log \left[\frac{1}{5} \sum_{k=1}^{m} 10^{0,1\left(L_{E P, d}\right) k}\right]
$$

Onde ( $\left.L_{E P, d}\right) k$ são os valores do $L_{E X}$ para cada um dos $m$, ou seis dias, de trabalho da semana considerada.

A seguir é apresentado um exemplo do procedimento de cálculo do nivel de exposição para subsidiar no entendimento da metodologia adotada. 
3.2.2 Exemplo de cálculo do nivel de exposição - $L_{E X}$ :

> Número de viagens por jornada $=4$ (a)

Tabela 3.1: Exemplo ilustrativo para a compreensão do cálculo do nivel de exposição semanal.

\begin{tabular}{lcccc}
\hline Trecho & $\mathrm{L}_{\text {Aeq }}-\mathrm{dB}(\mathrm{A})$ & Tempo - min & $\mathrm{Tt}(\mathrm{min})$ & $\mathrm{L}_{E X}-\mathrm{dB}(\mathrm{A})$ \\
\hline $\mathrm{A}-\mathrm{B}$ & $85,2(\mathrm{~b})$ & $70(\mathrm{~d})$ & $280(\mathrm{~g})$ & $82,9(\mathrm{j})$ \\
$\mathrm{B}-\mathrm{A}$ & $83,9(\mathrm{c})$ & $80(\mathrm{e})$ & $320(\mathrm{~h})$ & $82,1(\mathrm{l})$ \\
\hline & & $150(\mathrm{f})$ & $600(\mathrm{i})$ & $\mathbf{8 5 , 5}(\mathrm{m})$ \\
\hline
\end{tabular}

- $a$ = número de viagens realizadas na jornada

- $b=$ nivel equivalente ponderado na escala " $A$ " registrado no percurso $A$ -

B

- $c=$ nivel equivalente ponderado na escala " $A$ " registrado no percurso $B$ -

C

- $d=$ tempo despendido, em minutos, no percurso $A-B$

- $e=$ tempo despendido, em minutos, no percurso $B-A$

- $f=d+e$

- $g=$ tempo total despendido, na jornada, referente ao percurso $\mathrm{A}-\mathrm{B}(\mathrm{Tt}=$ $a \times d)$

- $h=$ tempo total despendido, na jornada, referente ao percurso $B-A$ (Tt $=a \times e)$

- $i=g+h$

- $j$ = nivel de exposição, em $\mathrm{dB}(\mathrm{A})$, considerando o nivel equivalente registrado e o tempo total despendido no percurso $A$ - $B$

$$
L_{E X}=L_{A e q}+10 \times \log \left(\frac{t_{e}}{t_{0}}\right)=b+10 \times \log \left(\frac{g}{480}\right)
$$

- $480=$ tempo, em minutos, correspondente a uma jornada diária de $8 \mathrm{~h}$. 
- $\quad I$ = nivel de exposição, em $\mathrm{dB}(\mathrm{A})$, considerando o nivel equivalente registrado e o tempo total despendido no percurso $B$ - A

$$
L_{E X}=L_{A e q}+10 \times \log \left(\frac{t_{e}}{t_{0}}\right)=c+10 \times \log \left(\frac{h}{480}\right)
$$

- $480=$ tempo, em minutos, correspondente a uma jornada diária de $8 \mathrm{~h}$.

- $m=$ nivel de exposição diário total considerando os dois niveis de exposição parciais ( $\mathrm{j}$ e l) calculados anteriormente.

$$
L_{E X}=10 \times \log \sum_{i}^{n} 10^{\frac{L_{i}}{10}}=10 \times \log \left(10^{\frac{i}{10}}+10^{\frac{l}{10}}\right)
$$

Portanto, O $L_{E x}$ diário é de $85,5 \mathrm{~dB}(\mathrm{~A})$

Como a jornada semanal do motorista compreende atividade aos sábados ou aos domingos, é necessário calcular-se a jornada semanal em relação à convencional de 5 dias.

Aos sábados ou aos domingos, são realizadas 6 e 7 viagens respectivamente. Todo o procedimento anterior é recalculado, considerando os valores acima ( $a=6$ e $a=7$ ), para se obter o nivel de exposição destes dias específicos.

Desse modo, foi obtido o $L_{E x}$ de $87,3 \mathrm{~dB}(\mathrm{~A})$ para o sábado e de 88,0 $\mathrm{dB}(\mathrm{A})$ para o domingo.

Calcula-se a média logaritmica destes dois valores do seguinte modo: 
Assim, obtém-se a média de $87,6 \mathrm{~dB}(\mathrm{~A})$.

Tabela 3.2: Exemplo ilustrativo com os niveis diários de exposição calculados.

\begin{tabular}{lc}
\hline Dia da semana & $\mathrm{LEx}_{\mathrm{Ex}}-\mathrm{dB}(\mathrm{A})(\mathrm{Li})$ \\
\hline Segunda-feira & 85,5 \\
Terça-feira & 85,5 \\
Quarta-feira & 85,5 \\
Quinta-feira & 85,5 \\
Sexta-feira & 85,5 \\
Sábado ou Domingo & 87,6 \\
\hline
\end{tabular}

Com este valor correspondente ao nivel de exposição da jornada realizada sábado ou domingo e o obtido anteriormente referente aos outros dias da semana, calcula-se o valor da exposição semanal, pela seguinte fórmula:

$$
L_{E P, w}=10 \times \log \frac{1}{5} \sum_{i}^{n} 10^{\frac{L_{i}}{10}}
$$

Assim, registra-se um nivel de exposição semanal de $86,7 \mathrm{~dB}(\mathrm{~A})$. 


\subsubsection{Avaliação do erro estatístico:}

O procedimento para a avaliação norteou-se pelos trabalhos elaborados por LEIDEL e LYNCH (1977), BRUNN e col. (1986) e BEHAR e PLENER (1984). O método adotado para controlar o erro da avaliação pressupõe que a distribuição dos niveis de ruido obedeça a curva normal. Esta hipótese de distribuição dos níveis sonoros é corroborada pelo projeto de norma ISO/DP 9612, citado por DAMONGEOT e KUSY (1990, P. 348). Estes autores analisaram meios estatísticos para se estimar o nível de exposição ao ruido e concluiram que o procedimento mais indicado seria a média aritmética e os limites de Student corrigidos. Foi aplicada esta metodologia sobre os dados obtidos neste trabalho para o cálculo das médias do nivel equivalente ponderado na escala $A$ (LAeq) e do nivel de exposição (Lex). Não foram observadas diferenças importantes entre os resultados encontrados pelos dois métodos.

Conforme LEIDEL e LYNCH (1977) os erros do instrumento utilizado e o da amostragem, o erro analítico e as oscilações ambientais são as três fontes habituais de variação em um procedimento de estimativa de exposição ocupacional. Normalmente, segundo os autores, as duas primeiras são menos importantes quando são cotejadas com as variações ambientais, as quais são determinadas por meio de um processo sucessivo de amostragem.

Com a adoção desta metodologia, o número suficiente de medidas ou de amostras para se estimar a exposição da população selecionada, foi ditado pelo intervalo de confiança para a estimativa por ponto. Desse modo, quando um intervalo de confiança da média de uma série de medidas foi inferior ou igual ao erro do equipamento em uso, a dimensão da amostra foi definida como suficiente e o procedimento de avaliação pôde ser classificado como concluido. Caso, por exemplo, o erro do medidor de nivel de pressão sonora seja de $\pm 1 \mathrm{~dB}(\mathrm{~A})$, o processo de coleta de amostras 
pôde ser finalizado quando a variabilidade da média da amostra esteve abaixo ou igual a este valor [com $(1-u) \%$ de confiança, onde $\alpha=$ nivel de errol. A fórmula a seguir foi aplicada para o cálculo do intervalo de confiança da média:

$$
x \pm t \times\left(\frac{\sigma}{\sqrt{n}}\right)
$$

onde: $x=$ Lex médio em $\mathrm{dB}(\mathrm{A})$ da distribuição amostral; $t$ = valor $\mathrm{da}$ distribuição t com ( $n$-1) graus de liberdade e um nível de confiança (1 - $\alpha$ ); $n$ = número de amostras e $\sigma=$ desvio padrão da distribuição amostral. 
3.2.4 Dimensionamento da amostra de medidas para a avaliação de exposıção ao ruído:

Considerando a inviabilidade de se avaliar toda a população de motoristas da empresa e a assumindo como um grupo homogêneo, foi adotado um procedimento de amostragem para a realização desta tarefa. $O$ dimensionamento da amostra de medidas para a avaliação de exposiçāo ao ruido baseou-se nas informações contidas nos estudos de LEIDEL e col. (1977) e de BEHAR e PLENER (1984). Os autores referem que duas grandezas devem ser estabelecidas para a construção da amostra. A proporção da amostra que apresenta o nivel de exposição mais elevado, com variação de 0 a 1 , é a primeira e é representada por $T$; enquanto que 0 segundo conceito $\alpha$ representa a probabilidade de não incluir nenhum trabalhador pertencente ao grupo com a maior exposição. A tabela abaixo, fundamentada neste conceito, apresenta o número necessário da amostra, segundo a dimensão do grupo homogêneo estudado.

Tabela 3.3: Indicação para o dimensionamento da amostra de acordo com o tamanho do grupo homogêneo, para $T=10 \%(0,1)$ e confiança $0,95(\alpha=0,05)$

\begin{tabular}{cccc}
\hline $\begin{array}{c}\text { Tamanho do } \\
\text { grupo homogêneo }\end{array}$ & $\begin{array}{c}\text { Número requerido } \\
\text { de empregados } \\
(\mathrm{n})\end{array}$ & $\begin{array}{c}\text { Tamanho do } \\
\text { grupo homogêneo }\end{array}$ & $\begin{array}{c}\text { Número requerido } \\
\text { de empregados } \\
(\mathrm{n})\end{array}$ \\
\hline 12 & 11 & $25-27$ & 17 \\
$13-14$ & 12 & $28-31$ & 18 \\
$15-16$ & 13 & $32-35$ & 19 \\
$17-18$ & 14 & $36-41$ & 20 \\
$19-21$ & 15 & $42-50$ & 21 \\
$22-24$ & 16 & $\geq 51$ & 29 \\
\hline
\end{tabular}

Fonte: LEIDEL e col. (1977); BEHAR e PLENER (1984) 
Assumindo os 658 motoristas empregados pela empresa como um grupo homogêneo, a tabela 3.3 indica que 29 trabalhadores deveriam ser objeto de avaliação.

Inicialmente, o número de avaliações por linha foi determinado de modo proporcional ao número de trabalhadores em cada uma, tendo como indicação o valor de 29 determinado acima. No entanto, medidas adicionais foram executadas com o fim de avaliar o erro estatístico (erro padrão $\leq 1$ $d B)$, conforme discutido anteriormente, buscando o valor de nível equivalente e 0 de exposição diária por modelo de ônibus, segundo o posicionamento do motor, dianteiro ou traseiro, medidas adicionais foram executadas gradualmente.

O procedimento de avaliação totalizou 46 viagens, com duração média de 105,4 min cada uma, compreendendo 92 medições e totalizando $80,8 \mathrm{~h}$ de trabalho liquido de campo. 
3.2.5 Cálculo do nivel de imissão sonora:

Após a determinação do nivel de exposição semanal para cada grupo de modelo de ônibus, ou seja, com motor localizado na seção dianteira ou entre - eixos e o com posicionamento traseiro, calculou-se o nivel de imissão $E_{A}$ (ISHII e col. 1992; NIOSH 1998), que representa um descritor da exposição ao ruído, para cada motorista, segundo o histórico do modelo empregado em sua atividade de condução do ônibus e o tempo de exposição. O nível de imissão $E_{A}$ é calculado por meio da seguinte fórmula:

$$
E_{A}=L e x+10 \log \left(\frac{T}{T_{0}}\right) \mathrm{dB}(\mathrm{A})
$$

onde:

$E_{A}$ refere-se ao nivel de imissão de ruido ponderado na escala $A ; L_{E x}, 0$ nivel de exposição semanal médio calculado; T, o tempo de exposição, ou de condução do veículo na empresa, em anos e $T_{0}$ representa o periodo de 1 ano.

O emprego de exposições acumuladas é mais indicado quando os efeitos são a longo prazo como é o caso de PAIR, segundo CHECKOWAY e col. (1989) 


\section{3 Avaliação da exposição à vibração de corpo inteiro:}

As diretrizes estabelecidas pela norma ISO-2631-1 (1985) foram respeitadas para a realização da avaliação. Para quantificar os valores da aceleração, foi utilizado um conjunto de equipamentos da marca Bruel \& Kjaer: medidor de vibração modelo 2231 , módulo para vibrações de corpo modelo 2522, calibrador modelo 4294 e acelerômetro triaxial de assento modelo 4322, este disposto na interface formada pelo motorista e o assento do veículo. A verificação da calibração foi realizada antes e após cada série de medidas. As medidas foram realizadas em condições cotidianas de operação e com a duração aproximada de 20 minutos cada. Todos os seis modelos de ônibus utilizados pela empresa foram objeto de avaliação.

A ponderação utilizada para as acelerações foi a sugerida pela norma ISO-2631-1 (1985), fornecendo assim os valores ponderados em cada eixo, a saber: $a_{x w}, a_{y w}$ e $a_{z w}$. De posse destes valores, foi determinada a somatória vetorial, por intermédio da seguinte fórmula:

$$
a=\sqrt{\left[\left(1,4 a_{x w}\right)^{2}+\left(1,4 a_{y w}\right)^{2}+a_{z w}^{2}\right]} \mathrm{m} / \mathrm{s}^{2} \text { r.m.s. }
$$

A dose de vibração será calculada obedecendo o princípio de energia equivalente, que emprega a dependência temporal estabelecida pela ISO2631-1 (1985) para exposições diárias:

$$
\text { Dose }=\sum_{i=1}^{n} a_{i}^{2} t_{i} \text { anos. } \mathrm{m}^{2} / \mathrm{s}^{4}
$$

onde: $\mathrm{t} i$ = tempo (anos de trabalho de jornada integral) dirigindo um veiculo $\mathrm{i}$ e ai $=$ aceleração ponderada ao longo do componente direcional predominante $(a z)$. 
Em virtude de haver expressivas dificuldades para reconstituir a exposição à vibração a cada modelo de ônibus empregado por trabalhador, tanto pela alternância de ônibus nas linhas como também pelo desconhecimento ou pela dificuldade dos motoristas em recordar sobre 0 ônibus operado, definiu-se por utilizar uma média dos valores observados.

A média foi calculada considerando o número de ônibus, a idade e aceleração por modelo de ônibus, tendo como referência a fórmula de cálculo da aceleração equivalente, conceito este desenvolvido por BOSHUIZEN e col. (1990) os quais propuseram o termo aceleração equivalente, que se define pela seguinte expressão:

$$
a_{e q}=\sqrt{\frac{1}{T} \sum_{i=1}^{n} a^{2}{ }_{i} t_{i}} \mathrm{~m} / \mathrm{s}^{2}
$$

onde:

$T=$ tempo total de exposição em anos;

$\mathrm{ti}=$ tempo (anos de trabalho de jornada integral) dirigindo um veículo $\mathrm{i}$;

ai = aceleração correspondente ao componente direcional predominante ou a soma vetorial da aceleração r.m.s. [root mean square] nas direções $\mathrm{x}$, y e $z$.

A título de exemplo, o procedimento para o cálculo da média é demonstrado na tabela a seguir:

Tabela 3.4: Exemplo ilustrativo para elucidar o cálculo da média da aceleração de vibração ponderada por tempo de uso e número de veículos na frota.

\begin{tabular}{lllllll}
\hline \multicolumn{2}{l}{ Modelo $\mathrm{n}$} & $\mathrm{t}$ & \multicolumn{2}{l}{$\mathrm{a}\left(\mathrm{m} / \mathrm{s}^{2}\right)$} & $\mathrm{n} \times$ anos $\mathrm{a}^{2}$ & $\mathrm{n} \times$ anos $\times \mathrm{a}^{2}$ \\
\hline $\mathrm{A}$ & 10 & 5 & 0,6 & 50 & 0,36 & 18,0 \\
$\mathrm{~B}$ & 20 & 7 & 0,9 & 140 & 0,81 & 113,4 \\
$\mathrm{C}$ & 30 & 10 & 0,7 & 300 & 0,49 & 147,0 \\
\hline & & & $\Sigma=$ & 490 & $\Sigma=$ & 278,4
\end{tabular}


Onde:

n: número de ônibus

t: Tempo médio de uso na empresa em anos;

a: valor da aceleração em $\mathrm{m} / \mathrm{s}^{2}$

Assim, a aceleração média neste exemplo hipotético será de

$$
a_{m}=\sqrt{\frac{\sum_{i=1}^{n} n_{i} \times t_{i} \times a_{i}^{2}}{\sum_{i=1}^{n} n_{i} \times t_{i}}}=0,73 \mathrm{~m} / \mathrm{s}^{2}
$$

Desta forma, a dose da vibração foi calculada para cada motorista, referindo-se à aceleração média calculada e o tempo de empresa como motorista. 


\subsection{Questionário:}

Empregou-se o questionário atualmente em uso no Centro de Referência em Saúde do Trabalhador do Estado de São Paulo - CEREST $S P$, para anamnese no ambulatório de fonoaudiologia, com modificações particulares para atender os interesses do estudo (ver anexo). Basicamente, as informações contempladas no prontuário da entrevista foram as seguintes: Identificação da empresa e do trabalhador; atividade na empresa; tempo na função que exerce e jornada de trabalho; tempo de trabalho (em anos) em cada modelo de ônibus analisado; extensão da exposição prévia ao ruido e à vibração de corpo inteiro; antecedentes pessoais (incluindo os otológicos, cirurgias otológicas, traumatismos cranianos, doenças que eventualmente podem acometer 0 aparelho auditivo, uso de drogas ototóxicas, hipertensão, Diabetes mellitus, e tabagismo); antecedentes familiares de perdas auditivas; histórico sobre serviço militar.

O questionário foi aplicado pelas fonoaudiólogas que realizaram o exame, devidamente esclarecidas e instruidas sobre o seu conteúdo e forma, contemplando as seguintes questões especificas para atender os objetivos deste estudo:

- Idade em anos;

- Tempo de empresa, como motorista, em anos: referiu-se ao tempo total acumulado, considerando também eventuais periodos em que o motorista tenha trabalhado anteriormente na empresa;

- Tempo de exposição prévia ao ruído em anos: atividade de motorista em ônibus urbano ou em veiculos de carga (caminhões) foi julgada como exposta ao ruido, bem como, naturalmente, em outros ramos notadamente classificados como expressivos e importantes para a exposição, como o metalúrgico, gráfico e outros. De qualquer modo, indagou-se ao motorista se aquela exposição era mais importante do que a atual. 
- Tempo de exposição prévia à $\mathrm{VCl}$ em anos: atividades desenvolvidas em quaisquer tipo de ônibus urbano ou interurbano, caminhōes, tratores e outros veículos de carga foram classificados como sendo de exposição à VCl. Atividade como cobrador, por exemplo, foi classificada como sendo de exposição à VCI mas não ao ruido.;

- Dose da exposição à VCl: calculada como apresentada anteriormente;

- Nível de imissão de ruído: calculado conforme exposto anteriormente, de acordo com os dois tipos agregados de ônibus conduzidos pelo motorista, como veículo dotado de motor dianteiro ou entre - eixos e o com motor traseiro.

- Hipertensão arterial: indagou-se ao motorista se ele faz uso de medicamentos para controlar a hipertensão arterial.

- Sem história,

- Com história;

- Uso de medicação ototóxica: a questão foi formulada com o propósito de verificar se o motorista utilizou por mais de duas semanas, qualquer medicamento, cuja administração tenha afetado a audição.

- Sem história,

- Com história;

- Diabetes: do mesmo modo aplicado para a questão concernente à hipertensão.

- Sem história,

- Com história;

- Tabagismo: Ex-fumante foi considerado como não fumante.

- Não fumante,

- Fumante;

- Antecedentes familiares de perda auditiva:

- Sem história,

- Com história; 
- Serviço militar:

- Sem história,

- Com história;

\subsection{Questões éticas:}

O procedimento da pesquisa tem seguido os princípios éticos estabelecidos pelo CONSELHO NACIONAL DE SAÚDE (1996).

A participação dos motoristas na pesquisa foi condicionada ao consentimento livre e esclarecido por parte deles. A realização de todo o procedimento, aplicação de questionário e a avaliação audiológica, mantevese vinculada à assinatura de termo de consentimento. 


\subsection{Avaliação audiológica}

Os exames foram realizados com repouso acústico igual ou superior a 12 horas (NIOSH 1998), por fonoaudiólogas do CEREST-SP, em cabina acústica, com audiòmetro MA-18 (Maico) e (SD25 V) calibrado segundo os requisitos da norma ISO-389 (1975) ou ANSI S3.6 (1969)

A avaliação audiológica constou das seguintes fases:

1. Anamnese clínica e ocupacional - coleta de informações sobre a história ocupacional do trabalhador para estabelecimento do nexo com o trabalho ou outros fatores que estejam causando o distúrbio de audição, no qual possibilitará o diagnóstico diferencial.

2. Meatoscopia - avaliação das condiçōes do conduto auditivo externo. Os casos com alteração (ex: presença de cerúmen) foram encaminhados para - otorrinolaringologista, devendo retornar posteriormente para a realização do exame.

3. Audiometria tonal por via aérea para estabelecimento dos limiares auditivos nas frequèncias de $250,500,1 \mathrm{k}, 2 \mathrm{k}, 3 \mathrm{k}, 4 \mathrm{k}, 6 \mathrm{k}$ e $8 \mathrm{kHz}$.

4. Audiometria tonal por via óssea nas frequèncias de $500,1 k, 2 k, 3 k$ e 4 $\mathrm{kHz}$ - realizada quando os limiares aéreos encontraram-se superiores a 25 dBNA.

5. Logoaudiometria (limiar de recepção de fala (SRT) e indice de reconhecimento de fala (IRF)) - avaliação da audição para a fala.

6. Imitanciometria (timpanometria, complacència e medidas do reflexo estapediano) - avaliação das condiçōes físicas e funcionais da orelha média, auxiliando no diagnóstico diferencial.

O critério adotado para a classificação das audiometrias foi o proposto por MERLUZZI e col. (1979). De acordo com esta metodologia, a classificação normal é conferida ao sujeito que apresenta um limiar auditivo igual ou inferior a 25 dB NA (ANSI S3.6 1969) para cada frequència considerada. Os casos de perda auditiva estão localizados nos grupos 1, 2 , 
3, 4 e 5, indicados conforme a gravidade como hipoacusia de primeiro, segundo, terceiro, quarto e quinto grau respectivamente. Perda auditiva categorizada por ruído e outra causa, e somente por outras causas acomodam-se nos grupos 6 e 7 respectivamente. Explanaçōes mais detalhadas sobre o critério eleito encontram-se mais adiante.

Segundo LÓBO e COSTA (1997) este método de classificação se enquadra no grupo denominado de análise visual. Através deste instrumento, a carta audiométrica é dividida em regiões, ocorrendo a alteração do grau à medida em que estas divisões forem sendo atingidas pelo traçado dos limiares.

De acordo com o critério estabelecido por MERLUZZI e col. (1979), para a avaliação da gravidade do comprometimento da audição, faz-se referência sobretudo aos limiares para as frequeencias de 500, 1000, 2000, 3000 e $4000 \mathrm{~Hz}$.

A classificação de grau 1 corresponde aos traçados audiométricos, cujos valores dos limiares das quatro primeiras freqüências citadas acima se enquadram na área considerada de normalidade $A(4 A)$. Sucessivamente, em relação à progressão da classificação, a de grau 2 , compreende as três primeiras frequências inseridas na área de normalidade (3A); a de grau 3 as duas primeiras (2A); a de grau 4 somente a primeira (1A) e finalmente a de grau 5 , nenhuma delas localizada na região de normalidade.

A seguir, há os traçados correspondentes às classificações discutidas para subsidiar no entendimento do critério adotado. 


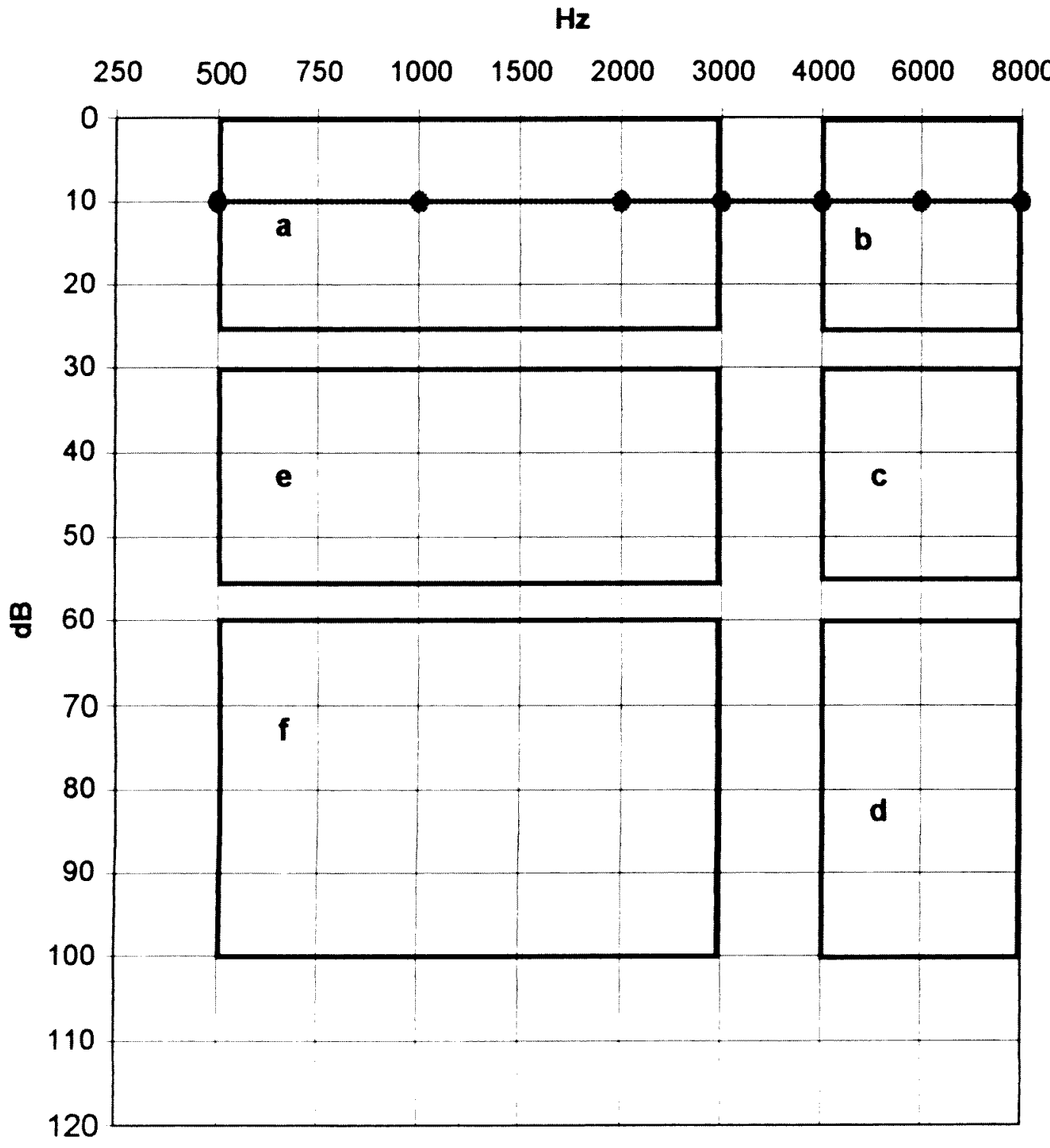

$4 A-B$

Figura 3.1: Traçado audiométrico correspondente à classificação de Grau 0 , normal, segundo critério de Merluzzi e col. (1979) 
$\mathrm{Hz}$

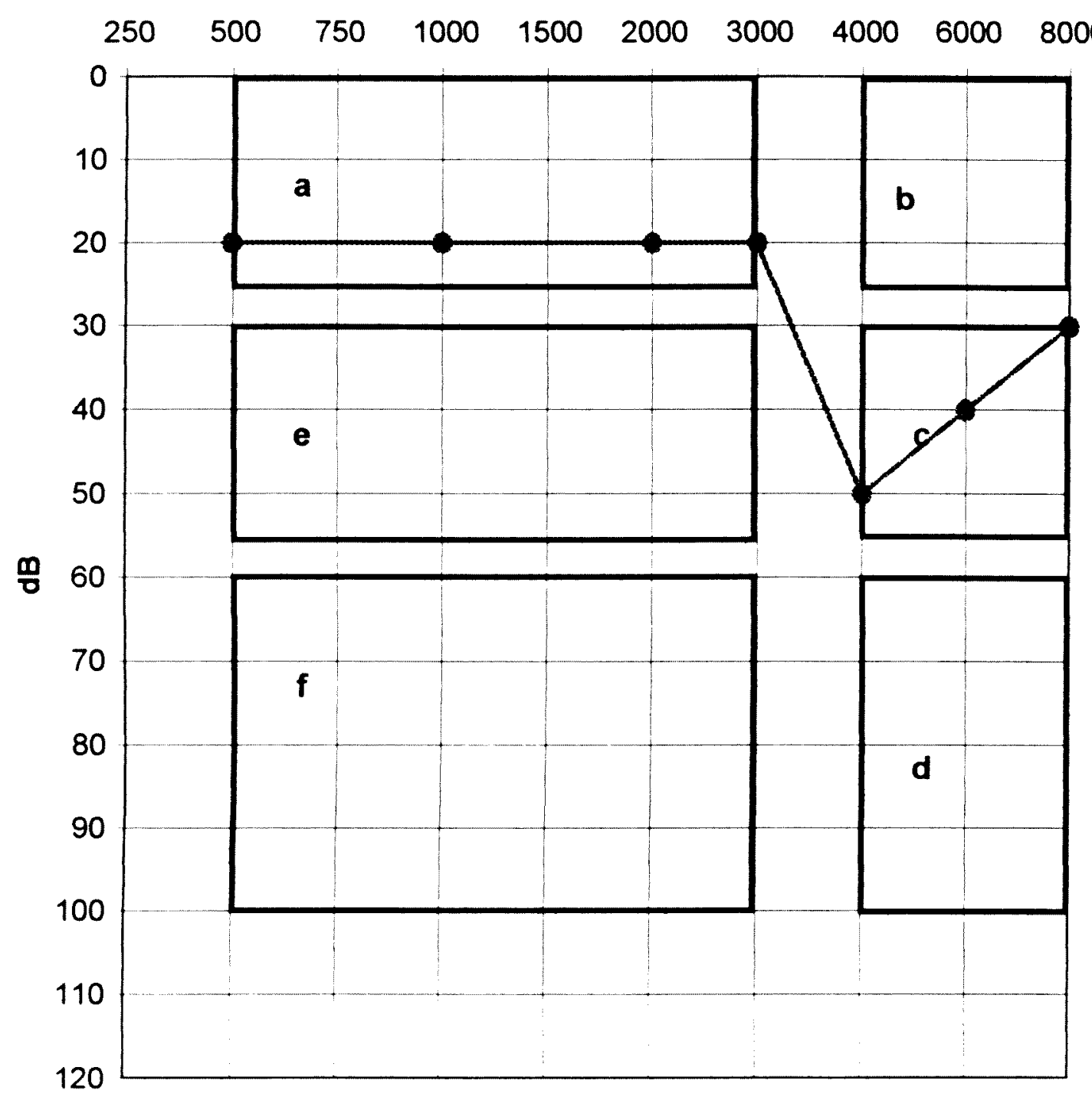

$$
\begin{gathered}
4 A-C \\
4 A-C-B \\
4 A-D-C
\end{gathered}
$$

Figura 3.2: Traçado audiométrico correspondente à classificação de Grau 1, segundo critério de Merluzzi e col. (1979) 
$\mathrm{Hz}$

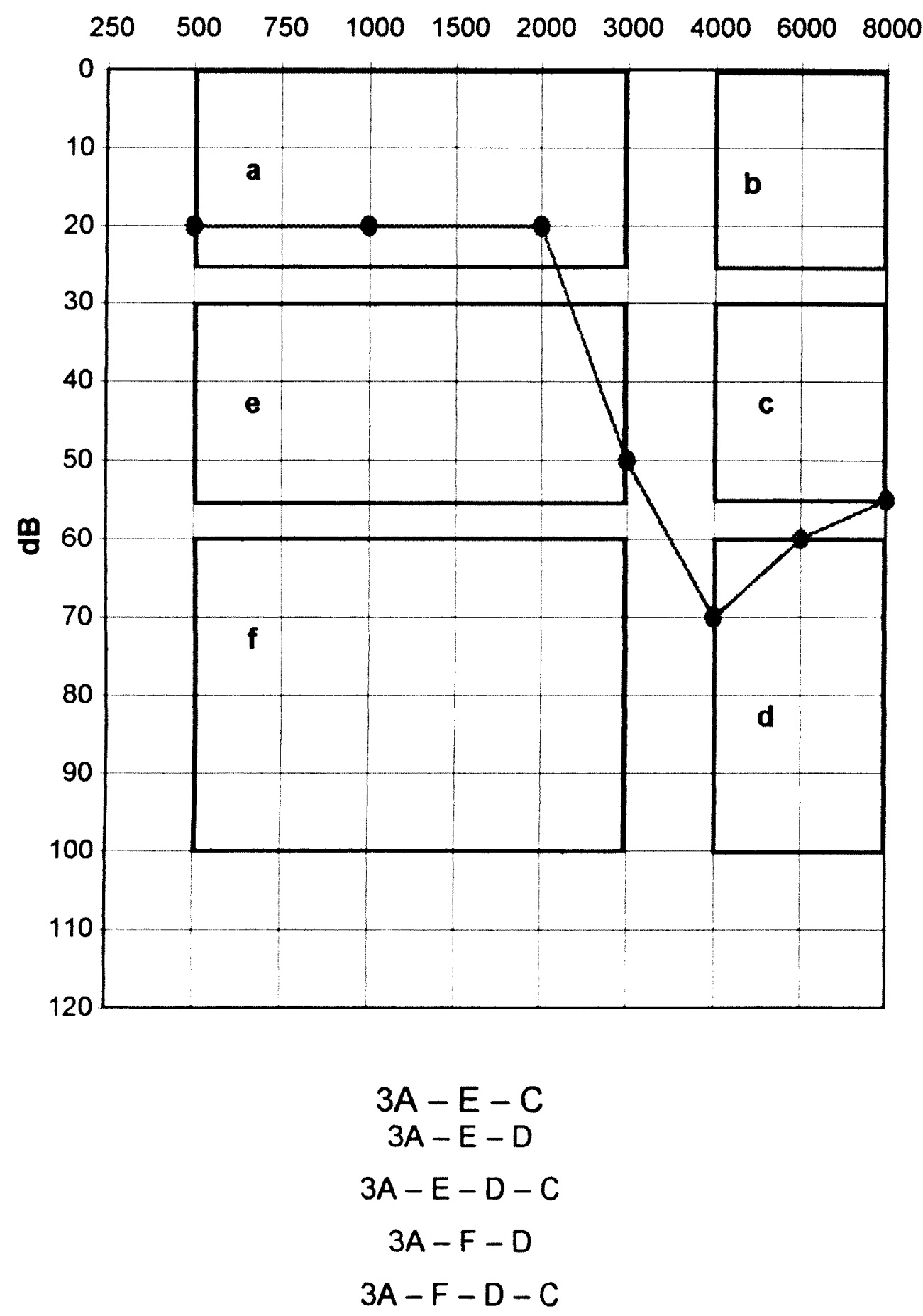

Figura 3.3: Traçado audiométrico correspondente à classificação de Grau 2, segundo critério de Merluzzi e col. (1979) 


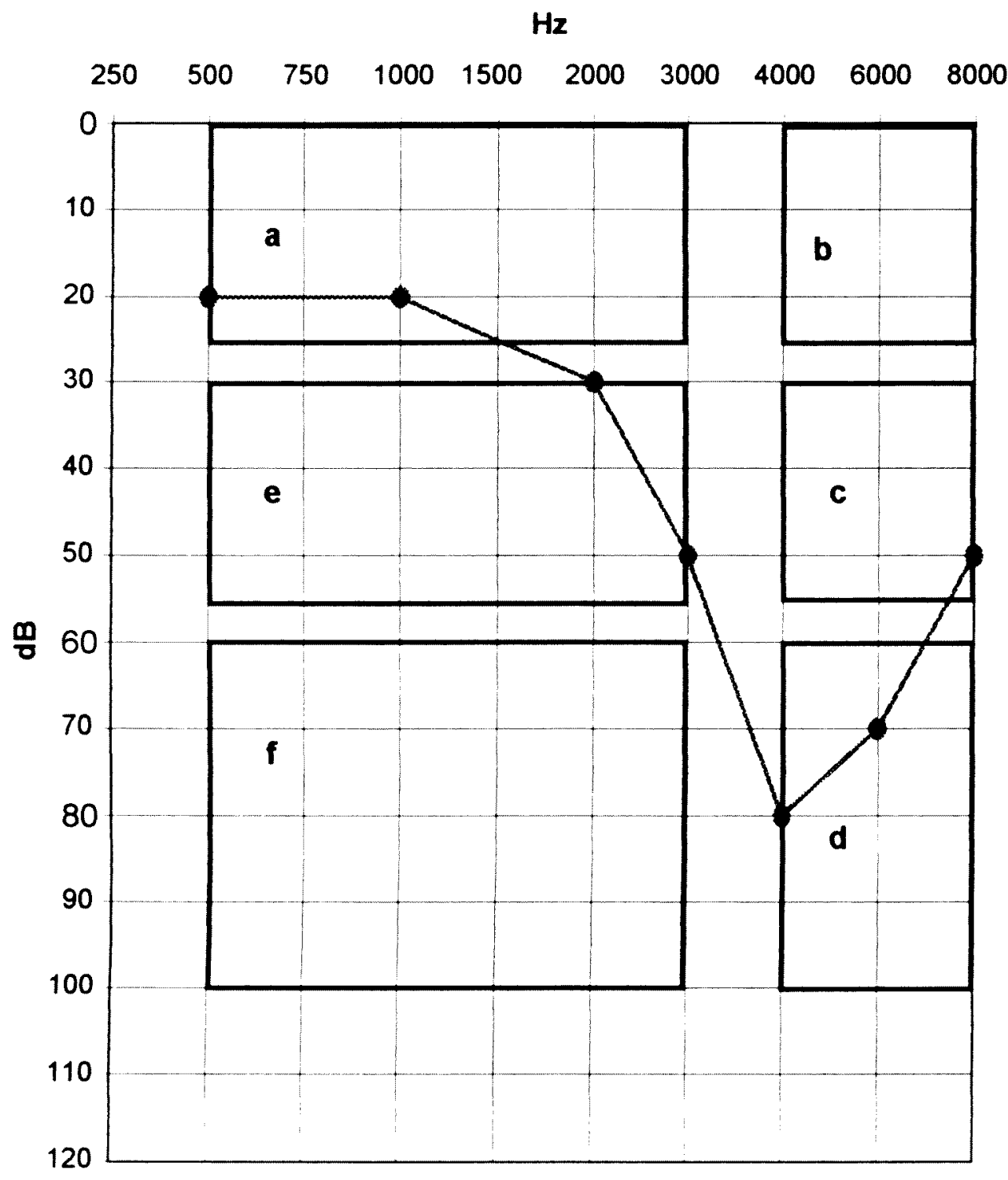

$$
\begin{gathered}
2 A-E-D-C \\
2 A-E-C \\
2 A-E-D \\
2 A-E-F-D-C \\
2 A-E-F-D
\end{gathered}
$$

Figura 3.4: Traçado audiométrico correspondente à classificaçắo de Grau 3, segundo critério de Merluzzi e col. (1979) 
$\mathrm{Hz}$

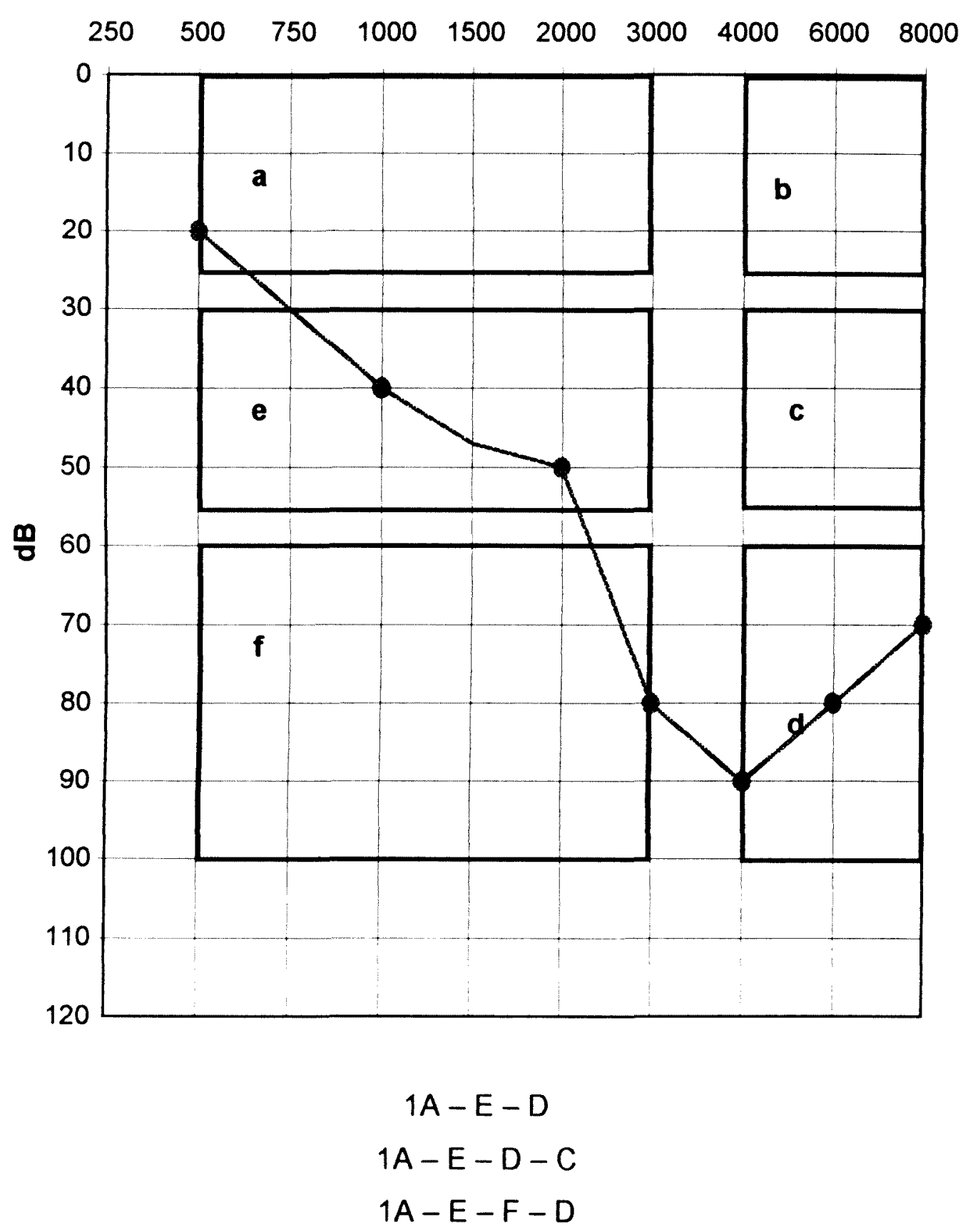

Figura 3.5: Traçado audiométrico correspondente à classificação de Grau 4, segundo critério de Merluzzi e col. (1979). 


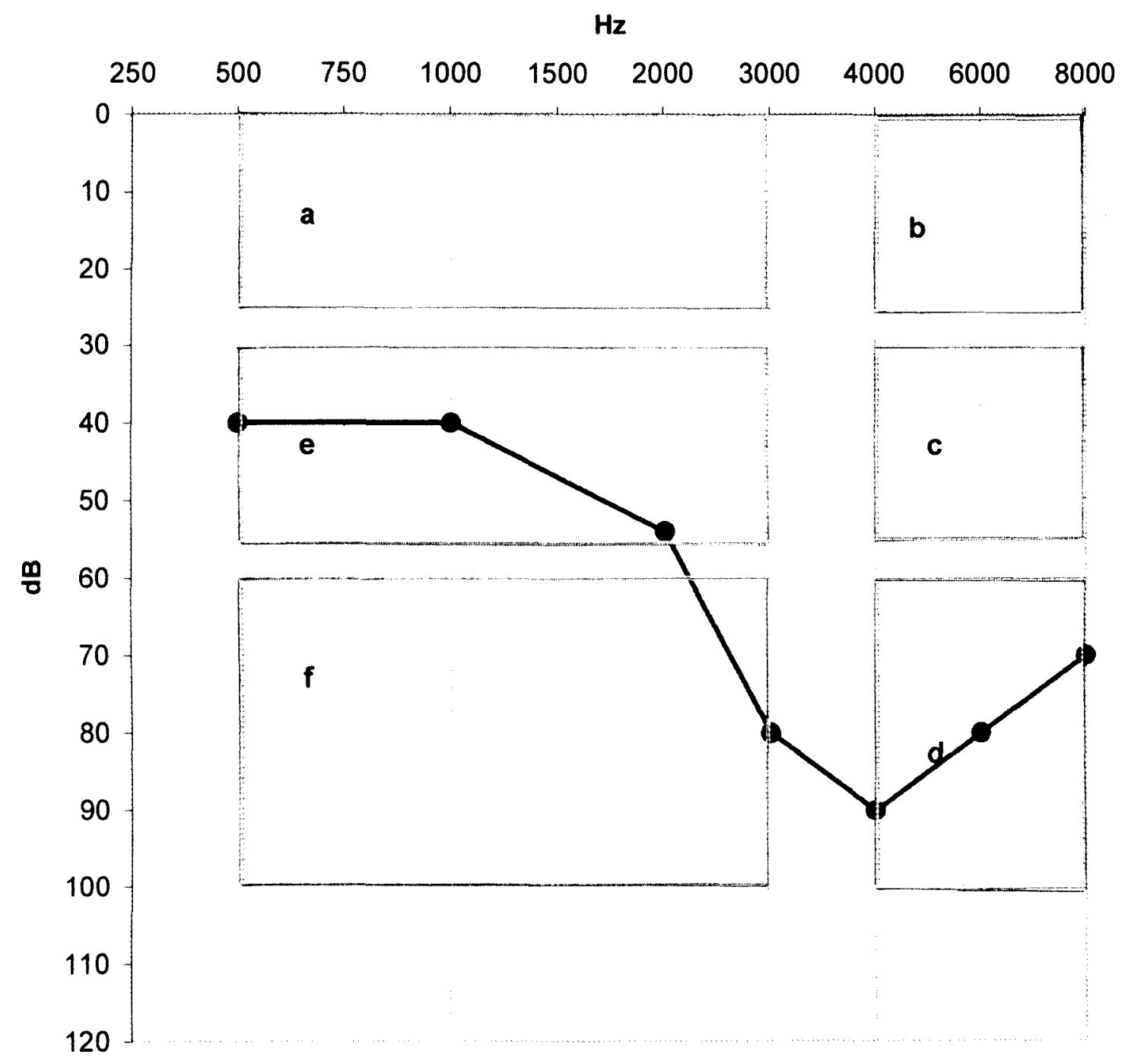

$$
\begin{gathered}
E-D \\
E-F-D \\
E-F-D-C \\
F-D
\end{gathered}
$$

Figura 3.6: Traçado audiométrico correspondente à classificação de Grau 5, segundo critério de Merluzzi e col. (1979). 
$\mathrm{Hz}$

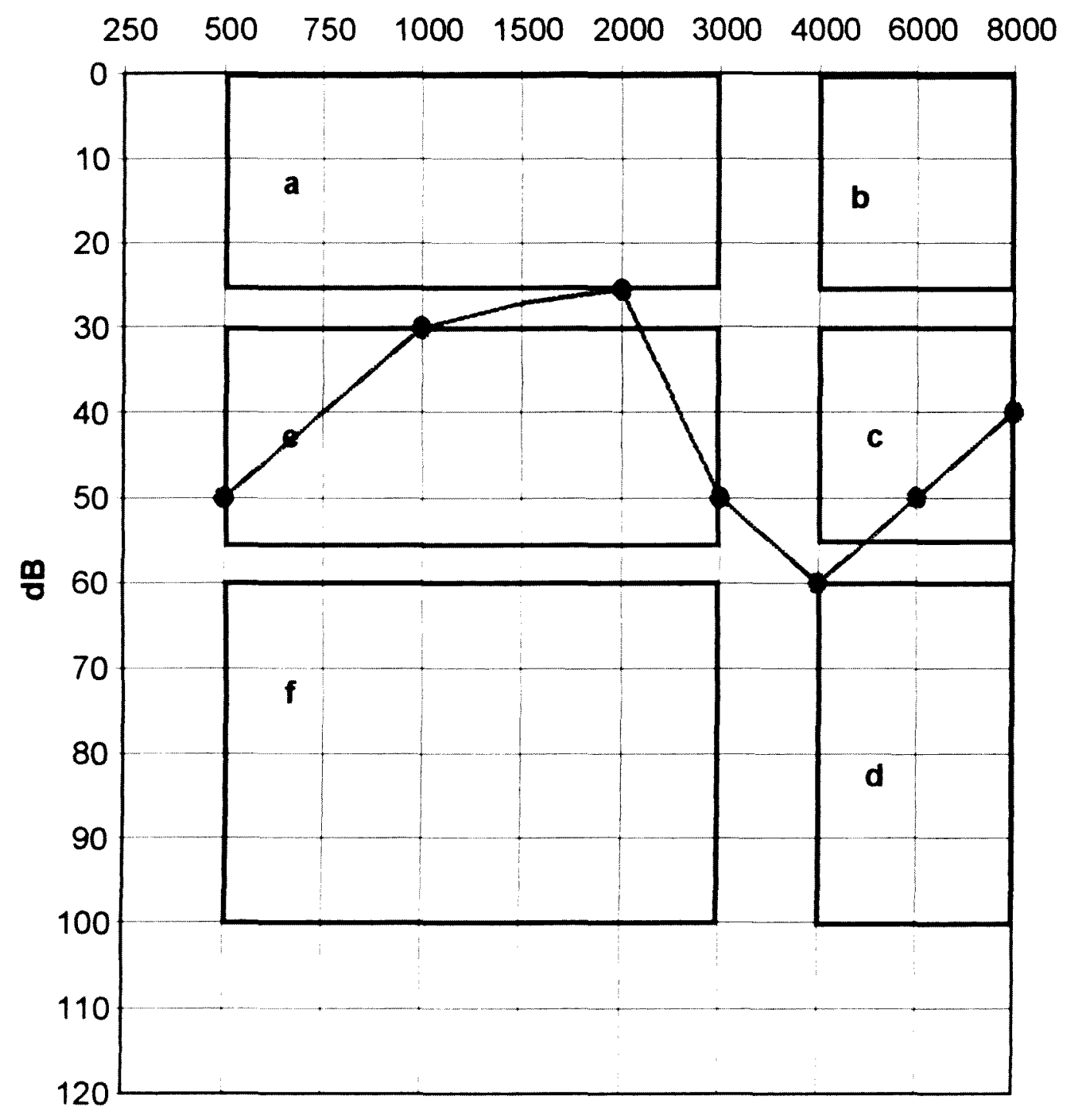

Figura 3.7: Traçado audiométrico correspondente à classificação de Grau 6, perda por ruido e outra causa, segundo critério de Merluzzi e col. (1979) 


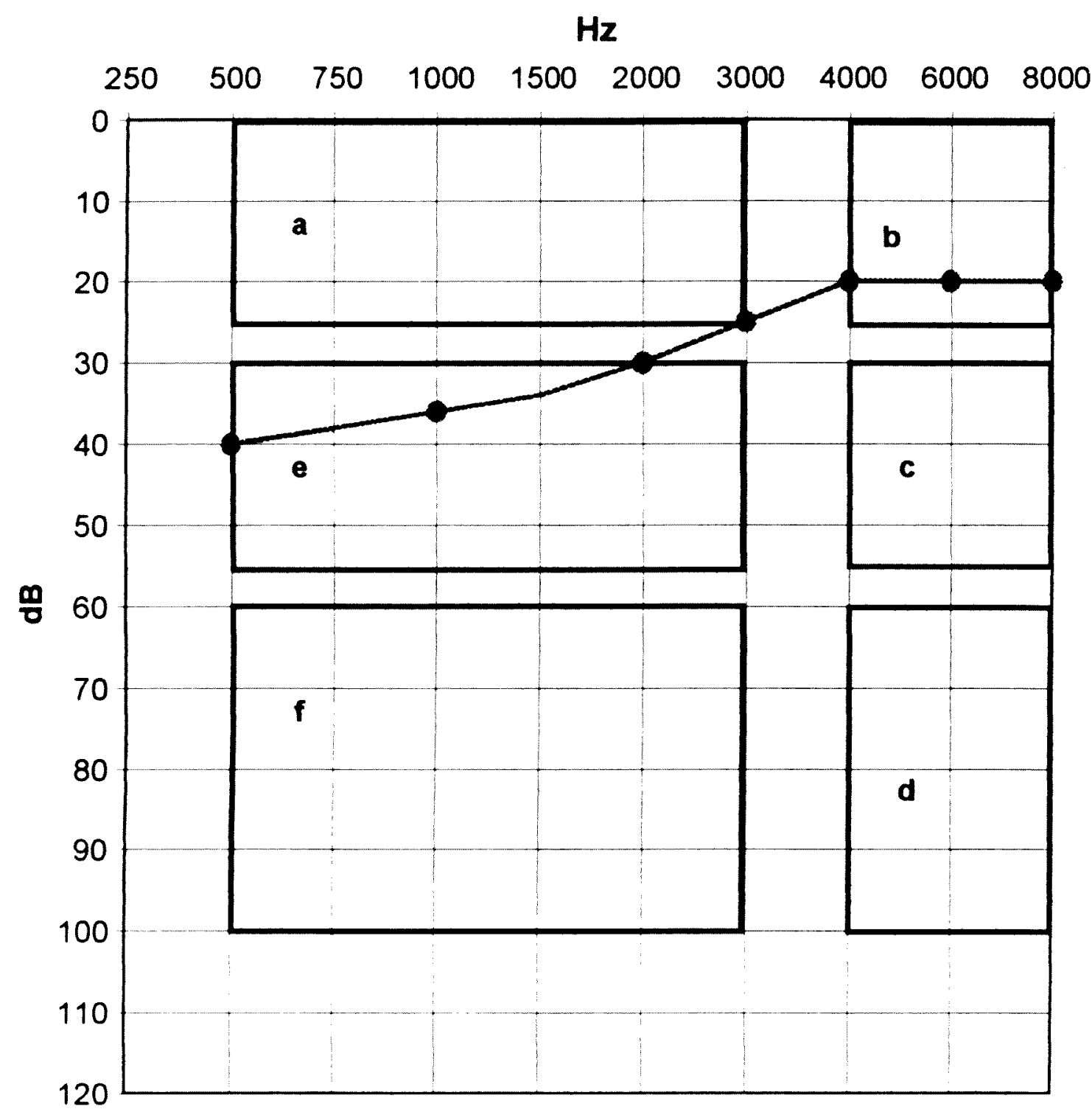

Figura 3.8: Traçado audiométrico correspondente à classificação de Grau 7 , perda por outras causas, segundo critério de Merluzzi e col. (1979) 


\subsection{Análise dos dados:}

Para descrever a associação entre variável dependente e o conjunto de variáveis explanatórias ou preditivas utilizou-se a técnica de regressão logística multivariada não condicional, com auxilio do programa de computador MULTLR (1989). Como afirma KELSEY (1986), variáveis de confusão desempenham um papel importante como fonte de viés em estudos transversais. Portanto, o método de regressão logística permite controlá-las.

A fim de se encontrar o modelo mais ajustado foi aplicada a metodologia progressiva passo a passo (stepwise forward) incluindo as variáveis por ordem decrescente de significância. Na construção do modelo multivariado, análises univariadas foram conduzidas, empregando como critério para entrada no processo de modelagem, um valor de $p<0,20$ fundamentado no teste da razão da máxima verossimilhança. A significância das variáveis no modelo final também foi verificada pelo mesmo teste da razão de verossimilhança, permitindo a permanência das variáveis com $p$ menor ou igual a 0,25 (HOSMER e LEMESHOW 1989).

A variável dependente no estudo foi do tipo dicotômica e representada por PAIR (traçado audiométrico sugestivo de PAIR) ou audição normal (compreendendo os traçados classificados como normal, ou seja, grau 0 , e as perdas não induzidas por ruído, classificações 6 e 7).

Desse modo, o denominado logito, ou o log do odds da variável dependente, do modelo de regressão logística é fornecido pela seguinte equação (HOSMER e LEMESHOW 1989):

$$
g(x)=\beta_{0}+\beta_{1} x_{1}+\beta_{2} x_{2}+\ldots+\beta_{n} x_{n}
$$

Onde 
Os coeficientes " $\beta$ " estimados para as variáveis independentes representam a taxa de mudança de uma funçăo da variável dependente por unidade de mudança na variável independente. Cada coeficiente estimado fornece uma estimativa do log do odds ajustando-se para todas as outras variáveis incluidas no modelo.

Uma outra maneira matemática de representar o modelo é dada pela seguinte expressão (HOSMER e LEMESHOW 1989):

$$
G=\ln \left[\frac{P}{(1-P)}\right]
$$

Onde $\mathrm{P}$ é a probabilidade de ocorrência do evento dependente e $\mathrm{G}$ é o logito ou o log do odds da variável dependente.

Desse modo, a probabilidade de ocorrência da variável dependente $(Y$ = 1/PAIR) foi representada pela equaçăo (HOSMER e LEMESHOW 1989):

$$
\operatorname{Prob}(Y=1)=\frac{1}{1+e^{-g(x)}}
$$

As variáveis explanatórias ou preditoras empregadas na análise foram as consideradas as mais relevantes no questionário e discutidas anteriormente. 


\section{RESULTADOS:}

\subsection{Característica da frota}

As caracteristicas de cunho mais técnico sobre os veiculos analisados encontram-se mais adiante e foram fundamentadas por informaçōes fornecidas tanto pelo fabricante dos veiculos como pelo departamento de manutenção da empresa.

A descrição da fonte de ruido constitui-se uma tarefa fundamental em um procedimento de avaliação. Por esta razão, serão descritas a seguir algumas caracteristicas dos veículos analisados que podem exercer influência na geração do ruído analisado. As informações correspondentes ao tipo de suspensão são relevantes para subsidiar a avaliação da exposição à vibração de corpo inteiro.

Os veículos utilizados pelos motoristas da empresa são os seguintes:

\section{Mercedes-Benz 1318:}

Este modelo constitui $52 \%$ da frota ( 168 ônibus) da empresa e possui motor localizado na seção dianteira do veículo ao lado do motorista e enclausurado por um capô, cujas caracteristicas de isolamento acústico não foram objeto de estudo. Observou-se que há um anel de borracha ao longo do perimetro da base do capô com o propósito de vedação acústica no momento do fechamento.

A geração de ruido, segundo os motoristas, é agravada quando ocorrem falhas na manutenção no capô de enclausuramento, particularmente em relação à vedação de borracha descrita. 
A suspensão existente neste veículo é do tipo feixe de molas semielipticas, que é considerada mais rígida e desconfortável e propicia a elevação da vibração segundo BOULANGER e col. (1992).

O assento, com amortecimento hidráulico, permite dois ajustes, vertical e horizontal, e possui o espaldar baixo. A abertura e fechamento das portas são realizados pneumaticamente, através de duas pequenas alavancas situadas ao lado esquerdo do posto. A média de idade dos veículos avaliados é de 7,9 $\pm 1,2$ anos.

\section{Mercedes-Benz 1620:}

Veículo com motor localizado na seção dianteira, que em sua maioria é dotado de carroçaria de concepção mais atualizada, fato que oferece um melhor isolamento para o ruído transmitido pelo motor. Alguns destes veículos são dotados da mesma carroçaria do modelo anterior, peculiaridade que o torna tão ruidoso como os veículos modelo 1318. A suspensão e o assento apresentam as mesmas características do modelo anterior. A média de idade dos veículos avaliados é de 4,3 $\pm 0,5$ anos.

\section{Mercedes-Benz 1721:}

Motor também localizado na seção dianteira do veículo ao lado do motorista, com características bastante similares ao modelo anterior. A média de idade dos veículos avaliados é de 2,0 anos.

\section{Mercedes-Benz $371 \mathrm{U}:$}

Veículo dotado de motor posicionado em sua parte traseira, que consequentemente apresenta um nivel de ruído significativamente menor para os condutores, como pode ser observado nos valores registrados. A 
suspensão do veículo é do tipo helicoidal por feixe de molas. A média de idade dos veículos avaliados foi de 9,0 anos.

\section{Mercedes-Benz 371 UL:}

Pode-se considerar como o modelo mais confortável utilizado pelos motoristas, pois além das características descritas do modelo anterior, ele é dotado de motor turbinado e suspensão pneumática no eixo frontal. A média de idade dos veículos avaliados foi de 4,6 $\pm 0,5$ anos.

\section{Volvo B-52:}

Veículo cujo motor se situa entre eixos, mas não eqüidistante e mais próximo do dianteiro. $\mathrm{O}$ assento tem as mesmas características dos modelos anteriormente discutidos. Estes veículos apresentavam uma idade média de 10,0 anos.

Conforme informações prestadas pelo principal construtor e pelo departamento de manutenção da empresa de transporte, as características fundamentais das suspensões dos veículos são apresentadas na tabela a seguir: 
Tabela 4.1: Caracteristicas fundamentais das suspensões utilizadas pelos veículos da empresa.

\begin{tabular}{|c|c|}
\hline Modelos & Suspensão \\
\hline OF-1318 & Feixes de molas semi-elípticas. \\
\hline OF-1620 & Feixe de molas semi-elipticas. \\
\hline $0-371 \mathrm{U}$ & $\begin{array}{l}\text { Molas helicoidais na dianteira e feixe de molas semi- } \\
\text { elípticas na traseira. }\end{array}$ \\
\hline O- 371 UL & $\begin{array}{l}\text { Dianteira pneumática e feixes de molas semi-elipticas na } \\
\text { traseira. }\end{array}$ \\
\hline OF-1721 & Feixe de molas semi-elipticas \\
\hline VOLVO & Pneumática em ambos os eixos*. \\
\hline
\end{tabular}

Fonte: Mercedes-Benz do Brasil S/A

* Informação prestada pelo departamento de manutenção da empresa de transporte coletivo. 
4.2 Avaliação de exposição ao ruido:

Os resultados referentes ao procedimento de avaliação de exposição ao ruído são apresentados na tabela 4.2 : 
® Tabela 4.2 : Avaliação de nivel de exposição ao ruido - resumo:

\begin{tabular}{|c|c|c|c|c|c|c|c|c|c|}
\hline \multirow[t]{3}{*}{ Linhas } & \multirow{3}{*}{$\begin{array}{c}\mathrm{N} .^{\circ} \text { da } \\
\text { avaliação }\end{array}$} & \multicolumn{2}{|c|}{ Onibus } & \multirow{3}{*}{$\begin{array}{c}\text { Viagens } \\
\text { por } \\
\text { dia }\end{array}$} & \multicolumn{2}{|c|}{$L_{\text {Aeq }}-d B(A)$} & \multicolumn{2}{|c|}{ Tempo - min } & \multirow[t]{3}{*}{$L_{E P, w}-d B(A)$} \\
\hline & & \multirow[t]{2}{*}{ Modelo } & \multirow[t]{2}{*}{ ano } & & & & & & \\
\hline & & & & & Ida & Volta & Ida & Volta & \\
\hline \multirow[t]{2}{*}{1} & 1.1 & 1620 & 1996 & 3,5 & 84,1 & 85,5 & 38,2 & 40,9 & 83,5 \\
\hline & 1.2 & 1620 & 1996 & 3,0 & 82,9 & 81,7 & 43,4 & 48,8 & 81,1 \\
\hline \multirow[t]{2}{*}{2} & 2.1 & 1318 & 1993 & 5,0 & 85,2 & 83,9 & 60,1 & 60,1 & 86,7 \\
\hline & 2.2 & 1620 & 1996 & 3,5 & 82,2 & 82,0 & 66,1 & 61,6 & 82,6 \\
\hline 3 & 3.1 & 1318 & 1993 & 5,5 & 81,9 & 80,9 & 32,6 & 38,1 & 81,5 \\
\hline \multirow[t]{4}{*}{4} & 4.1 & 1318 & 1991 & 7,0 & 84,5 & 84,2 & 30,0 & 34,4 & 85,0 \\
\hline & 4.2 & Volvo & 1991 & 6,0 & 81,4 & 80,4 & 25,4 & 28,6 & 80,1 \\
\hline & 4.3 & Volvo & 1991 & 7,0 & 79,4 & 78,2 & 33,8 & 35,3 & 79,7 \\
\hline & 4.4 & Volvo & 1991 & 7,0 & 80,0 & 80,3 & 35,6 & 32,5 & 81.1 \\
\hline 5 & 5.1 & 1318 & 1994 & 7,0 & 84,2 & 83,5 & 30,9 & 31,5 & 84,3 \\
\hline \multirow[t]{2}{*}{6} & 6.1 & 1318 & 1993 & 4,0 & 82,1 & 82,5 & 59,4 & 54,8 & 82,9 \\
\hline & 6.2 & 1318 & 1993 & 4,0 & 83,4 & 82,6 & 51,8 & 47,8 & 83,0 \\
\hline \multirow[t]{2}{*}{7} & 7.1 & 1620 & 1996 & 4,0 & 79,5 & 80,0 & 59,4 & 54,8 & 81,0 \\
\hline & 7.2 & 1620 & 1996 & 3,0 & 83,0 & 81,8 & 74,2 & 85,1 & 83,4 \\
\hline
\end{tabular}


ஐ

Tabela 4.2 - continuação

\begin{tabular}{|c|c|c|c|c|c|c|c|c|c|}
\hline \multirow[t]{3}{*}{ Linhas } & \multirow{3}{*}{$\begin{array}{c}\mathrm{N} .^{0} \text { da } \\
\text { avaliação }\end{array}$} & \multicolumn{2}{|c|}{ Ônibus } & \multirow{3}{*}{$\begin{array}{c}\text { Viagens } \\
\text { por } \\
\text { dia }\end{array}$} & \multicolumn{2}{|c|}{$L_{\text {Aeq }}-d B(A)$} & \multicolumn{2}{|c|}{ Tempo-min } & \multirow[t]{3}{*}{$L_{E P, w}-\mathbf{d B}(A)$} \\
\hline & & \multirow[t]{2}{*}{ Modelo } & \multirow[t]{2}{*}{ ano } & & & & & & \\
\hline & & & & & Ida & Volta & Ida & Volta & \\
\hline \multirow[t]{2}{*}{8} & 8.1 & 1620 & 1995 & 4,0 & 84,7 & 84,1 & 65,6 & 75,0 & 85,9 \\
\hline & 8.2 & 1620 & 1995 & 3,0 & 85,4 & 84,9 & 55,0 & 57,8 & 84,4 \\
\hline \multirow[t]{2}{*}{9} & 9.1 & 1318 & 1991 & 7,0 & 83,9 & 81,8 & 24,2 & 32,1 & 82,9 \\
\hline & 9.2 & 1620 & 1996 & 10,0 & 83,1 & 82,6 & 25,4 & 24,8 & 83,8 \\
\hline 10 & 10.1 & 1318 & 1991 & 6,0 & 83,0 & 83,2 & 39,1 & 31,5 & 83,5 \\
\hline 11 & 11.1 & 1318 & 1995 & 7,0 & 84,3 & 84,3 & 31,4 & 28,5 & 84,6 \\
\hline 12 & 12.1 & 1318 & 1990 & 6,0 & 84,5 & 83,8 & 28,7 & 31,7 & 83,8 \\
\hline \multirow[t]{4}{*}{13} & 13.1 & 1318 & 1992 & 3,0 & 85,1 & 83,7 & 80,4 & 95,7 & 86,0 \\
\hline & 13.2 & 1721 & 1998 & 3,0 & 82,2 & 81,2 & 69,6 & 71,9 & 82,2 \\
\hline & 13.3 & 1721 & 1998 & 3,0 & 81,2 & 80,9 & 87,0 & 94,3 & 82,6 \\
\hline & 13.4 & 1721 & 1998 & 3,0 & 80,9 & 80,4 & 99,8 & 99,5 & 82,6 \\
\hline 14 & 14.1 & 1318 & 1991 & 5,5 & 83,0 & 83,3 & 48,6 & 44,8 & 84,8 \\
\hline 15 & 15.1 & 1318 & 1993 & 14,0 & 85,5 & 84,5 & 11,2 & 9,9 & 83,8 \\
\hline 16 & 16.1 & 1318 & 1991 & 9,0 & 86,9 & 86,0 & 25,6 & 26,7 & 87,3 \\
\hline
\end{tabular}




\begin{tabular}{|c|c|c|c|c|c|c|c|c|c|}
\hline \multirow[t]{3}{*}{ Linhas } & \multirow{3}{*}{$\begin{array}{c}\mathrm{N} \cdot{ }^{\circ} \text { da } \\
\text { avaliação }\end{array}$} & \multicolumn{2}{|c|}{ Onibus } & \multirow{3}{*}{$\begin{array}{c}\text { Viagens } \\
\text { por } \\
\text { dia }\end{array}$} & \multicolumn{2}{|c|}{$L_{A e q}-d B(A)$} & \multicolumn{2}{|c|}{ Tempo-min } & \multirow[t]{3}{*}{$L_{E P, w}-\mathbf{d B}(A)$} \\
\hline & & Modelo & ano & & & & & & \\
\hline & & & & & Ida & Volta & Ida & Volta & \\
\hline \multirow[t]{2}{*}{17} & 17.1 & Volvo & 1991 & 6,0 & 79,0 & 80,2 & 34,2 & 42,3 & 80,4 \\
\hline & 17.2 & 1620 & 1995 & 5,0 & 82,0 & 82,7 & 40,3 & 39,6 & 82,7 \\
\hline \multirow[t]{3}{*}{18} & 18.1 & $371 \mathrm{U}$ & 1991 & 6,0 & 73,9 & 75,8 & 86,0 & 80,5 & 78,2 \\
\hline & 18.2 & $371 \mathrm{U}$ & 1991 & 3,0 & 74,0 & 72,9 & 83,1 & 85,7 & 74,7 \\
\hline & 18.3 & $371 \mathrm{U}$ & 1991 & 3,0 & 76,5 & 75,2 & 83,1 & 73,3 & 76,9 \\
\hline \multirow[t]{5}{*}{19} & 19.1 & $371 \mathrm{UL}$ & 1995 & 3,0 & 78,4 & 79,2 & 53,2 & 58,9 & 78,3 \\
\hline & 19.2 & 371 UL & 1995 & 3,0 & 77,3 & 75,1 & 66,3 & 75,5 & 76,8 \\
\hline & 19.3 & $371 \mathrm{UL}$ & 1996 & 3,0 & 76,8 & 77,0 & 62,5 & 77,0 & 76,7 \\
\hline & 19.4 & 371 UL & 1996 & 3,0 & 75,4 & 77,5 & 76,3 & 70,9 & 77,2 \\
\hline & 19.5 & 371 UL & 1995 & 3,0 & 76,1 & 77,5 & 66,2 & 69,8 & 77,2 \\
\hline \multirow[t]{2}{*}{20} & 20.1 & 1620 & 1996 & 5,0 & 82,5 & 82,4 & 61,9 & 72,1 & 84,8 \\
\hline & 20.2 & 1318 & 1992 & 3,0 & 84,6 & 84,5 & 72,2 & 73,1 & 85,2 \\
\hline \multirow[t]{2}{*}{21} & 21.1 & 1318 & 1992 & 3,0 & 84,6 & 85,5 & 78,7 & 75,8 & 85,9 \\
\hline & 21.2 & 1318 & 1992 & 3,0 & 86,2 & 86,2 & 73,2 & 59,5 & 86,4 \\
\hline
\end{tabular}


ต Tabela 4.2 - continuação

\begin{tabular}{|c|c|c|c|c|c|c|c|c|c|}
\hline \multirow[t]{3}{*}{ Linhas } & \multirow{3}{*}{$\begin{array}{c}\mathrm{N}{ }^{\circ} \text { da } \\
\text { avaliação }\end{array}$} & \multicolumn{2}{|c|}{ Ónibus } & \multirow{3}{*}{$\begin{array}{c}\text { Viagens } \\
\text { por } \\
\text { dia }\end{array}$} & \multicolumn{2}{|c|}{$L_{\text {Aeq }}-d B(A)$} & \multicolumn{2}{|c|}{ Tempo-min } & \multirow[t]{3}{*}{$L_{E P, w}-d B(A)$} \\
\hline & & \multirow[t]{2}{*}{ Modelo } & \multirow[t]{2}{*}{ ano } & & & & & & \\
\hline & & & & & Ida & Volta & Ida & Volta & \\
\hline 22 & 22.1 & 1318 & 1991 & 6,0 & 84,2 & 84,2 & 31,0 & 42,2 & 85,0 \\
\hline 23 & 23.1 & 1318 & 1992 & 4,0 & 85,1 & 84,2 & 44,8 & 50,5 & 84,6 \\
\hline 24 & 24.1 & 1318 & 1992 & 10,0 & 84,6 & 83,5 & 16,2 & 16,0 & 83,2 \\
\hline 25 & 25.1 & 1318 & 1992 & 8,0 & 84,2 & 84,0 & 23,9 & 23,0 & 83,8 \\
\hline
\end{tabular}


Fundamentando-se nos resultados das avaliaçōes de campo, foi calculada a média dos valores do nível equivalente ponderado na escala $A$ ( $L_{\text {Aeq }}$ ) dos dois grupos de modelos de ônibus, motor dianteiro ou entre- eixos e traseiro. Para o primeiro grupo, a média foi de $83,1 \pm 1,9 \mathrm{~dB}(\mathrm{~A})$, e para os veículos do segundo grupo, a média registrada foi de 76,2 $\pm 1,7 \mathrm{~dB}(\mathrm{~A})$. $A$ diferença encontrada entre as médias dos dois modelos foi considerada estatisticamente significante $(p<0,0001)^{7}$. Diante destes valores obtidos, é possivel afirmar que 0 valor da média dos niveis equivalentes $\left(L_{A e q}\right)$ dos ônibus com motor dianteiro é 4,9 vezes o valor da média do ônibus que possui o motor localizado e sua seção traseira.

Lançando mão dos dados colhidos pela avaliação, estimou-se a jornada semanal média dos motoristas, cujo resultado foi de 46,2 $\pm 10,5 \mathrm{~h}$. Destaca-se que a jornada semanal oficial dos motoristas é de 43 horas semanais, implicando que, com base na média e desvio - padrão calculados, há a probabilidade de $62 \%$ dos motoristas ultrapassarem esta cifra.

Agrupando os valores dos niveis de exposiçăo calculados para os modelos de ônibus com motor posicionado na seção dianteira e entre eixos, ou seja, os modelos 1318,1620, 1721 e VOLVO, obtém-se o seguinte valor médio para o nivel de exposição semanal ( $\left.L_{E P}, w\right)$ :

${ }^{7}$ Teste $t$ de Student. 
Tabela 4.3: Nivel de exposição semanal médio de modelos de ônibus com motor posicionado na seção dianteira utilizados pela empresa de transporte:

\begin{tabular}{ccccc}
\hline Linhas & \multirow{N}{*}{$\begin{array}{c}\text { N. da } \\
\text { avaliação }\end{array}$} & \multicolumn{2}{c}{ Onibus } & LEP, w - dB(A) \\
\cline { 3 - 4 } & Modelo & ano & \\
\hline 1 & 1.1 & 1620 & 1996 & 83,5 \\
& 1.2 & 1620 & 1996 & 81,1 \\
\hline $\mathbf{2}$ & 2.1 & 1318 & 1993 & 86,7 \\
& 2.2 & 1620 & 1996 & 82,6 \\
\hline $\mathbf{3}$ & 3.1 & 1318 & 1993 & 81,5 \\
\hline $\mathbf{4}$ & 4.1 & 1318 & 1991 & 85,0 \\
& 4.2 & Volvo & 1991 & 80,1 \\
& 4.3 & Volvo & 1991 & 79,7 \\
& 4.4 & Volvo & 1991 & 81,1 \\
\hline $\mathbf{5}$ & 5.1 & 1318 & 1994 & 84,3 \\
\hline $\mathbf{6}$ & 6.1 & 1318 & 1993 & 82,9 \\
& 6.2 & 1318 & 1993 & 83,0 \\
\hline $\mathbf{7}$ & 7.1 & 1620 & 1996 & 81,0 \\
& 7.2 & 1620 & 1996 & 83,4 \\
\hline $\mathbf{8}$ & 8.1 & 1318 & 1995 & 85,9 \\
& 8.2 & 1318 & 1995 & 84,4 \\
\hline $\mathbf{9}$ & 9.1 & 1318 & 1991 & 82,9 \\
& 9.2 & 1620 & 1996 & 83,8 \\
\hline $\mathbf{1 0}$ & 10.1 & 1318 & 1991 & 83,5 \\
$\mathbf{1 1}$ & 11.1 & 1318 & 1995 & 84,6 \\
\hline $\mathbf{1 2}$ & 12.1 & 1318 & 1990 & 83,8 \\
\hline & & & &
\end{tabular}


Tabela 4.3 - continuação

\begin{tabular}{|c|c|c|c|c|}
\hline \multirow{2}{*}{$\begin{array}{c}\text { Linhas } \\
13 \\
\end{array}$} & \multirow{2}{*}{$\begin{array}{c}\begin{array}{c}\mathrm{N} .^{\circ} \mathrm{da} \\
\text { avaliação }\end{array} \\
13.1\end{array}$} & \multicolumn{2}{|c|}{ Ónibus } & \multirow{2}{*}{$\begin{array}{c}\text { LEP, } w-d B(A) \\
86,0\end{array}$} \\
\hline & & 1318 & 1992 & \\
\hline & 13.2 & 1721 & 1998 & 82,2 \\
\hline & 13.3 & 1721 & 1998 & 82,6 \\
\hline & 13.4 & 1721 & 1998 & 82,6 \\
\hline 14 & 14.1 & 1318 & 1991 & 84,8 \\
\hline 15 & 15.1 & 1318 & 1993 & 83,8 \\
\hline 16 & 16.1 & 1318 & 1991 & 87,3 \\
\hline \multirow[t]{2}{*}{17} & 17.1 & Volvo & 1991 & 80,4 \\
\hline & 17.2 & 1620 & 1995 & 82,7 \\
\hline \multirow[t]{2}{*}{20} & 20.1 & 1620 & 1996 & 84,8 \\
\hline & 20.2 & 1318 & 1992 & 85,2 \\
\hline \multirow[t]{2}{*}{21} & 21.1 & 1318 & 1992 & 85,9 \\
\hline & 21.2 & 1318 & 1992 & 86,4 \\
\hline 22 & 22.1 & 1318 & 1991 & 85,0 \\
\hline 23 & 23.1 & 1318 & 1992 & 84,6 \\
\hline 24 & 24.1 & 1318 & 1992 & 83,2 \\
\hline \multirow[t]{4}{*}{25} & 25.1 & 1318 & 1992 & 83,8 \\
\hline & & & Média = & 83,6 \\
\hline & & \multicolumn{2}{|c|}{ Desvio - padrão $=$} & 1,9 \\
\hline & & \multicolumn{2}{|c|}{ Erro - padrão $=$} & 0,6 \\
\hline
\end{tabular}

Pode ser observado na tabela acima que o erro - padrão é inferior a 1 $\mathrm{dB}$, erro do equipamento, indicando portanto um número suficiente de amostras.

Em referência aos modelos com motor localizado na seção traseira e adotando o mesmo procedimento anterior, os seguintes valores podem ser observados 
Tabela 4.4: Nivel de exposição médio dos modelos de ônibus com motor posicionado na seção traseira utilizado na empresa de transporte.

\begin{tabular}{|c|c|c|c|c|}
\hline \multirow[t]{2}{*}{ Linhas } & \multirow{2}{*}{$\begin{array}{c}\text { N.º da } \\
\text { avaiiação }\end{array}$} & \multicolumn{2}{|c|}{ Ônibus } & \multirow[t]{2}{*}{$L_{E P, w}-d B(A)$} \\
\hline & & Modeio & ano & \\
\hline \multirow[t]{3}{*}{18} & 18.1 & 3710 & 1991 & 78,2 \\
\hline & 18.2 & $371 \mathrm{U}$ & 1991 & 74,7 \\
\hline & 18.3 & $371 U$ & 1991 & 76,9 \\
\hline \multirow[t]{8}{*}{19} & 19.1 & $371 \mathrm{UL}$ & 1995 & 78,3 \\
\hline & 19.2 & $371 \mathrm{UL}$ & 1995 & 76,8 \\
\hline & 19.3 & $371 \mathrm{UL}$ & 1996 & 76,7 \\
\hline & 19.4 & $371 \mathrm{UL}$ & 1996 & 77,2 \\
\hline & 19.5 & 371 UL & 1995 & 77,2 \\
\hline & \multicolumn{3}{|c|}{ Média $=$} & 77,0 \\
\hline & \multicolumn{3}{|c|}{ Desvio - padrão = } & 1,1 \\
\hline & & \multicolumn{2}{|c|}{ Erro - padrão = } & 0,9 \\
\hline
\end{tabular}

Desde que foi assumido que a distribuição dos valores do nivel de exposição ao ruido obedece à curva normal, há a possibilidade de se calcular a probabilidade de superação de determinados niveis de interesse (BEHAR e PLENER 1984).

No primeiro caso, para ônibus com motores dianteiros ou entre eixos, a probabilidade de haver a superação do nivel de exposição de 85 $\mathrm{dB}(\mathrm{A})$, que representa o limite de tolerância para $8 \mathrm{~h}$ de exposição em diversos critérios de risco, dotados de consistência epidemiológica (ACGIH 1996; NIOSH 1998; FUNDACENTRO 1999 ) é de $22,4 \%$.

Já para os ônibus com motor traseiro, não há a possibilidade de superação do nivel de $65 \mathrm{~dB}(\mathrm{~A})$. 
No modelo 1318 foram realizadas 22 avaliações, sendo que a média encontrada do nivel de exposição foi de $84,3 \pm 1,4 \mathrm{~dB}(\mathrm{~A})$. Lembrando que se partiu do pressuposto que a distribuição dos valores dos niveis de ruído obedece uma curva normal, este resultado permitiu calcular que há a probabilidade de $31,0 \%$ dos motoristas, que utilizam este tipo de ônibus, estarem expostos a niveis acima de $85,0 \mathrm{~dB}(\mathrm{~A})$ e $95,5 \%$ estarem acima de 82,0 dB(A), nivel de ação estabelecido para o critério aplicado (FUNDACENTRO 1999).

Oito avaliações foram realizadas no modelo 1620 , cujo motor também é posicionado na dianteira do veículo. Este modelo apresenta vedação do capô mais adequada para abatimento de ruído, segundo informações dos trabalhadores. Neste caso, a média encontrada foi de $83,1 \pm 1,9 \mathrm{~dB}(\mathrm{~A})$, sendo que $16,1 \%$ dos motoristas que operam este ônibus podem estar expostos a niveis acima de $85,0 \mathrm{~dB}(\mathrm{~A})$ e $71,9 \%$ estão expostos a niveis acima de $82,0 \mathrm{~dB}(\mathrm{~A})$ (Nivel de ação).

Os modelos com motor traseiro apresentam uma média de $77,0 \pm 1,1$ $\mathrm{dB}(\mathrm{A})$, sem motoristas expostos acima do nivel de ação.

No caso do modelo Volvo, com motor entre-eixos, o valor da média foi de $80,7 \pm 1,1 \mathrm{~dB}(\mathrm{~A})$. Logo não há possibilidade de motoristas estarem expostos a niveis acima de $85,0 \mathrm{~dB}(\mathrm{~A})$ e $15,4 \%$ deles podem estar expostos a um nivel acima de $82,0 \mathrm{~dB}(\mathrm{~A})$.

Os trabalhadores corroboraram que há outras fontes de emissão de ruido além do motor e foram observadas durante as avaliações, tais como: impacto das portas com eventual liberação de ar comprimido no momento de sua abertura e de seu fechamento, vibração dos vidros das janelas contra o metal, por falta de emborrachamento adequado, choques de metal contra metal (colunas de ferro sem fixação adequada, etc.). Basicamente estes problemas ocorrem em função de falhas na manutenção. 


\subsection{Avaliação da vibraçăo de corpo inteiro:}

O procedimento de avaliação dos seis modelos de ônibus da empresa, em condições normais de operação, gerou seguintes resultados:

Tabela 4.5: Valores dos níveis de aceleração da vibração ponderada em freqüència (aw em $\mathrm{m} / \mathrm{s}^{2}$ r.m.s.) transmitidas ao corpo dos motoristas de ônibus através do assento, nas três direçōes ortogonais (awx; awy; awz) dos seis modelos utilizados pela empresa, com o respectivo valor da somatória:

\begin{tabular}{lcccc}
\hline $\begin{array}{l}\text { Modelo } \\
\text { do }\end{array}$ & $\begin{array}{c}\text { awx } \\
\left(\mathrm{m} / \mathrm{s}^{2}\right)\end{array}$ & $\begin{array}{c}\text { awy } \\
\left(\mathrm{m} / \mathrm{s}^{2}\right)\end{array}$ & $\begin{array}{c}\text { awz } \\
\left(\mathrm{m} / \mathrm{s}^{2}\right)\end{array}$ & $\begin{array}{l}\text { Somatória vetorial }\left(\mathrm{m} / \mathrm{s}^{2}\right) \\
\text { ônibus }\end{array}$ \\
\hline 1318 & 0,196 & 0,141 & 0,596 & 0,74 \\
1620 & 0,173 & 0,304 & 0,952 & 1,09 \\
1721 & 0,167 & 0,326 & 0,932 & 1,07 \\
$371 U$ & 0,086 & 0,280 & 0,932 & 1,02 \\
$371 U L$ & 0,215 & 0,268 & 0,868 & 1,00 \\
Volvo & 0,167 & 0,250 & 0,812 & 0,91 \\
\hline
\end{tabular}

Aplicando-se o procedimento apresentado na metodologia para cálculo da média ponderada por tempo de uso e número de veiculos na frota da empresa, o seguinte resultado é obtido: 
Tabela 4.6: Cálculo da média ponderada por número de veículos e tempo de uso considerando os seis modelos em uso na frota da empresa e o valor da somatória vetorial da aceleração de cada um:

\begin{tabular}{|c|c|c|c|c|c|}
\hline $\begin{array}{l}\text { Modelo } \\
\text { do } \\
\text { ônibus }\end{array}$ & $\begin{array}{l}\text { n: número } \\
\text { de veículos }\end{array}$ & $\begin{array}{l}\text { t: tempo } \\
\text { médio de } \\
\text { uso (anos) }\end{array}$ & $\begin{array}{c}a^{2}: \\
\text { quadrado da } \\
\text { somatória } \\
\text { vetorial } \\
\left(\mathrm{m}^{2} / \mathrm{s}^{4}\right)\end{array}$ & $n \times t$ & $n \times t \times a^{2}$ \\
\hline 1318 & 186 & 7,9 & 0,55 & 1469,4 & 804,6 \\
\hline 1620 & 86 & 4,3 & 1,14 & 369,8 & 423,4 \\
\hline 1721 & 19 & 2,0 & 1,12 & 38,0 & 42,7 \\
\hline $371 U$ & 10 & 9,0 & 1,04 & 90,0 & 93,6 \\
\hline 371 UL & 37 & 4,6 & 0,98 & 170,2 & 166,8 \\
\hline Volvo & 22 & 10,0 & 0,83 & 220,0 & 182,2 \\
\hline Total & 360 & - & - & 2357,4 & 1713,4 \\
\hline
\end{tabular}

Desse modo, é obtido o valor médio:

$a_{m}=\sqrt{\frac{\sum n \times t \times a^{2}}{\sum n \times t}}=\sqrt{\frac{1713,4}{2357,4}}=0,85 \mathrm{~m} / \mathrm{s}^{2}$

Os tempos de exposição à vibração de corpo inteiro permitidos, determinados através da leitura do gráfico 4.1 e considerando os valores obtidos para os seis modelos de ônibus estudados, conforme as determinaçōes da norma ISO-2631-1 (1985) são apresentados na tabela abaixo 
Tabela 4.7 : Tempo de exposição permitido para a atividade de condução dos seis modelos de ônibus utilizados pela empresa, de acordo com a norma ISO-2631-1 (1985).

\begin{tabular}{cccc}
\hline Modelo do ônibus & $\begin{array}{c}\text { Somatória vetorial da } \\
\text { aceleração }\left(\mathrm{m} / \mathrm{s}^{2}\right)\end{array}$ & \multicolumn{2}{c}{ Tempo de exposição permitido } \\
\cline { 3 - 4 } & 0,74 & 6 & Horas \\
\hline 1318 & 1,09 & 3 & 30 \\
1620 & 1,07 & 4 & 50 \\
1721 & 1,02 & 4 & - \\
$371 U$ & 1,00 & 4 & 20 \\
$371 U L$ & 0,91 & 5 & 25 \\
VOLVO & & & - \\
\hline
\end{tabular}

Pode-se observar que todos os valores registrados encontram-se acima do limite de tolerância para $8 \mathrm{~h}$ de exposição diária, que é de 0,63 $\mathrm{m} / \mathrm{s}^{2}$. O modelo que apresentou o maior valor da aceleração da vibração foi o 1620, com tempo permitido de $3 \mathrm{~h}$ e $50 \mathrm{~min}$ por dia; enquanto que no modelo 1318 foi registrado o menor, associado um tempo permitido de $6 \mathrm{~h}$ e $30 \mathrm{~min} / \mathrm{dia}$. 


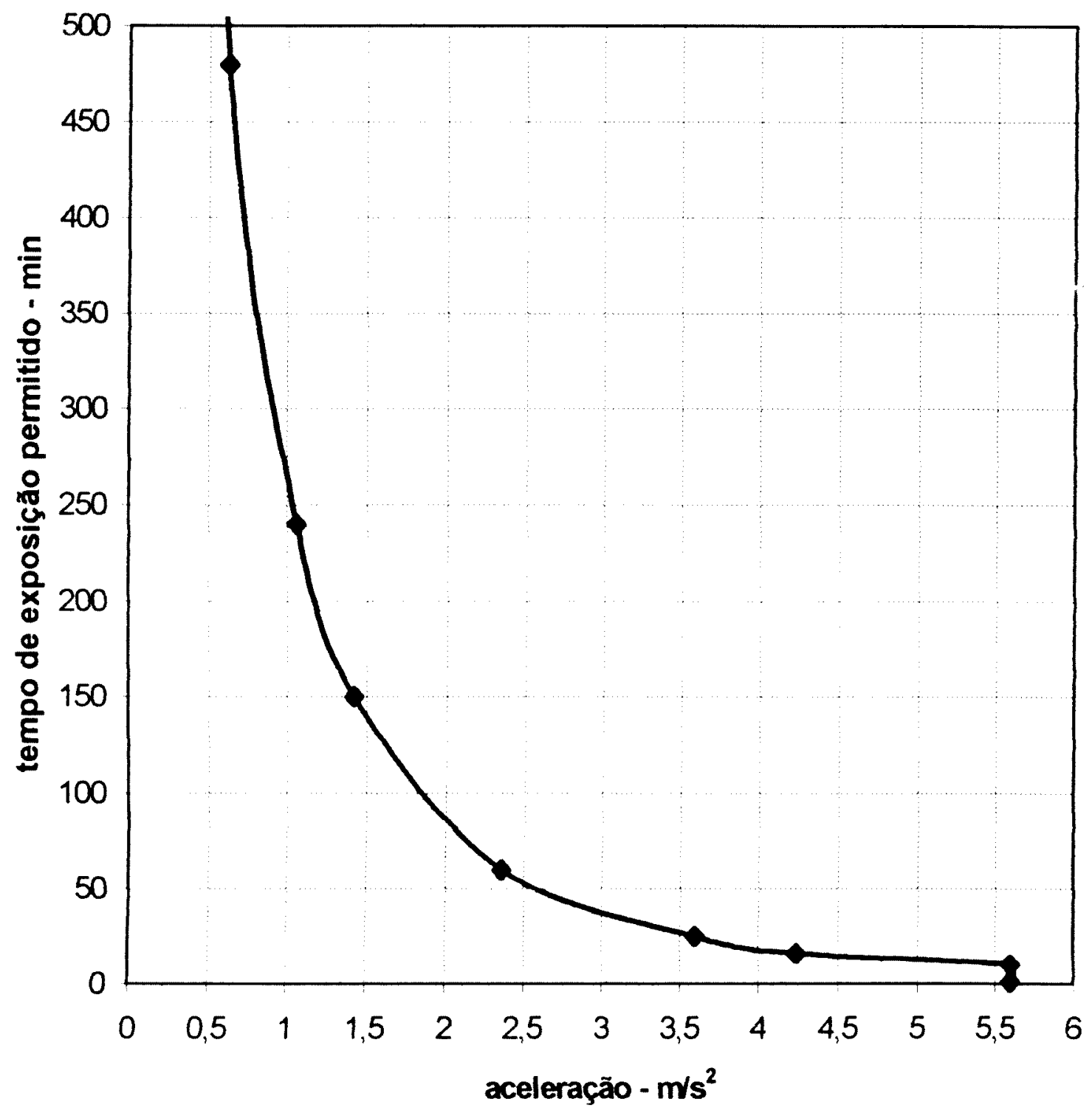

Gráfico 4.1: Tempo de exposição permitido em função da aceleração segundo a norma ISO-2631-1 (1985). 


\subsection{Avaliação audiológica:}

Foram avaliados 182 motoristas, encaminhados pela empresa, dos quais 31 não ingressaram no estudo por não se enquadrarem nos grupos construidos com base no tempo de empresa como motorista. Dos 151 remanescentes com caracteristicas compativeis com os critérios delineados segundo tempo na empresa, um foi excluido por suspeita de perfuração da membrana timpânica com encaminhamento ao otorrinolaringologista, um por obstrução do canal auditivo por cera e não houve retorno para submeter-se à nova avaliação e 8 por pertencerem aos grupos de classificação seis ou sete. Desse modo, totalizou-se uma população de 141 motoristas, sendo 74 $(52,5 \%)$ do grupo com tempo de motorista na empresa inferior ou igual a 3 anos e $67(47,5 \%)$ com 5 anos ou mais.

Em referência à população geral de motoristas, foi encontrada uma taxa de prevalència de PAIR de $35 \%$. No grupo classificado como exposto, ou seja, com 5 anos ou mais como motorista na empresa, esta taxa foi de $46 \%$ (31), enquanto que no de referência, ou seja, com 3 anos ou menos como motorista foi de $24 \%$ (18). A diferença entre as duas taxas observadas é estatisticamente significante $(p<0,01)^{8}$.

No grupo de expostos, dos 31 casos classificados como PAIR, foram registrados dois casos $(6,5 \%)$ como grau três, $10(32,3 \%)$ como grau dois e $19(61,3 \%)$ como grau um. Já no grupo de referência, dos 18 casos de PAIR, quatro $(22,2 \%)$ se enquadraram na classificação de grau dois e 14 $(77,8 \%)$ na de grau um.

\footnotetext{
${ }^{8}$ Teste do Qui-quadrado
} 


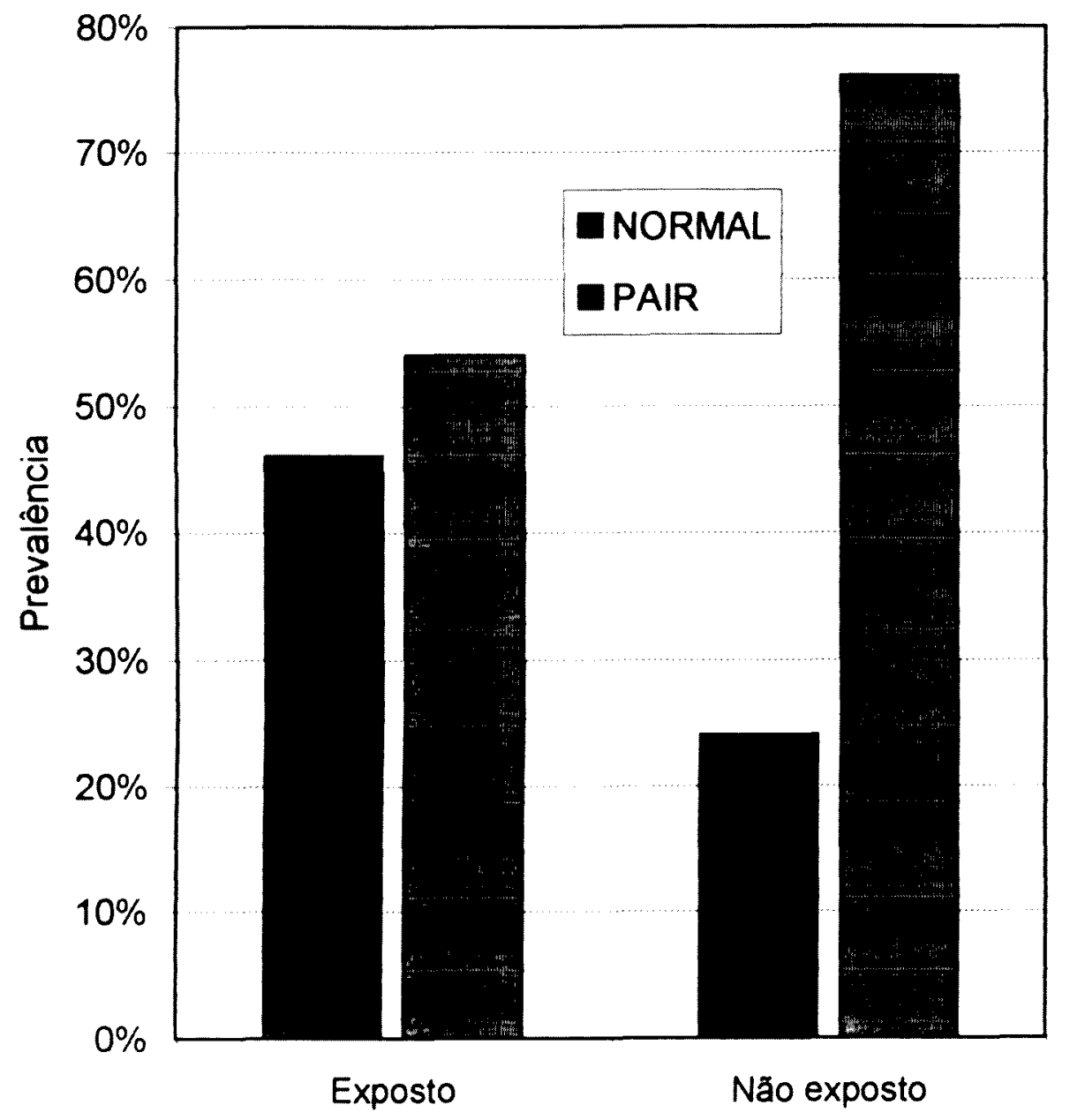

Gráfico 4.2: Taxas de prevalência de traçado sugestivo de PAIR e de normalidade, segundo o critério MERLUZZI e col. (1979), distribuidas por grupo de exposição. 


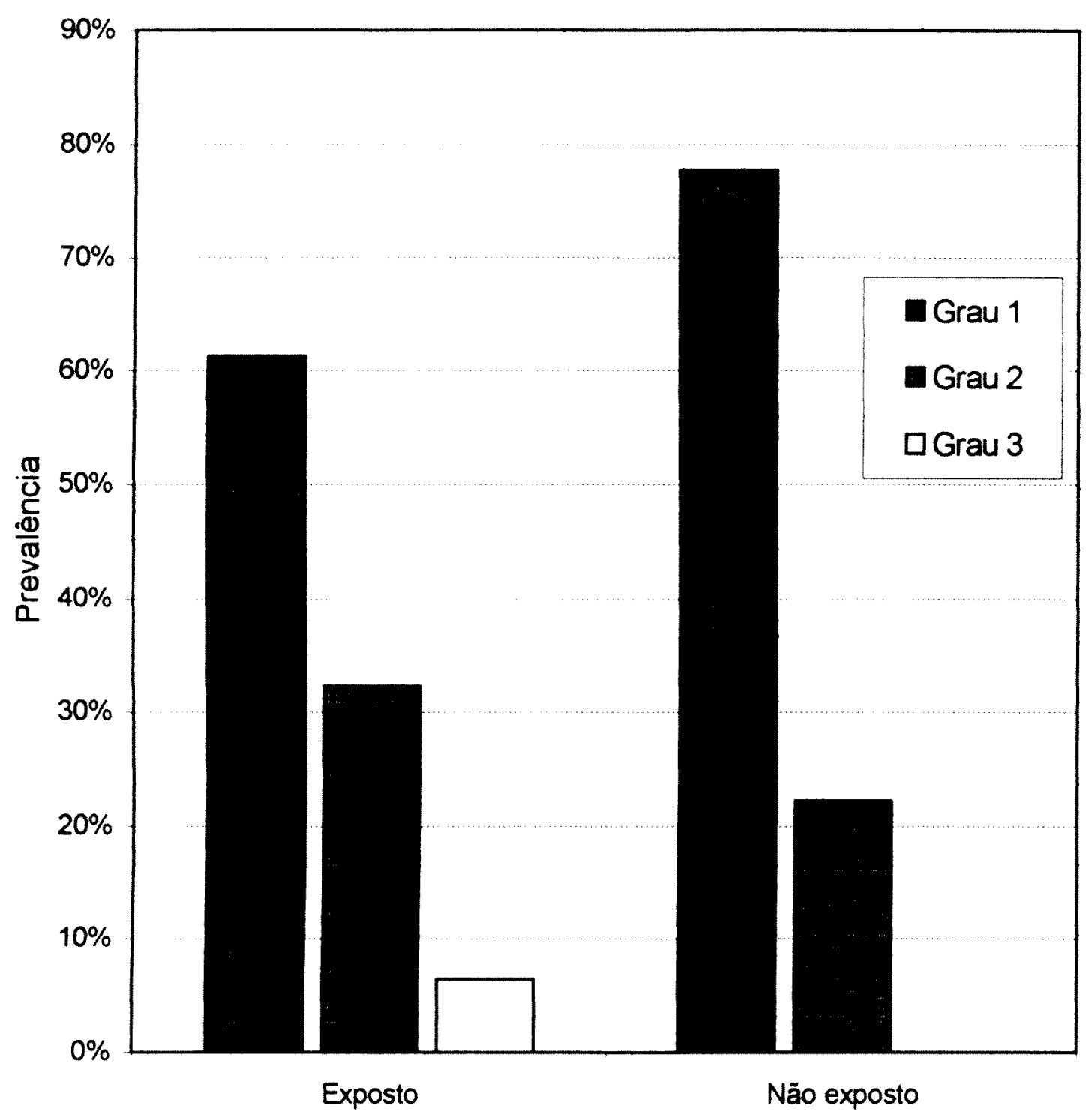

Gráfico 4.3: Distribuição da classificação dos traçados sugestivos de PAIR, segundo o critério MERLUZZI e col. (1979), por grupo de exposição.

Em relação à distribuição de PAIR por idade, foi registrada, no grupo de "não - expostos", uma taxa de prevalência de $11 \%$ para faixa de idade de 25 a 35 anos exclusive, de $27 \%$ na faixa de 35 a 45 anos exclusive e de $44 \%$ para os motoristas com 45 anos ou mais. No grupo de "expostos" as 
taxas encontradas, na mesma ordem de faixa de idades, foi de $0 \%, 38 \%$ e $52 \%$.

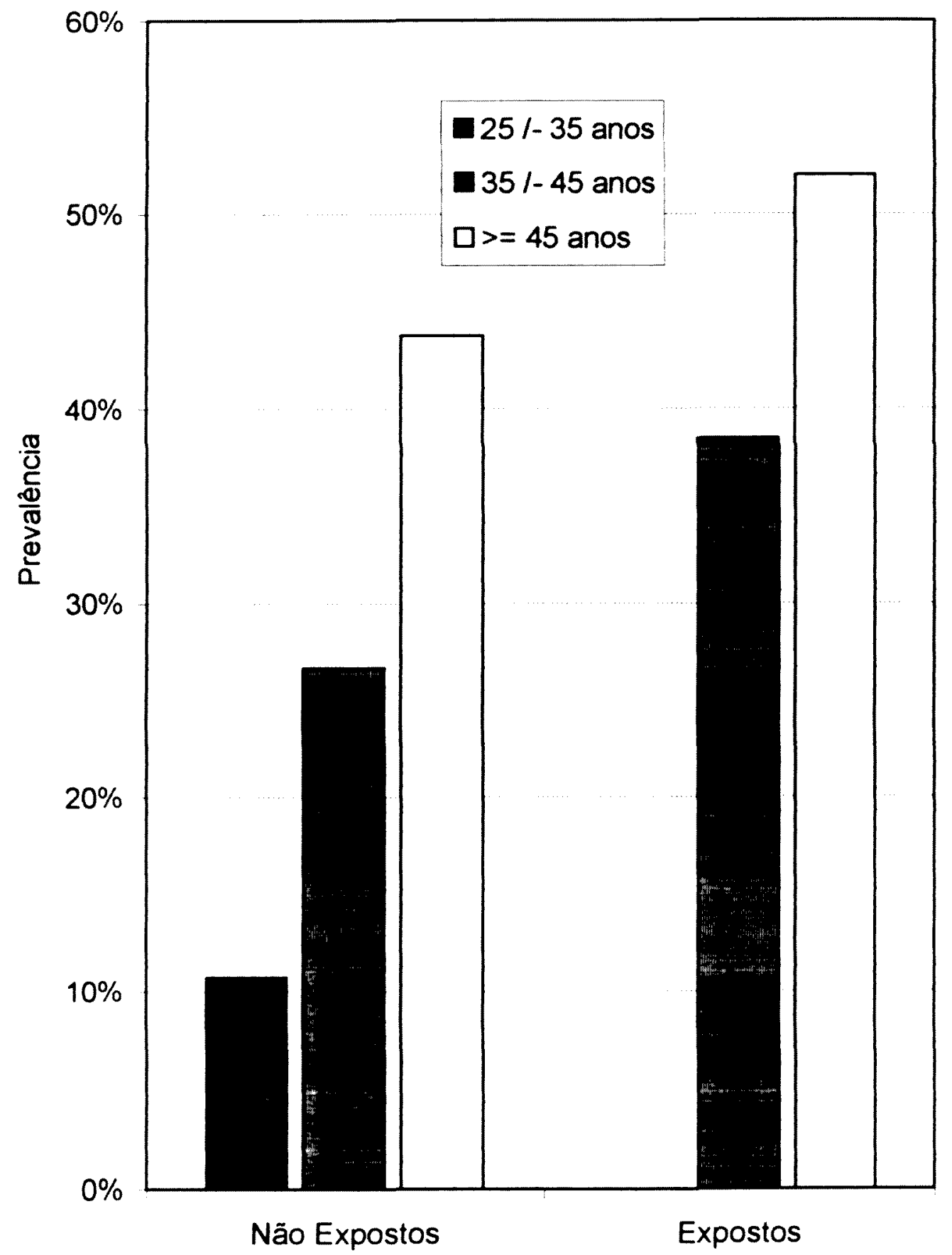

Gráfico 4.4: Distribuição da prevalência dos traçados sugestivos de PAIR, segundo o critério MERLUZZI e col. (1979), por idade e grupo de exposição 


\subsection{Características fundamentais da população de condutores analisada}

A tabela a seguir descreve as características da população estudadas, de acordo com as variáveis empregadas para a construção do modelo multivariado. Com o fim de verificar diferenças entre os dois grupos, aplicou-se o teste- $t$ de Student para as variáveis contínuas e o teste do Quiquadrado para as categóricas. São apresentadas as médias com os respectivos desvios - padrão entre parênteses para as variáveis continuas e os números de casos com as porcentagens entre parênteses para as variáveis categóricas.

Tabela 4.7: Caracteristicas dos motoristas com tempo na função na empresa maior ou igual a 5 anos ("expostos") e daqueles com este tempo menor ou igual a 3 anos (não - expostos).

\begin{tabular}{|c|c|c|c|}
\hline Variável & $\begin{array}{l}\text { Exposto } \\
(n=67)\end{array}$ & $\begin{array}{l}\text { Não - exposto } \\
(n=74)\end{array}$ & Valor de $p$ \\
\hline Idade (anos) & $47,7(8,3)$ & $38,8(7,7)$ & $<0,001$ \\
\hline Imissão de ruido $E_{A}(d B(A))$ & $91,3(3,7)$ & $84,2(3,3)$ & $<0,001$ \\
\hline Dose de vibração $\left(\mathrm{m}^{2} / \mathrm{s}^{4}\right)$ & $6,8(3,9)$ & $1,2(0,5)$ & $<0,001$ \\
\hline $\begin{array}{l}\text { Tempo de exposição prévia ao } \\
\text { ruído (anos) }\end{array}$ & $11(6,0)$ & $8,1(6,6)$ & 0,008 \\
\hline $\begin{array}{l}\text { Tempo de exposição prévia à VCl } \\
\text { (anos) }\end{array}$ & $10,7(6,4)$ & $8,8(6,4)$ & 0,07 \\
\hline Histórico de hipertensão arterial (n) & $12(17,9)$ & $4(5,4)$ & 0,02 \\
\hline Histórico de diabetes $(n)$ & $5(7,5)$ & $2(2,7)$ & 0,19 \\
\hline $\begin{array}{l}\text { Histórico de antecedentes } \\
\text { familiares }(n)\end{array}$ & $5(7,5)$ & $4(5,4)$ & 0,62 \\
\hline Tabagismo $(n)$ & $21(31,3)$ & $25(33,8)$ & 0,75 \\
\hline
\end{tabular}


Tabela 4.7: continuação:

\begin{tabular}{lccc}
\hline Variável & $\begin{array}{c}\text { Exposto } \\
(n=67)\end{array}$ & $\begin{array}{c}\text { Não - exposto } \\
(n=74)\end{array}$ & Valor de $\rho$ \\
\hline $\begin{array}{l}\text { Histórico de uso de medicamentos } \\
\text { ototóxicos }(n)\end{array}$ & $4(6,0)$ & $4(5,4)$ & 0,88 \\
Serviço militar $(n)$ & $7(10,4)$ & $4(5,4)$ & 0,26 \\
\hline
\end{tabular}

Como descrito na metodologia deste trabalho, o tempo acumulado na empresa como motorista serviu como referência para a construção dos dois grupos de comparação. Os dados sobre o tempo acumulado como motorista não são apresentados na tabela anterior. No entanto, efetuando a comparação entre os dois grupos, verificou-se que a média de tempo acumulado na empresa como motorista no grupo exposto foi de $9,4 \pm 5,3$ anos, enquanto que no grupo não exposto foi de 1,7 $\pm 0,7$ anos. $A$ diferença entre os dois valores é estatisticamente significante $(p<0,001)$. Deve ser assinalado que existe uma correlação extremamente importante entre a variável tempo de exposição acumulado na empresa como motorista e dose de vibração. Na verdade, o valor desta correlação é 1,0 , pois na formulação da dose de vibração encerra este tempo de empresa. Logo, não foi possivel trabalhar com as duas variáveis simultaneamente, nem estimar o efeito independente de cada uma, pois perturbava a modelagem, indicando um problema de colinearidade entre as variáveis.

Pode-se observar na tabela acima que a média de idade dos motoristas pertencentes ao grupo exposto é significativamente superior a dos motoristas do não exposto $(\rho<0,001)$. Da mesma ordem de grandeza, foram os valores de $p$ encontrados para as variáveis Imissãc de ruído $\left(E_{A}\right)$ e dose de vibração, indicando que o nivel de exposição do grupo considerado exposto é significativamente maior do que o grupo não - exposto. 0 grupo exposto apresenta uma exposição prévia ao ruído significativamente maior do que o não - exposto $(p=0,008)$, no entanto não foi encontrada diferença estatisticamente significante em relação à exposição prévia à vibração de 
corpo inteiro. Em referência às variáveis categóricas, somente a relacionada com o histórico de hipertensão arterial apresentou diferença significante entre os dois grupos $(p=0,02)$, ou seja, no grupo considerado como exposto o número de casos é significativamente maior do que no grupo não exposto. 


\subsection{Análise por regressão logística:}

Definiu-se pela apresentação de três modelos oriundos da aplicação da regressão logística, cuja finalidade foi a de analisar simultaneamente os fatores potenciais para a ocorrência de perda auditiva induzida por ruido, bem como verificar a existência de associação importante com a variáve! correspondente à exposição à vibração de corpo inteiro com o devido controle para as outras possíveis variáveis de confusão.

Anteriormente à apresentação dos resultados obtidos pela análise univariada, serão exibidas as tabelas de contingência correspondentes às variáveis em análise. Estabeleceu-se como ponto de corte, a mediana da distribuição dos valores das variáveis contínuas IDADE, $E_{A}$ (nível de imissão de ruido), DOSE (dose de vibração), TEPR (tempo de exposição prévia ao ruido) e TEPV (tempo de exposição prévia à vibração). Desse modo, estas foram transformadas em categóricas. 
Tabela 4.8: Tabelas de contingência para as variáveis estudadas de acordo com a ocorrência de PAIR e respectivas taxas de prevalência.

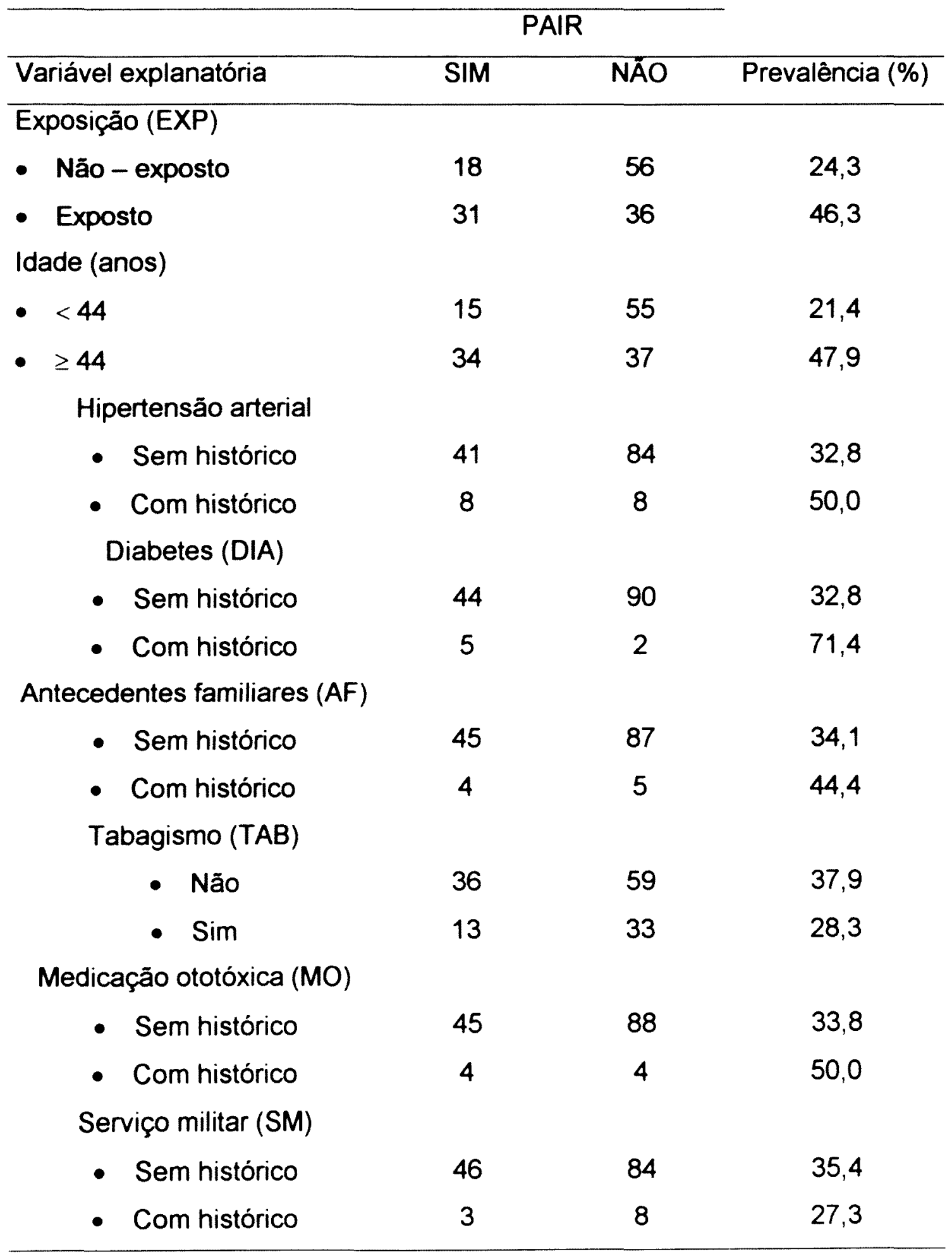


Tabela 4.8: continuação

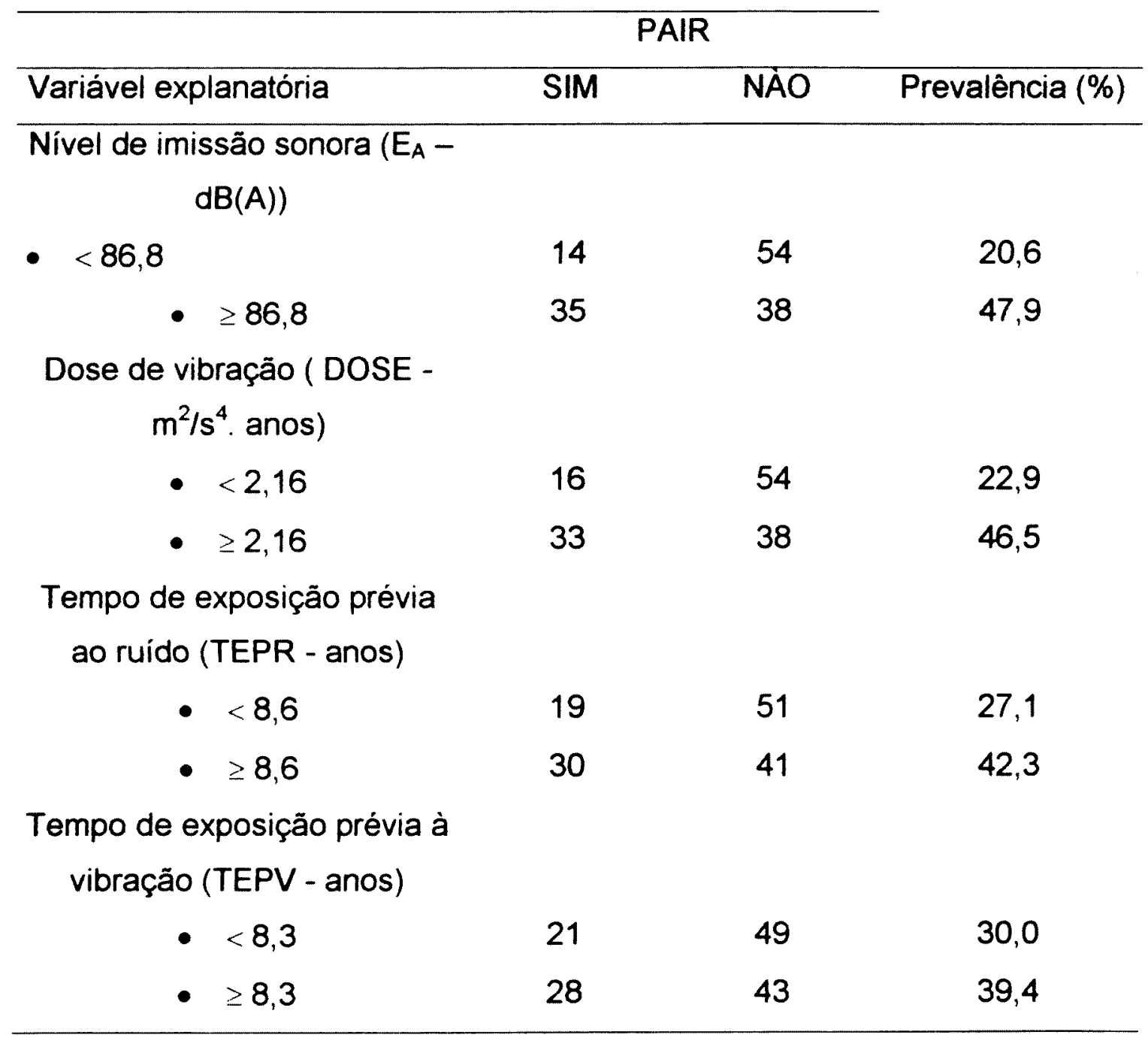

A tabela a seguir apresenta os dados resultantes da análise univariada com os respectivos valores brutos da Razão de Chances (RC) e o valor de $\rho$ do teste da razão da máxima verossimilhança. 
Tabela 4.9: Análise univariada apresentando as razōes de chances, os intervalos de confiança (IC 95\%) e o valor de $p$ do teste da razão da máxima verossimilhança para os efeitos das variáveis explanatórias na ocorrência de PAIR:

\section{Variável explanatória \\ Exposição (EXP)}

Razão de

Chances (RC)
Intervalo de confiança (95\%)
- Não - exposto

- Exposto

Idade (anos)

- $<44$

- $\geq 44$

Hipertensão arterial

- Sem histórico

- Com histórico

Diabetes (DIA)

- Sem histórico

- Com histórico

Antecedentes familiares (AF)

- Sem histórico

- Com histórico

Tabagismo (TAB)

- Não

- Sim
1,0

2,68

$1,31-5,48$

0,0009

1,0

3,37

$1,61-7,04$

0,1829

1,0

2,05

$0,72-5,85$

0,0424

1,0

5,11

$0,95-27,4$

0,5347

1,0

1,55

$0,40-6,04$

0,2557

1,0

0,65

$0,30-1,39$

Medicação ototóxica (MO)

- Sem histórico

1,0

- Com histórico

1,96

$0,47-8,19$ 
Tabela 4.9: continuação.

\begin{tabular}{|c|c|c|c|}
\hline Variável explanatória & $\begin{array}{c}\text { Razão de } \\
\text { Chances (RC) }\end{array}$ & $\begin{array}{c}\text { Intervalo de } \\
\text { confiança (95\%) }\end{array}$ & $p$ \\
\hline Serviço militar (SM) & & & 0,5807 \\
\hline - Sem histórico & 1,0 & & \\
\hline - Com histórico & 0,68 & $0,17-2,70$ & \\
\hline $\begin{array}{l}\text { Nivel de imissão sonora }\left(E_{A}-\right. \\
\qquad d B(A))\end{array}$ & & & 0,0006 \\
\hline$\cdot<86,8$ & 1,0 & & \\
\hline - $\quad \geq 86,8$ & 3,55 & $1,68-7,49$ & \\
\hline $\begin{array}{l}\text { Dose de vibração ( DOSE - } \\
\qquad \mathrm{m}^{2} / \mathrm{s}^{4} \text {. anos) }\end{array}$ & & & 0,0030 \\
\hline - $<2,16$ & 1,0 & & \\
\hline - $\geq 2,16$ & 2,93 & $1,42-6,06$ & \\
\hline $\begin{array}{c}\text { Tempo de exposição prévia } \\
\text { ao ruído (TEPR - anos) }\end{array}$ & & & 0,0596 \\
\hline$\bullet<8,6$ & 1,0 & & \\
\hline$\bullet \geq 8,6$ & $1, .96$ & $0,97-3,98$ & \\
\hline $\begin{array}{c}\text { Tempo de exposição prévia à } \\
\text { vibração (TEPV - anos) }\end{array}$ & & & 0,2388 \\
\hline • $<8,3$ & 1,0 & & \\
\hline - $\quad \geq 8,3$ & 1,52 & $0,76-3,06$ & \\
\hline
\end{tabular}

Conforme os resultados apresentados na tabela anterior, sobretudo observando o valor de $p$, constata-se que as variáveis que podem entrar para a construção do modelo são: nivel de imissão sonora $\left(E_{A}\right)$; idade (IDADE); histórico de diabetes (DIA); dose de vibração (DOSE), exposição (EXP); tempo de exposição prévia ao ruido (TEPR) e histórico de hipertensão arterial (HA). 
Empregando a metodologia descrita anteriormente para a seleção das variáveis mais representativas estatisticamente $(p<0,20)$ e deliberadamente mantendo somente a variável DOSE, alcançou-se o seguinte resultado.

Tabela 4.10: Análise multivariada apresentando as razóes de chances, os intervalos de confiança (IC 95\%) e o valor de $p$ do teste da razão da máxima verossimilhança para os efeitos das variáveis explanatórias e significantes na ocorrência de PAIR:

\begin{tabular}{|c|c|c|c|}
\hline Variável preditora & $\begin{array}{c}\text { Razão de } \\
\text { chances (RC) }\end{array}$ & $\begin{array}{c}\text { Intervalo de } \\
\text { confiança (95\%) }\end{array}$ & $p$ \\
\hline Idade (anos) & & & 0,0298 \\
\hline - $<44$ & 1,0 & - & \\
\hline - $\quad \geq 44$ & 2,49 & $1,08-5,73$ & \\
\hline Diabetes (DIA) & & & 0,0462 \\
\hline - Sem histórico & 1,0 & & \\
\hline - Com histórico & 5,39 & $0,93-31,3$ & \\
\hline $\begin{array}{l}\text { Nivel de imissão sonora }\left(E_{A}-\right. \\
d B(A))\end{array}$ & & & 0,0417 \\
\hline - $<86,8$ & 1,0 & & \\
\hline - $\quad \geq 86,8$ & 2,66 & $1,02-6,87$ & \\
\hline $\begin{array}{l}\text { Dose de vibração ( DOSE - } \\
\mathrm{m}^{2} / \mathrm{s}^{4} \text {. anos) }\end{array}$ & & & 0,8833 \\
\hline - $<2,16$ & 1,0 & & \\
\hline - $\geq 2,16$ & 1,08 & $0,40-2,87$ & \\
\hline
\end{tabular}

Pode-se observar, através da tabela acima, que a variável DOSE não é significante, uma vez que o seu valor de $p$ é bem superior a 0,20 .

Cabe destacar que foram testadas as possiveis interações, no entanto não produzindo nenhum resultado estatisticamente significante 
Desse modo, retirando-a do modelo anterior, encontramos os seguintes resultados demonstrados na tabela a seguir:

Tabela 4.11: Análise multivariada apresentando as razões de chances, os intervalos de confiança (IC 95\%) e o valor de $p$ do teste da razão da máxima verossimilhança para os efeitos das variáveis explanatórias e significantes na ocorrência de PAIR - modelo 1:

\begin{tabular}{lccc}
\hline Variável preditora & $\begin{array}{c}\text { Razão de } \\
\text { chances (RC) }\end{array}$ & $\begin{array}{c}\text { Intervalo de } \\
\text { confiança (95\%) }\end{array}$ & p \\
\hline Idade (anos) & 1,0 & $\mathbf{0 , 0 1 9 8}$ \\
- $\quad 44$ & 2,54 & $1,15-5,62$ & \\
- $\geq 44$ & & & $\mathbf{0 , 0 4 3 4}$ \\
Diabetes (DIA) & 1,0 & & \\
- Sem histórico & 5,46 & $0,95-31,4$ & \\
- Com histórico & & & $\mathbf{0 , 0 1 1 7}$ \\
Nivel de imissão sonora (EA & & & \\
dB(A)) & & & \\
- $<86,8$ & 1,0 & $1,24-6,15$ & \\
- $\geq 86,8$ & 2,76 & & \\
\hline
\end{tabular}

Verifica-se que todas as variáveis eleitas para este modelo final apresentam significância, uma vez que os valores de $p$ registrados são bem menores do que 0,20 .

Fundamentando-se neste modelo ajustado a probabilidade de ocorrência da variável dependente $(Y=1 / P A I R)$ é representada pela seguinte equação:

$$
\operatorname{Pr} o b(Y=1)=\frac{1}{1+e^{-g(x)}}
$$


Onde $g(x)$ é igual $a$ :

$$
g(x)=-1,8163+1,015(E a \geq 86,8)+0,9327(I D A D E \geq 44)+1,6976(D I A)
$$

A equação acima demonstra a probabilidade de PAIR ou de traçado sugestivo de PAIR, controlada por idade, nivel de imissão sonora e histórico de diabetes.

Aplicando a fórmula acima é possivel calcular a probabilidade de ocorrência de PAIR ou de traçado sugestivo de PAIR para as diferentes situações de exposição:

Tabela 4.12: Estimativas de probabilidade de ocorrência de PAIR segundo a equação do modelo 1 :

Situação de exposição
Probabilidade

$(\%)$

Nivel de exposição ao ruído inferior a $86,8 \mathrm{~dB}(\mathrm{~A})$, idade abaixo de 44 anos e sem histórico de diabetes.

Idade de $\mathbf{4 4}$ anos ou mais; nivel de exposiçāo ao ruído inferior a 29,2 86,8 dB(A) e sem histórico de diabetes

Nivel de exposição superior ou igual a $86,8 \mathrm{~dB}(\mathrm{~A})$; idade abaixo 31,0 de 44 anos e sem histórico de diabetes.

Nivel de exposição ao ruído inferior a $86,8 \mathrm{~dB}(\mathrm{~A})$, idade abaixo de 47,0 44 anos e com histórico de diabetes.

Idade de 44 anos ou mais; nível de exposição ao ruido superior 53,3 ou igual a $86,8 \mathrm{~dB}(\mathrm{~A})$ e sem histórico de diabetes Idade de 44 anos ou mais; com histórico de diabetes e nivel de 69,3 exposição ao ruido inferior a $86,8 \mathrm{~dB}(\mathrm{~A})$. 
Tabela 4.12: continuação

Situação de exposição Probabilidade

(\%)

Nivel de exposição ao ruído superior ou igual a $86,8 \mathrm{~dB}(\mathrm{~A})$; com $\quad 71,0$ histórico de diabetes e idade abaixo de 44 anos.

Idade de 44 anos ou mais, histórico de diabetes e com nivel de 86,2 exposição ao ruido superior ou igual a $86,8 \mathrm{~dB}(\mathrm{~A})$.

A tabela de contingência correspondente ao segundo modelo, definido para integrar aos resultados, é praticamente similar ao primeiro, diferindo apenas em relação às variáveis idade, nível de imissão de ruído e dose de vibraçāo. Os pontos de corte das duas primeiras são apresentados nas tabelas de contingência a seguir e a variável dose de vibração foi manipulada como contínua.

Tabela 4.13: Tabelas de contingência para as variáveis idade e nivel de imissão de vibração e respectivas taxas de prevalência por estrato para o segundo modelo segundo a ocorrência de PAIR:

\begin{tabular}{lccc}
\hline \multicolumn{3}{c}{ PAIR } & \\
\cline { 1 - 2 } Variável preditora & SIM & NÁO & Prevalência (\%) \\
\cline { 1 - 2 } ldade (anos) & 3 & 31 & 8,8 \\
- $<36$ & 12 & 24 & 33,3 \\
- $\quad 36 /-44$ & 34 & 37 & 47,9 \\
- $\geq 44$ & & & \\
Nivel de imissão sonora $\left(\mathrm{E}_{\mathrm{A}}-\right.$ & & & \\
dB(A)) & 15 & 56 & 21,1 \\
- $<87,0$ & 16 & 18 & 47,1 \\
- $87 /-91,3$ & 18 & 18 & 50,0 \\
- $\geq 91,3$ & & & \\
\hline
\end{tabular}


Tabela 4.14: Análise univariada apresentando as razōes de chances, os intervalos de confiança (IC 95\%) e o valor de $\rho$ do teste da razão da máxima verossimilhança para os efeitos das variáveis explanatórias idade, nível de imissão sonora e dose de vibração para o segundo modelo na ocorrência de PAIR.

\begin{tabular}{|c|c|c|c|}
\hline Variável preditora & $\begin{array}{c}\text { Razão de } \\
\text { Chances (RC) }\end{array}$ & $\begin{array}{c}\text { Intervalo de } \\
\text { confiança (95\%) }\end{array}$ & $p$ \\
\hline Idade (anos) & & & 0,0001 \\
\hline - $<36$ & 1,0 & - & \\
\hline - $36 /-44$ & 5,17 & $1,31-20,4$ & \\
\hline - $\quad \geq 44$ & 9,50 & $2,66-33,9$ & \\
\hline $\begin{array}{l}\text { Nível de imissão sonora }\left(E_{A}-\right. \\
d B(A))\end{array}$ & & & 0,0025 \\
\hline - $\quad<87,0$ & 1,0 & & \\
\hline - $87 /-91,3$ & 3,32 & $1,37-8,02$ & \\
\hline - $\geq 91,3$ & 3,73 & $1,57-8,88$ & \\
\hline $\begin{array}{l}\text { Dose de vibração } \\
\left(\mathrm{m}^{2} / \mathrm{s}^{4} \cdot \text { anos }\right)\end{array}$ & 1,15 & $1,05-1,27$ & 0,0024 \\
\hline
\end{tabular}

Por meio da adoção do critério de inclusão por nivel hierárquico do valor do teste da máxima verossimilhança em ordem decrescente, o procedimento de construção do modelo pode ser observado a seguir: 
Tabela 4.15: Apresentação do procedimento progressivo de inclusão de variáveis para o segundo modelo.

\begin{tabular}{|c|c|c|c|c|c|}
\hline Fase & & Variável & $\begin{array}{c}\text { Razão de } \\
\text { Chances - } \\
\text { RC }\end{array}$ & $\begin{array}{c}\text { Intervalo de } \\
\text { confiança } \\
(95 \%)\end{array}$ & $p$ \\
\hline & & - $<36$ & 1,0 & & \\
\hline \multirow[t]{3}{*}{1} & Idade & - $36 /-44$ & 5,17 & $1,31-20,39$ & 0,0001 \\
\hline & & - $\geq 44$ & 9,50 & $2,66-33,92$ & \\
\hline & & - $<36$ & 1,0 & & \\
\hline \multirow[t]{6}{*}{2} & Idade & - $36 /-44$ & 4,82 & $1,22-19,12$ & 0,0046 \\
\hline & & - $\quad \geq 44$ & 6,97 & $1,83-26,52$ & \\
\hline & Dose & - & 1,08 & $0,97-1,20$ & 0,1317 \\
\hline & & - $<36$ & 1,0 & & \\
\hline & Idade & - $36 /-44$ & 5,14 & $1,26-20,92$ & 0,0052 \\
\hline & & - $\geq 44$ & 6,92 & $1,79-26,65$ & \\
\hline \multirow[t]{7}{*}{3} & Dose & - & 1,06 & $0,90-1,23$ & 0,4956 \\
\hline & & - $<87,0$ & 1,0 & & \\
\hline & $E_{A}$ & - $87,0 /-91,3$ & 2,82 & $1,08-7,36$ & 0,1014 \\
\hline & & - $\quad \geq 91,3$ & 1,67 & $0,41-6,76$ & \\
\hline & & - $<36$ & 1,0 & & \\
\hline & Idade & - $36 /-44$ & 4,50 & $1,08-18,64$ & 0,0098 \\
\hline & & - $\geq 44$ & 6,40 & $1,65-24,88$ & \\
\hline \multirow[t]{5}{*}{4} & Dose & - & 1,07 & $0,91-1,25$ & 0,4146 \\
\hline & & - $<87,0$ & 1,0 & & \\
\hline & $E_{A}$ & - $87,0 /-91,3$ & 2,92 & $1,10-7,20$ & 0,0858 \\
\hline & & - $\geq 91,3$ & 1,49 & $0,36-6,23$ & \\
\hline & DIA & - & 4,41 & $0,77-25,22$ & 0,0777 \\
\hline
\end{tabular}

Observa-se pela tabela acima, que na fase dois houve uma alteração importante do valor de RC para o terceiro estrato da variável idade. 
provocada pela inclusão da variável dose de vibraçăo, sugerindo ser de confusăo. A interaçăo foi testada; contudo năo foi alcançado nenhum resultado expressivo. Também nesta mesma fase, é possivel argüir que há uma indicaçăo de associaçăo da variável dose de vibraçăo com a ocorrência de PAIR.

$\mathrm{Na}$ fase 3, a rigor, pode-se notar que a significância da variável DOSE já permitiria a sua exclusão. Na última fase, a quarta, com a definiçăo do modelo, o nível de significância da variável dose de vibraçăo aponta que ela pouco contribui para a equação final. Sem a variável dose, as variáveis idade e nivel de imissăo de ruído apresentariam um valor de $p$ inferior a 0,05 .

É relevante assinalar que se deparou com uma incoerência nesta modelagem em relação à variável nivel de imissão de nuido. $O$ terceiro estrato, ou seja, nível de imissão se ruído superior o igual a $91,3 \mathrm{~dB}(\mathrm{~A})$ apresentou um valor de $R C$ ajustado de 1,49 , inferior ao segundo $\left(E_{A}\right.$ entre $87,0 \mathrm{~dB}(\mathrm{~A})$ e 91,3 exclusive) de 2,92. Possivelmente este fato deve-se a um viés peculiar aos estudos de prevaléncia que será abordado mais adiante.

A despeito do valor de $\rho$ da variável dose de vibração não apresentar um nivel significante, a seguinte equação pode ser estabelecida a partir do modelo definido na fase 4 do procedimento de modelagem.

$$
\operatorname{Pr} o b(Y=1)=\frac{1}{1+e^{-g(x)}}
$$

Onde $g(x)$ é igual a :

$$
g_{(x)}=-2,8309+1,5037 I_{2}+1,8570 I_{3}+0,0646 D+1,0715 E_{2}+0,4019 E_{3}+1,4837 D I A
$$

A equação demonstra a probabilidade de PAIR ou de traçado sugestivo de PAIR, controlada por idade, dose de vibração, nivel de imissão 
sonora e histórico de diabetes. A elevaçāo da probabilidade de ocorrência de PAIR está relacionada ao incremento da idade, do nivel de imissão sonora e com a presença de histórico de diabetes, apontada pelos sinais dos coeficientes das variáveis constantes no modelo.

As notaçōes da equação acima correspondem a:

12: estrato da variável IDADE, 36 a 44 anos exclusive;

13: estrato da variável IDADE, maior ou igual a 44 anos;

D: variável DOSE;

$E_{A}$ 2: estrato da variável $E_{A}$ (nivel de exposição ao ruído), 87,0 a 91,3 dB(A) exclusive;

$E_{A} 3$ : estrato da variável $E_{A}$ (nivel de exposição ao ruído) maior ou igual a $91,3 \mathrm{~dB}(\mathrm{~A})$;

DIA: correspondente ao histórico de diabetes.

As estimativas de probabilidades para algumas situaçōes de exposição são apresentadas na tabela seguinte. 
Tabela 4.16: Estimativa de probabilidade de ocorrência de PAIR segundo as situações de exposição descritas fundamentando-se na equação do modelo 2 :

Situação de exposição

Probabilidade

(\%)

Nivel de exposição ao ruído inferior a $87,0 \mathrm{~dB}(\mathrm{~A})$, idade abaixo de 6,0 36 anos e sem histórico de diabetes.

Nivel de exposição ao ruído superior ou igual a $87,0 \mathrm{~dB}(\mathrm{~A})$ e 15,0 inferior a 91,3 dB(A); idade abaixo de 36 anos e sem histórico de diabetes.

Nivel de exposição ao ruído inferior a $87,0 \mathrm{~dB}(\mathrm{~A})$, idade entre 36 21,0 e 44 anos exclusive e sem histórico de diabetes.

Nivel de exposição ao ruido inferior a $87,0 \mathrm{~dB}(\mathrm{~A})$, idade abaixo de 21,0 36 anos e com histórico de diabetes.

Idade maior ou igual a 44 anos; nivel de exposição ao ruido 27,0 inferior a $87,0 \mathrm{~dB}(\mathrm{~A})$ e sem histórico de diabetes.

Idade abaixo de 36 anos, nivel de exposição ao ruído superior ou 43,0 igual a $87,0 \mathrm{~dB}(\mathrm{~A})$ e inferior a $91,3 \mathrm{~dB}(\mathrm{~A})$ e com histórico de diabetes.

Idade entre 36 e 44 anos exclusive e com nivel de exposição ao 44,0 ruido superior ou igual a $87,0 \mathrm{~dB}(\mathrm{~A})$ e inferior a $91,3 \mathrm{~dB}(\mathrm{~A})$ e sem histórico de diabetes.

Idade maior ou igual a 44 anos; nivel de exposição ao ruído 52,0 superior ou igual a $87,0 \mathrm{~dB}(\mathrm{~A})$ e inferior a $91,3 \mathrm{~dB}(\mathrm{~A})$ e sem histórico de diabetes.

Idade entre 36 e 44 anos exclusive; nivel de exposiçăo ao ruido 54,0 inferior a 87,0 dB(A) e com histórico de diabetes.

Idade maior ou igual a 44 anos; nivel de exposição ao ruido 62,0 inferior a $87,0 \mathrm{~dB}(\mathrm{~A})$ e com histórico de diabetes. 
Tabela 4.16: continuação.

Situação de exposição Probabilidade

(\%)

Idade entre 36 e 44 anos exclusive e com nivel de exposição ao 77,0 ruído superior ou igual a 87,0 dB(A) e inferior a $91,3 \mathrm{~dB}(\mathrm{~A})$. e com histórico de diabetes.

Idade maior ou igual a 44 anos; nivel de exposição ao ruído 83,0 superior ou igual a $87,0 \mathrm{~dB}(\mathrm{~A})$ e inferior a $91,3 \mathrm{~dB}(\mathrm{~A})$ e com histórico de diabetes.

Outras circunstâncias de exposiçăo, dependentes da variável dose de vibração, são apresentadas no gráfico 4.5. Na primeira curva traçada pode ser verificada a evolução da estimativa da probabilidade de PAIR de acordo com a dose de vibração, compreendendo uma situação de exposição em que o nivel de imissão de ruído é inferior a $87,0 \mathrm{~dB}(\mathrm{~A})$, a idade abaixo de 36 anos e ausência de histórico de diabetes. Nesta circunstância, um valor da dose de vibração de $10 \mathrm{~m}^{2} / \mathrm{s}^{4}$.anos, ou 13,84 anos de exposição aos veículos envolvidos neste estudo, apenas como exemplo, corresponde a uma probabilidade de PAIR de $10 \%$. Na situação mais extrema, indicada pelo último traçado da curva no gráfico 4.5 , para a característica de exposição correspondente a idade acima de 44 anos, nivel de imissão de ruido igual ou superior a $87,0 \mathrm{~dB}(\mathrm{~A})$ e inferior a $91,3 \mathrm{~dB}(\mathrm{~A})$ e presença de histórico de diabetes, a probabilidade para a mesma dose de vibração é de $90 \%$ 


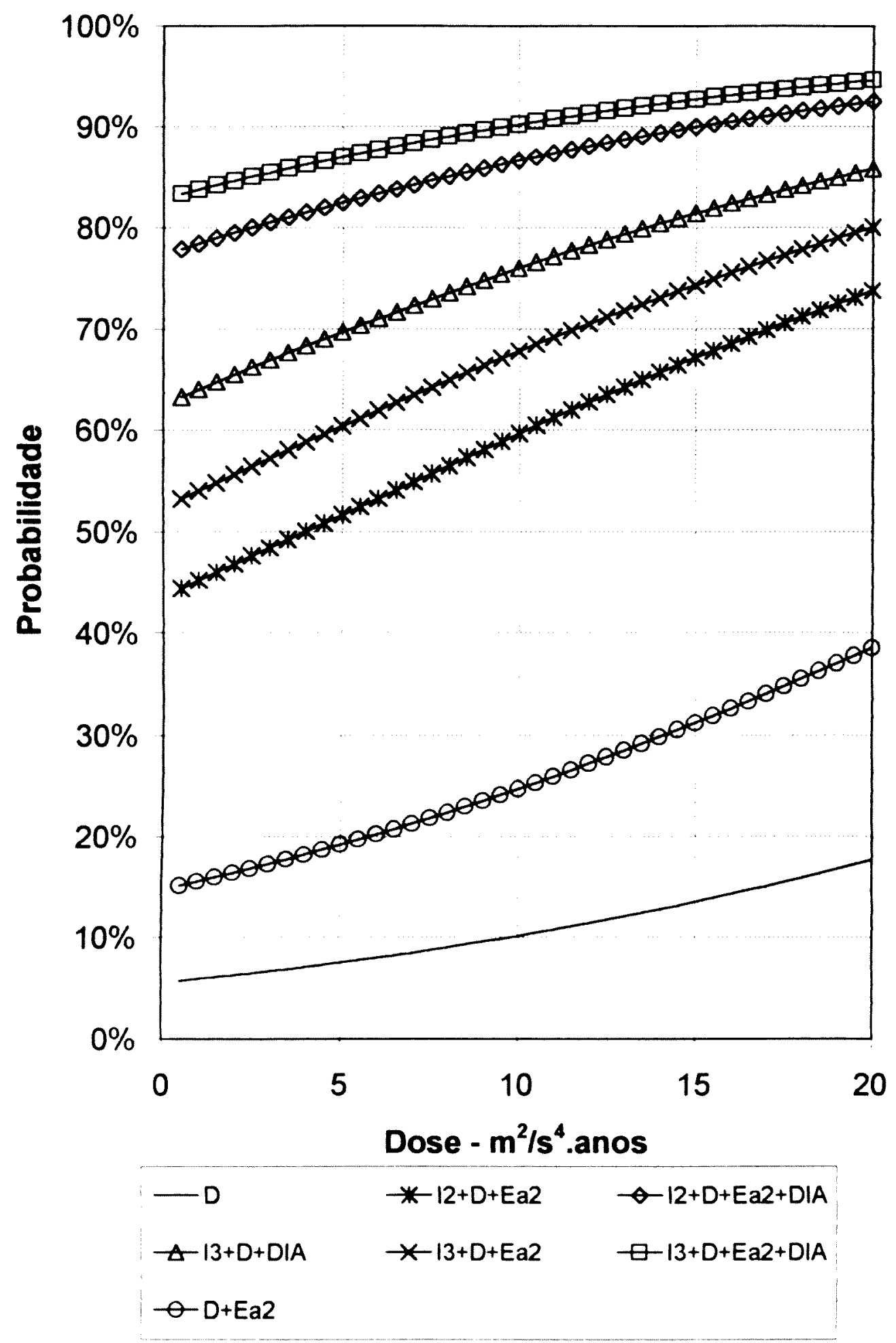

Gráfico 4.5: Estimativa de probabilidade de PAIR para as situaçōes de exposição na legenda, segundo a evolução da dose de vibração e com base no segundo modelo. 
Outro modelo julgado como interessante para inserção no estudo sobre o qual deverá ser analisado com maior profundidade no tópico da discussão, foi obtido com a retirada, da população estudada, dos motoristas com tempo superior a 15 anos na função na empresa. A variável DOSE foi mantida como continua, categorizando as variáveis IDADE definindo como ponto de corte o percentil 25 e a mediana da distribuição dos valores; $E_{A}$ (nivel de imissão sonora) com pontos de corte estabelecidos a partir da mediana e do percentil 75 e por fim TEPR (tempo de exposição prévia ao ruido) e TEPV(tempo de exposição prévia à vibração), ambos a partir da mediana.

Inicialmente serão apresentadas as tabelas de contingência correspondentes: 
Tabela 4.17: Tabelas de contingência para as variáveis estudadas de acordo com a ocorrência de PAIR e respectivas taxas de prevalència para o terceiro modelo.

\begin{tabular}{|c|c|c|c|}
\hline \multirow{2}{*}{ Variável explanatória } & \multicolumn{2}{|c|}{ PAIR } & \multirow[b]{2}{*}{ Prevalência (\%) } \\
\hline & SIM & NẢO & \\
\hline \multicolumn{4}{|l|}{ Exposição (EXP) } \\
\hline - Não-exposto & 18 & 56 & 24,3 \\
\hline - Exposto & 26 & 31 & 45,6 \\
\hline \multicolumn{4}{|l|}{ Idade (anos) } \\
\hline - $<35$ & 3 & 29 & 9,4 \\
\hline - $35 /-43$ & 9 & 23 & 28,1 \\
\hline - $\geq 43$ & 32 & 35 & 47,8 \\
\hline \multicolumn{4}{|l|}{ Hipertensão arterial } \\
\hline - Sem histórico & 37 & 79 & 31,9 \\
\hline - Com histórico & 7 & 8 & 46,7 \\
\hline \multicolumn{4}{|l|}{ Diabetes (DIA) } \\
\hline - Sem histórico & 39 & 85 & 31,5 \\
\hline - Com histórico & 5 & 2 & 71,4 \\
\hline \multicolumn{4}{|c|}{ Antecedentes familiares (AF) } \\
\hline - Sem histórico & 40 & 82 & 32,8 \\
\hline - Com histórico & 4 & 5 & 44,4 \\
\hline \multicolumn{4}{|l|}{ Tabagismo (TAB) } \\
\hline - Não & 33 & 56 & 37,1 \\
\hline - $\operatorname{sim}$ & 11 & 31 & 26,2 \\
\hline \multicolumn{4}{|c|}{ Medicação ototóxica (MO) } \\
\hline - Sem histórico & 41 & 83 & 33,1 \\
\hline - Com histórico & 3 & 4 & 42,9 \\
\hline
\end{tabular}


Tabela 4.17: continuação.

\begin{tabular}{lccc}
\hline \multicolumn{3}{c}{ PAIR } & \\
\cline { 1 - 2 } Variável explanatória & SIM & NÁO & Prevalência (\%) \\
\cline { 1 - 2 } Serviço militar (SM) & 41 & 82 & 33,3 \\
- Sem histórico & 3 & 5 & 37,5 \\
- Com histórico & & & \\
Nivel de imissão sonora (EA - & & & \\
dB(A)) & 13 & 47 & 21,7 \\
- $<86,5$ & 16 & 19 & 45,7 \\
- $86,5 /$ - 90,8 & 15 & 21 & 41,7 \\
- $\geq 90,8$ & & & \\
Tempo de exposição prévia & & & \\
ao ruido (TEPR - anos) & 17 & 48 & 26,2 \\
- $<9,0$ & 27 & 39 & 40,9 \\
- $\geq 9,0$ & & & \\
Tempo de exposição prévia à & & & \\
vibração (TEPV - anos) & 19 & 46 & 29,2 \\
- $<8,5$ & 25 & 41 & 37,9 \\
- $\geq 8,5$ & & & \\
\hline
\end{tabular}

A análise univariada, a partir deste critério, produziu os seguintes valores: 
Tabela 4.18: Análise univariada apresentando as razões de chances, os intervalos de confiança (IC 95\%) e o valor de $p$ do teste da razão da máxima verossimilhança para os efeitos das variáveis explanatórias na ocorrência de PAIR para o terceiro modelo:

\begin{tabular}{lccc}
\hline Variável preditora & $\begin{array}{c}\text { Razão de } \\
\text { chances (RC) }\end{array}$ & $\begin{array}{c}\text { Intervalo de } \\
\text { confiança (95\%) }\end{array}$ & $p$ \\
\hline
\end{tabular}

\section{Exposição (EXP)}

- Não-exposto

- Exposto

Idade (anos)

- $<35$

- $35 /-43$

- $\geq 43$

Hipertensão arterial

- Sem histórico

- Com histórico

Diabetes (DIA)

- Sem histórico

- Com histórico

Antecedentes familiares (AF)

- Sem histórico

- Com histórico

Tabagismo (TAB)

- Não

- Sim

Medicação ototóxica (MO)

- Sem histórico

- Com histórico
1,0

2,61

$1,24-5,49$

0,0003

1,0

3,78

$0,92-15,6$

8,84

$2,45-31,8$

0,2645

1,0

1,87

$0,63-5,54$

0,0354

1,0

5,45

$1,01-29,3$

0,4835

1,0

1,64

$0,42-6,44$

0,2127

1,0

0,60

$0,27-1,36$

0,6001

1,0

1,52

$0,32-7,10$ 
Tabela 4.18: continuação.

\begin{tabular}{|c|c|c|c|}
\hline Variável explanatória & $\begin{array}{c}\text { Razão de } \\
\text { chances (RC) }\end{array}$ & $\begin{array}{c}\text { Intervalo de } \\
\text { confiança (95\%) }\end{array}$ & $p$ \\
\hline Serviço militar (SM) & & & 0,8105 \\
\hline - Sem histórico & 1,0 & & \\
\hline - Com histórico & 1,20 & $0,27-5,27$ & \\
\hline $\begin{array}{l}\text { Nivel de imissão sonora }\left(E_{A}-\right. \\
d B(A))\end{array}$ & & & 0,0255 \\
\hline - $<86,5$ & 1,0 & & \\
\hline - $86,5 /-90,8$ & 3,04 & $1,23-7,53$ & \\
\hline - $\quad \geq 90,8$ & 2,58 & $1,05-6,37$ & \\
\hline $\begin{array}{l}\text { Dose de vibração ( DOSE - } \\
\mathrm{m}^{2} / \mathrm{s}^{4} \text {. anos) }\end{array}$ & 1,29 & $1,11-1,49$ & 0,0006 \\
\hline $\begin{array}{l}\text { Tempo de exposição prévia } \\
\text { ao ruído (TEPR - anos) }\end{array}$ & & & 0,0728 \\
\hline - $<9,0$ & 1,0 & & \\
\hline - $\quad \geq 9,0$ & $1, .96$ & $0,93-4,93$ & \\
\hline $\begin{array}{l}\text { Tempo de exposição prévia à } \\
\text { vibração (TEPV - anos) }\end{array}$ & & & 0,2941 \\
\hline - $<8,5$ & 1,0 & & \\
\hline - $\quad \geq 8,5$ & 1,48 & $0,71-3,06$ & \\
\hline
\end{tabular}


Adotando critério similar descrito anteriormente para a construção do modelo, o seguinte resultado é obtido:

Tabela 4.19: Análise multivariada apresentando as razōes de chances, os intervalos de confiança (IC 95\%) e o valor de $p$ do teste da razão da máxima verossimilhança para os efeitos das variáveis explanatórias e significantes na ocorrência de PAIR para o terceiro modelo.

\begin{tabular}{|c|c|c|c|}
\hline Variável explanatória & $\begin{array}{c}\text { Razão de } \\
\text { chances (RC) }\end{array}$ & $\begin{array}{c}\text { Intervalo de } \\
\text { confiança }(95 \%)\end{array}$ & $p$ \\
\hline Idade (anos) & & & 0,0389 \\
\hline - $<35$ & 1,0 & - & \\
\hline - $35 /-43$ & 2,97 & $0,68-13,0$ & \\
\hline - $\quad \geq 43$ & 5,16 & $1,28-20,7$ & \\
\hline Diabetes (DIA) & & & 0,1342 \\
\hline - Sem histórico & 1,0 & & \\
\hline - Com histórico & 3,55 & $0,62-20,2$ & \\
\hline Nivel de imissão sonora $\left(E_{\bar{A}}\right.$ & & & 0,0270 \\
\hline$-d B(A))$ & & & \\
\hline - $<86,6$ & 1,0 & & \\
\hline - $86,6 i-90,8$ & 2,55 & $0,93-6,96$ & \\
\hline - $\geq 90,8$ & 0,44 & $0.09-2.06$ & \\
\hline $\begin{array}{l}\text { Dose de vibração (DOSE - } \\
\mathrm{m}^{2} / \mathrm{s}^{4} \text {. anos) }\end{array}$ & 1,37 & $1,05-1,79$ & 0,0185 \\
\hline
\end{tabular}

Portanto, a aplicação deste modelo gera a seguinte equação:

$$
\operatorname{Prob}(Y=1)=\frac{1}{1+e^{g(x)}}
$$

onde $g(x)$ é igual a 
$g_{(x)}=-3,0597+1,0898 I_{2}+1,6404 I_{3}+0,3150 D+0,9354 E a_{2}-0,8207 E a_{3}+1,2659 D I A$

As notações da equação acima apresentam correspondem a:

12: estrato da variável IDADE, 35 a 43 anos exclusive;

13: estrato da variável IDADE, maior ou igual a 43 anos;

D: variável DOSE;

$E_{A}$ 2: estrato da variável $E_{A}$ (nível de exposição ao ruído), 86,6 a 90,8 dB(A) exclusive;

$E_{A} 3$ : estrato da variável $E_{A}$ (nivel de exposição ao ruido) maior ou igual a $90,8 \mathrm{~dB}(\mathrm{~A})$;

DIA: correspondente ao histórico de diabetes.

Observa-se que o coeficiente do terceiro estrato $\left(E_{A} \geq 90,8 d B(A)\right)$ da variável nivel de exposição ao ruido é negativo, gerando uma Razão de Chances de 0,44 , ou seja, apresentando um efeito de proteção. Trata-se naturalmente de incongruência expressiva, provocada possivelmente por um viés de seleção, denominado "viés do sobrevivente" (BERNARD e FINE, 1997). No tópico destinado à discussão estes aspectos serão abordados com mais propriedade.

Por sua vez, foi registrada uma RC ajustada referente ao segundo estrato da variável nivel de imissão de ruído de 2,55 (IC. 95\% 0,93-6,96). Para a variável histórico de diabetes, o valor da RC ajustada, conforme este modelo, foi de 3,55 (IC 95\% 0,62-20,2).

Valores da RC ajustada de 2,97 (IC $95 \% 0,68-13,0$ ) e de 5,16 (IC $95 \% 1,28-20,7)$ foram observados para os dois estratos da variável idade, o correspondente à faixa de 35 a abaixo de 43 anos e o superior ou igual a 43 anos, respectivamente.

Assim, novamente é possivel calcular a probabilidade de PAIR, ou de traçado sugestivo desta, para determinadas circunstâncias de exposição independentes da influência da variável dose de vibração. 
Tabela 4.20: Estimativas de probabilidade de ocorrência de PAIR segundo algumas características de exposição e baseando-se na equação do terceiro modelo.

Característica de exposição

Probabilidade

(\%)

Nivel de exposição ao ruido inferior a 86,6 dB(A), idade abaixo de 4,0

35 anos e sem histórico de diabetes.

Nivel de exposição ao ruido superior ou igual a $86,6 \mathrm{~dB}(\mathrm{~A})$ e 11,0 inferior a 90,8 dB(A); idade abaixo de 35 anos e sem histórico de diabetes.

Nivel de exposição ao ruido inferior a $86,6 \mathrm{~dB}(\mathrm{~A})$, idade entre 35 12,0 e 43 anos exclusive e sem histórico de diabetes.

Nivel de exposição ao ruido inferior a $86,6 \mathrm{~dB}(\mathrm{~A})$, idade abaixo de 14,0 35 anos e com histórico de diabetes.

Idade maior ou igual a 43 anos; nivel de exposição ao ruido 19,0 inferior a 86,6 dB(A) e sem histórico de diabetes.

Idade entre 35 e 43 anos exclusive e com nivel de exposição ao 26,0 ruido superior ou igual a $86,6 \mathrm{~dB}(\mathrm{~A})$, inferior a $90,8 \mathrm{~dB}(\mathrm{~A})$ e sem histórico de diabetes.

Idade abaixo de 35 anos, nivel de exposição ao ruido superior ou 30,0 igual a $86,6 \mathrm{~dB}(\mathrm{~A})$ e inferior a $90,8 \mathrm{~dB}(\mathrm{~A})$ e com histórico de diabetes.

Idade entre 35 e 43 anos exclusive; nivel de exposição ao ruído 33,0 inferior a 86,6 dB(A) e com histórico de diabetes.

Idade maior ou igual a 43 anos; nivel de exposição ao ruido 38,0 superior ou igual a $86,6 \mathrm{~dB}(\mathrm{~A})$ e inferior a $90,8 \mathrm{~dB}(\mathrm{~A})$ e sem histórico de diabetes.

Idade maior ou igual a 43 anos; nivel de exposição ao ruido 46,0 inferior a $86,6 \mathrm{~dB}(\mathrm{~A})$ e com histórico de diabetes. 
Tabela 4.20: continuação.

Característica de exposição

Probabilidade

(\%)

Idade entre 35 e 43 anos exclusive e com nível de exposição ao 56,0 ruido superior ou igual a $86,6 \mathrm{~dB}(\mathrm{~A})$ e inferior a $90,8 \mathrm{~dB}(\mathrm{~A})$. e com histórico de diabetes.

Idade maior ou igual a 43 anos; nivel de exposição ao ruido 69,0 superior ou igual a $86,6 \mathrm{~dB}(\mathrm{~A})$ e inferior a $90,8 \mathrm{~dB}(\mathrm{~A})$ e com histórico de diabetes.

Outras características de exposição, envolvendo a variável correspondente à dose de vibração, estão representadas no gráfico 4.6. Deliberadamente, as situações que envolvem o terceiro estrato do nivel de exposição ao ruido não foram inseridas no gráfico, em virtude da incongruência registrada, provocada por um viés de seleção. As notações aplicadas são as mesmas utilizadas na expressão acima. 


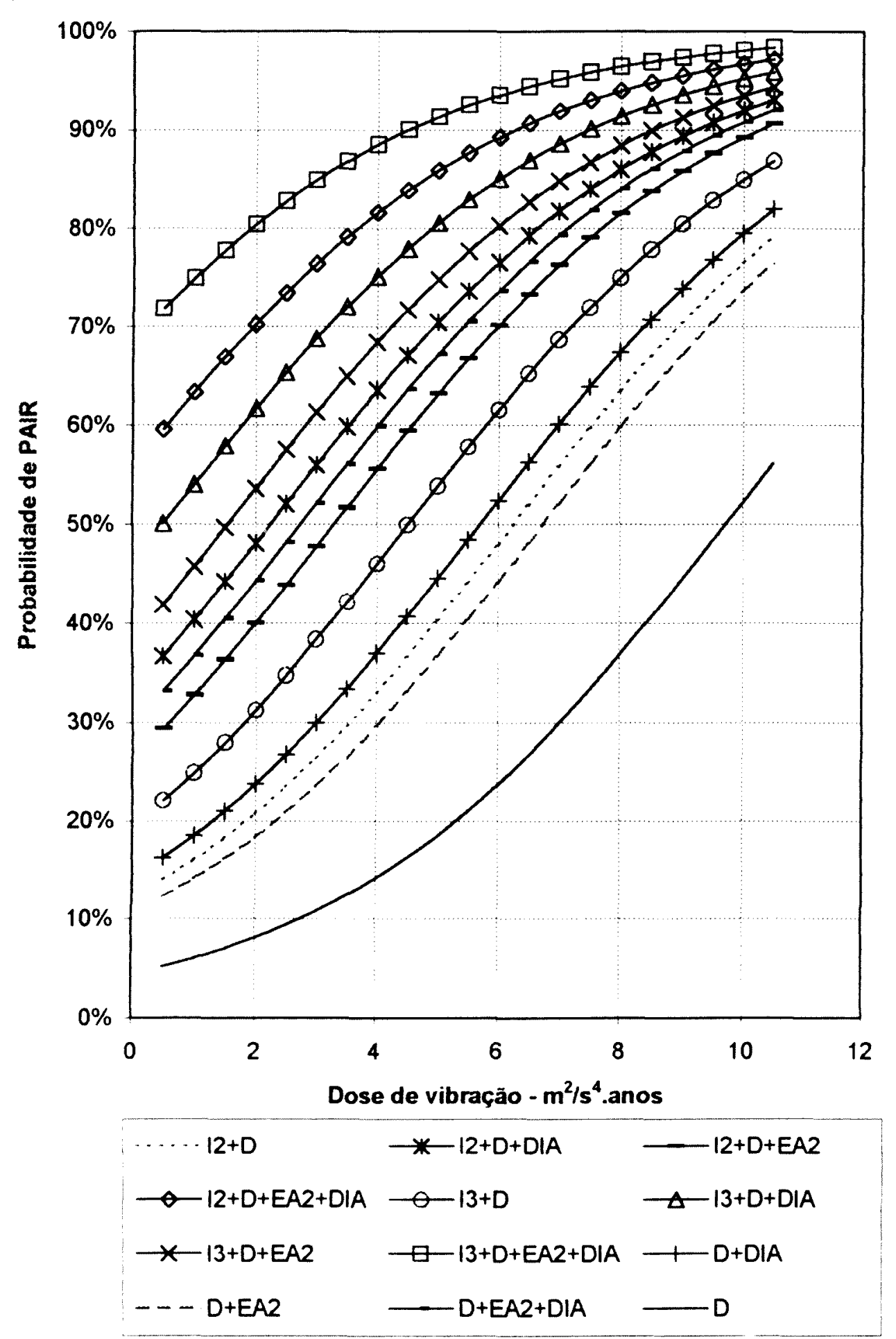

Gráfico 4.6: Estimativa de probabilidade de PAIR para as situações de exposição na legenda, segundo a evolução da dose de vibração e com base no terceiro modelo 
O coeficiente referente à variável dose de vibração baseado na terceira modelagem é superior ao obtido no segundo modelo, gerando assim uma Razão de Chances mais importante para a ocorrência de PAIR. No caso em questão, este valor foi de 1,37 (IC 95\% 1,05 - 1,79)

No gráico anterior pode-se observar o comportamento da probabilidade de ocorrencia de PAIR segundo o incremento da dose de vibração. A primeira curva representada no gráfico 4.6, por exemplo, corresponde a uma característica de exposição à $\mathrm{VCl}$, a um nível de imissão de ruido inferior a $86,6 \mathrm{~dB}(\mathrm{~A})$, sem histórico de diabetes e idade abaixo de 35 anos. Nesta situação, de modo ilustrativo, com a dose de vibração de $10 \mathrm{~m}^{2} / \mathrm{s}^{4}$.anos, ou 13,84 anos de exposição aos veículos considerados no estudo, a estimativa de probabilidade de PAIR seria de $52 \%$.

A curva logo acima da última descrita reporta-se à exposição à $\mathrm{VCl}$, a um nivel de imissão de ruído entre $86,6 \mathrm{~dB}(\mathrm{~A})$ e $90,8 \mathrm{~dB}(\mathrm{~A})$ exclusive, sem histórico de diabetes e com idade inferior a 35 anos. Empregando o mesmo ponto de dose de vibração como exemplo, ou $10 \mathrm{~m}^{2} / \mathrm{s}^{4}$.anos, observa-se que a estimativa de probabilidade de ocorrência de PAIR é de $74 \%$. 


\section{DISCUSSÃo}

\subsection{Aspectos sobre a exposição ao ruído:}

Além das fontes predominantes de ruído presentes em um veiculo a diesel, apresentadas na introdução, é possivel acrescentar outras em nosso caso de estudo, como a liberação indevida de ar comprimido durante o procedimento de abertura e fechamento das portas em alguns veículos, a conversação entre passageiros e o ruido externo gerado pelo tráfego da rua. Nas condiçōes observadas de tráfego, não há a possibilidade de a interação entre o pneu e o pavimento constituir-se como fonte dominante, uma vez que a velocidade média dos veículos é de aproximadamente $20 \mathrm{~km} / \mathrm{h}$.

Importante observar que os modelos de ônibus com motor localizado em sua parte dianteira apresentam, naturalmente, um maior nivel de imissão de ruido, que também está associada à caracteristica de encarroçamento. Pôde ser verificado que o mesmo modelo de ônibus 1620 da Mercedes-Benz apresenta diferenças relevantes de emissão de ruido, em virtude do tipo de carroçaria utilizada e particularmente a configuração do capô que enclausura o motor. Foi verificado, na linha 8, por exemplo, que os veículos utilizados correspondem ao modelo Mercedes-Benz 1620, fabricado em 1995, com a mesma estrutura da carroçaria empregada nos modelos Mercedes-Benz 1318, que os torna tão ruidosos como o último, que é mais antigo. Portanto, observa-se que a estrutura da carroçaria, particularmente 0 enclausuramento, ou o capô, sobre o motor, desempenha influência importante sobre o nivel sonoro recebido pelo motorista.

Constatou-se que os valores dos niveis equivalentes de ruido $\left(L_{\text {Aeq }}\right)$ emitidos pelos veículos com motor posicionado na seção dianteira são significativamente mais elevados do que os que apresentam o motor na seção traseira. É permitido afirmar também que o valor da média dos niveis 
equivalentes $\left(L_{\text {Aeq }}\right)$ dos ônibus com motor dianteiro é praticamente cinco vezes o valor da média do veículo dotado de motor na seção traseira.

Este cotejamento entre os dois grupos de modelos também é ilustrativo para argumentar que a fonte predominante de ruído no posto de trabalho do motorista é o motor, quando localizado na seção dianteira. Tendo como referência $O$ valor do $L_{\text {Aeq }}$ obtido para o ônibus com motor traseiro, assinala-se que 0 valor do $L_{\text {Aeq }}$ registrado corresponde a um conjunto de fontes compreendendo o ruido externo, conversação dos passageiros em menor grau, o motor e outras. Estima-se que $O L_{\text {Aeq }}$ médio somente do motor, efetuando a diferença entre as duas médias encontradas, seja da ordem de $82,1 \mathrm{~dB}(\mathrm{~A})$. Cabe também destacar que as linhas da empresa que possuem veículos dotados de motor na seção traseira trafegam por regiōes centrais da cidade de São Paulo, cujo ruído ambiental é mais importante, sobretudo pelo maior volume de tráfego. MOURA e CARDOSO (2001), por exemplo, constataram que as médias observadas dos niveis equivalentes ponderados na escala " $A$ " ( $L_{\text {Aeq }}$ ) para regiōes da cidade de São Paulo com trânsito denso e local apresentam uma diferença estatisticamente significante. Para a primeira situação, o valor registrado foi de $75,9 \mathrm{~dB}(\mathrm{~A})$, enquanto que para o segundo, $61,1 \mathrm{~dB}(\mathrm{~A})$.

A necessidade de implantação de um Programa de Conservação Auditiva emerge diante dos resultados aqui observados, sobretudo em relação à operação dos ônibus com motor na dianteira. A adoção deste procedimento de prevenção da PAIR é corroborada também por MARQUES (1998), que também abordou a exposição de motoristas de ônibus urbanos ao ruido.

Esta questão relacionada à exposição ao ruído e o risco de PAIR em motoristas de ônibus é abordada em poucos estudos, conforme pôde ser observado na introdução deste trabalho. PATWARDHAN e col. (1991) documentaram, em estudo de prevalência empreendido, uma faixa de ríveis 
de ruido muito ampla, 89 a $106 \mathrm{~dB}(\mathrm{~A})$, que não possibilitam uma estimativa consolidada da exposição do motorista.

Em condições basicamente similares de exposição, para motoristas de ônibus com motor dianteiro, motoristas de caminhão foram a população de estudo de VAN den HEEVER e ROETS (1996), os quais obtiveram resultados que apontam risco para esta atividade, uma vez que os valores encontravam-se acima do limite estabelecido ( $85 \mathrm{~dB}(\mathrm{~A})$ para uma jornada de $8 \mathrm{~h}$ e fator de troca igual a 3). CAMPANA (1973) também já encontrara resultados semelhantes, comparando os resultados da avaliação com os limites definidos pela norma brasileira $(85 \mathrm{~dB}(\mathrm{~A})$ para uma jornada de $8 \mathrm{~h}$ e fator de troca igual a 5).

A associação entre a posição do motor e o valor da dose de ruído obtida foi demonstrada por FONSECA e col. (1993), os quais reportaram que a dose de ruído excedia a unidade nos veículos onde o motor situava-se na seção dianteira.

Depreende-se, portanto, a partir da leitura dos resultados obtidos por este trabalho, bem como por outros que se detiveram sobre a questão da exposição ao ruido, que a atividade de condução de ônibus com motor dianteiro constitui-se como uma caracteristica de exposição que representa risco de PAIR.

A média do nivel de exposição semanal encontrada para os motoristas condutores de ônibus com motor na dianteira pode não ser considerada elevada de fato, considerando o critério de referência de 85 $\mathrm{dB}(\mathrm{A})$ para 8 horas. No entanto, verificou-se que existe a probabilidade de superação dos niveis de exposição limite de $85,0 \mathrm{~dB}(\mathrm{~A})$ e de ação de 82,0 $\mathrm{dB}(\mathrm{A})$. Em referência à exposição dos motoristas que conduzem ônibus com motor na seção traseira, não há possibilidade de superação de nenhum dos dois limites considerados 
Diante destas ponderaçōes no tocante à exposição ao ruido, constata-se a viabilidade do uso de ónibus com motor localizado na seçăo traseira, por se tratar de um desenho racional, que contribui para a prevenção de agravos à saúde, particularmente a PAIR.

Oportuno ressaltar as longas jornadas praticadas pelos motoristas as quais representam uma variável relevante para 0 incremento do nivel de exposição ao ruído. A jornada semanal média encontrada para a população amostrada no procedimento de avaliaçăo ambiental foi de 46,2 $\pm 10,5 \mathrm{~h}$. $O$ contrato de trabalho dos motoristas estipula uma jornada semanal de $43 \mathrm{~h}$. Convém ressaltar de que a Convenção 153-1979 da OIT (Organização Internacional do Trabalho) especifica para trabalhadores em transporte, da qual o governo brasileiro não é signatário ainda, estabelece, entre outras medidas, uma jornada semanal máxima de $40 \mathrm{~h}$, com direito a folga semanal composta por dois dias (INTERNATIONAL LABOUR ORGANIZATION 1979). Os motoristas de ônibus, população deste estudo, desfrutam de apenas uma folga semanal.

Reportando-se especialmente ao primeiro modelo final da regressão logística, classificado como o mais ajustado, cujo estrato da variável imissão de ruído $\left(E_{A}\right)$ maior ou igual a $86,8 \mathrm{~dB}(\mathrm{~A})$ corresponde a uma Razão de Chances de 2,76 (IC 95\% 1,24 - 6,15), é possivel determinar o tempo necessário, em anos, para atingir este valor, de acordo com o nivel de exposição calculado para cada grupo de modelo de ônibus. Para os motoristas que conduzem ônibus com motor dianteiro, associados a uma estimativa de nivel médio de exposição de $83,6 \mathrm{~dB}(\mathrm{~A})$, este tempo seria de apenas 2,1 anos, enquanto para o outro grupo, conduzindo motor traseiro, com nivel médio de exposição de $77,0 \mathrm{~dB}(\mathrm{~A}), 9,5$ anos. 


\subsection{Aspectos sobre a exposição à vibração:}

Os valores da aceleração de vibração obtidos através da avaliação podem ser considerados elevados, quando comparados com outros estudos abarcando análises em ônibus e mesmo outros veiculos importantes.

Na pesquisa desenvolvida por BOVENZI e ZADINI (1992) envolvendo motoristas de ônibus da cidade de Turim, Itália, a média do valor da aceleração no eixo $Z$ de seis ônibus avaliados foi de $0,39 \mathrm{~m} / \mathrm{s}^{2}$, enquanto que neste estudo a magnitude encontrada para o mesmo eixo foi de 0,85 $\mathrm{m} / \mathrm{s}^{2}, 2,2$ vezes o primeiro valor.

Seguindo a metodologia expressa pela ISO-2631-1 (1985), LEWIS e GRIFFIN (1998) obtiveram o valor da aceleração de $0,58 \mathrm{~m} / \mathrm{s}^{2}$, para ônibus trafegando em pista regular, referente ao pior eixo. Este resultado foi atingido em pesquisa, cujo propósito foi o de comparar os procedimentos de avaliação de exposição à vibração de corpo inteiro presentes nas normas atuais.

A representatividade da magnitude destes valores da aceleração encontrados também pode ser cotejada com alguns exemplos extraídos da literatura técnica. A organização sueca denominada Instituto Nacional de Vida no Trabalho (NATIONAL INSTITUTE OF WORKING LIFE 2000) mantém um banco de dados na rede mundial de computadores, no qual há diversos exemplos de resultados de avaliação de vibração de corpo inteiro. Como exemplo, valores da somatória da aceleração da vibração dos três eixos ortogonais para uma escavadeira, uma pá carregadeira e um trator escavadeira foram de $0,70 \mathrm{~m} / \mathrm{s}^{2}, 0,66 \mathrm{~m} / \mathrm{s}^{2}$ e $0,83 \mathrm{~m} / \mathrm{s}^{2}$ respectivamente. Constata-se que as somatórias das acelerações de cinco dos seis modelos de ônibus avaliados nesta pesquisa superaram estas cifras. A somatória da aceleração da vibração no modelo 1318 , de $0,74 \mathrm{~m} / \mathrm{s}^{2}$, está acima dos dois valores iniciais. 
A despeito de ter sido empregada a norma britânica para avaliação, que gera resultados diferentes, sobretudo em razão da ponderação em freqüência, é interessante citar o trabalho desenvolvido por PALMER e col. (2000a), os quais produziram um levantamento de valores representativos das magnitudes de vibração no eixo $z$ de veículos considerados relevantes para a exposição. No caso de ônibus, o valor médio encontrado foi de 0,6 $\mathrm{m} / \mathrm{s}^{2}$ (awz.).

No trabalho desenvolvido por FUTATSUKA e col. (1998), a média dos valores do vetor somatória da vibração foi de $0,77 \mathrm{~m} / \mathrm{s}^{2}$, abaixo do encontrado em nosso estudo, $0,97 \mathrm{~m} / \mathrm{s}^{2}$, considerando apenas os valores da aceleração e não o número de veículos e o tempo de utilização.

Possivelmente, a variável referente ao estado do pavimento, ou a qualidade das vias da cidade de São Paulo, contribuiu de modo significativo para a geração dos valores observados. Com efeito, a qualidade do pavimento exerce influência relevante no valor da aceleraçăo da vibração, de acordo com BOULANGER e col. (1992). Estes pesquisadores avaliaram o ambiente vibratório em caminhões e constataram que, em trechos em mau estado de conservação, houve uma elevação nos valores de aceleração equivalente, da ordem de 1,0 a $1,5 \mathrm{~m} / \mathrm{s}^{2}$.

A influência da característica do pavimento sobre os niveis da aceleração da vibração também é exposta em estudo conduzido por GRIFFIN (1978), pelo qual o autor analisou 16 veículos em 4 tipos de superficie, duas em mau estado de conservação e duas em boas condições. Como exemplo, um ônibus de pequeno porte apresentou niveis de aceleração no assento do motorista, na direção vertical (eixo - z), em torno de $0,90 \mathrm{~m} / \mathrm{s}^{2}$, enquanto que em pistas em bom estado, estes valores estiveram abaixo de $0,50 \mathrm{~m} / \mathrm{s}^{2}$. 
Ademais, interessante destacar, que os procedimentos de manutenção dos pavimentos das vias públicas adotados no pais são considerados obsoletos por BODI e BALBO (1998), os quais apontam a necessidade de implantação de um sistema de gerenciamento de pavimentos.

Naturalmente os fatores associados à suspensão do ônibus e do assento desempenharam também papéis importantes. $O$ assento pode estar se comportando como um amplificador da vibração. Seria, portanto, necessário, uma avaliação de vibração complementar no piso do ỏnibus com o fim de determinar a transmisibilidade do assento.

Uma incoerència que emerge dos dados obtidos do procedimento de avaliaçăo é ter encontrado o menor valor da aceleração de vibração no modelo de ônibus considerado como o mais antigo e o dotado do tipo impróprio de suspensão, que é o caso da suspensão semi-eliptica ou por feixe de molas (DONATI e col. 1993). Contraditoriamente, os modelos com suspensão pneumática apresentaram valores da somatória do vetor aceleração da vibração mais elevados. Cabe destacar que os trajetos realizados pelos modelos foram similares àqueles percorridos durante 0 cotidiano de trabalho. Possivelmente, deve haver uma manutenção imprópria deste tipo de suspensão, que geraria estes valores superiores aos encontrados no modelo com suspensão mais rigida.

A opção pela utilização de suspensões pneumáticas como meio de redução da transmissão de vibrações em lugar dos tipos fundamentados sobre molas, como a semi-elipticas, é ratificada por OZKAYA e col. (1997). Esta conclusão foi elaborada a partir de estudo comparativo entre estas categorias de suspensão empregadas em trens do metrô, encontrando valores de redução de até $31 \%$ nos veículos dotados de suspensão pneumática. 


\subsection{Meios de prevenção}

Os principios fundamentais de prevenção de agravos à saúde decorrentes da exposição à vibração de corpo inteiro nortearam-se pelo trabalho desenvolvido por DONATI e col. (1993) e por publicação de instituto governamental britânico na área de saúde e segurança (HSE 1996).

Inicialmente, da mesma forma como são confeccionadas as diretrizes essenciais para a redução de ruído, deve se ter a fonte como objetivo para intervir, com o propósito de reduzir os niveis de exposição. Desta forma, é conveniente a seleção do veículo em função do piso ou da tarefa que será executada, de aplicar manutenção e informar os operadores a respeito dos métodos de trabalho mais indicados. É importante a redução das irregularidades do pavimento sobre as quais se deslocam os veículos. Interessante salientar que esta medida envolve outros sujeitos na realidade de exposição à vibração de corpo inteiro do motorista, que é o poder público municipal responsável pela manutenção das vias públicas.

O assento deverá ser montado firmemente sobre uma superficie rigida. Deverá ser igualmente assegurado que o assento não apresente jogo excessivo.

Em um veiculo, a transmissão das vibrações ao condutor pode ser reduzida por meio de elementos isolantes instalados em pontos distintos. A função dos pneus é a de filtrar as pequenas rugosidades do solo. Caso este processo năo se realize, eles podem induzir movimentos de baixa freqüência. Portanto, é interessante verificar se os pneus são os indicados para o tipo de veículo e se estão devidamente calibrados para a situação em que serão empregados. 
Como descrito anteriormente, as suspensões do chassi semielipticas, consideradas obsoletas pela literatura consultada, estão sendo progressivamente substituídas pelas parabólicas ou pneumáticas, que oferecem uma redução mais eficiente da vibração.

Outro meio disponivel para isolar e controlar as vibrações é a cabina suspensa. Somente as cabinas suspensas, denominadas de baixa freqüência, são eficazes para reduzir as vibraçōes transmitidas ao condutor, devido ao rolamento.

O assento comporta-se como a última fase de suspensão que antecede 0 posto de trabalho do motorista. A maioria dos assentos suspensos é concebida de modo a assegurar um isolamento unicamente segundo o eixo vertical ( $z$ ). Como visto na introdução deste trabalho, na prática, as medidas realizadas nos assentos de um grande número de veículos têm mostrado que, muito freqüentemente, eles amplificam as vibrações ao invés de reduzi-las. $O$ assento deve se submeter a uma manutenção eficiente, sobretudo nos componentes de sua suspensão. A compatibilidade entre a suspensão e o peso do trabalhador deve ser valorizada, lembrando que há a disponibilidade de alguns assentos dotados de ajuste automático, em conformidade com o peso do motorista.

O estabelecimento de uma politica de prevenção de agravos à saúde devido à exposição à $\mathrm{VCl}$ envolve os seguintes aspectos fundamentais, além dos princípios elencados anteriormente:

- Aquisição de veiculos e máquinas que exponham os trabalhadores a niveis mais baixos de exposição, em consonância com os ditames da Diretiva Européia sobre máquinas (EUROPEAN AGENCY FOR SAFETY AND HEALTH AT WORK, 1998);

- Indagar ao fabricante e ao fornecedor se os veículos foram testados em condições similares a do cotidiano dos trabalhadores; 
- Buscar informaçōes junto ao fabricante e ao fornecedor, os meios apropriados de manutenção para minimizar a exposição dos trabalhadores.

O método de aplicação desta política pode se inspirar nos conceitos do programa relatado por YAMADA e SAKAKIBARA (1998), que contempla os seguintes componentes essenciais: melhorias nos veiculos; normalização, em particular sobre o tempo de operação; programa médico, envolvendo exame e terapia precoces e formação e educação de trabalhadores.

\subsubsection{Contribuição da normalização:}

A última versão da norma ISO-2631-1 (1997) contém diversos e complexos métodos para avaliação da vibração, de acordo com GRIFFIN (1998), que afirma também que é um documento difícil de ser resumido. A norma não faz mais referência ao limite de exposição, alegando que "não existem dados suficientes para a definição de uma relação quantitativa entre exposição à vibração e risco à saúde. Portanto não é possível avaliar a vibração transmitida ao corpo em termos de probabilidade de risco para exposiçסes de diversas magnitudes e durações".

GRIFFIN (1998) ainda acrescenta que o conteúdo da norma ISO2631-1 (1997), que encerra procedimentos alternativos e complexos de avaliação, é incompativel ao atual estado de conhecimento sobre o tema. Esta possibilidade de aplicação dos procedimentos propostos pode gerar valores amplamente distintos de uma mesma realidade de trabalho. Além disso, o emprego de métodos de diagnóstico diferentes pode gerar desacordo se a exposição à vibração é aceitável ou não.

De modo bastante sucinto, a norma ISO-2631-1 (1997) define e fornece filtros de freqüencia para 4 principais efeitos da vibração: 
degradação da saúde; prejuizo de atividades, como controle das mãos e visão; prejuizo no conforto e "mal do transporte" (cinetose).

Em referência aos eixos de vibração, a norma estabelece que os três eixos do sistema ortogonal de coordenadas devem ser avaliados, considerando três posições: sentada, em pé e deitada. No entanto, em seu conteúdo especifico, como nas ponderaçōes em freqüência para os possiveis efeitos sobre a saúde, a abordagem restringe-se à posição sentada. A norma estimula que a vibração seja feita no eixo longitudinal (costas - peito) no espaldar, porém nāo considera posteriormente para a estimativa da gravidade da vibração.

Os fatores de 1,4 para os eixos $x$ e y, na posição sentada, ainda permanecem, como na versão anterior. Para se estimar os efeitos à saúde, somente o valor de maior magnitude é considerado para ser confrontado com os valores de orientação contidos no anexo. A somatória vetorial é indicada na avaliação de conforto. Entretanto, uma nota na norma declara que se dois ou mais eixos apresentam magnitudes similares, pode-se utilizar a somatória vetorial, ou seja, considerando os três eixos.

A Norma Britânica (BS - 6841 1987), em vigor no Reino Unido, para GRIFFIN (1990a) é filosoficamente diferente, pois fornece uma metodologia completa e definida para medir e avaliar a vibração, levando em conta a resposta humana, diferentemente da linha seguida pela norma da ISO, a qual somente fornece limites para a vibração.

Resumidamente, as principais caracteristicas da norma são as seguintes: è aplicável à vibração aleatória, estacionária e com choques repetidos, cobrindo a freqüência de 0,5 a $80 \mathrm{~Hz}$; define vias de quantificar a gravidade da exposição na faixa de freqüências de $0,1-0,5 \mathrm{~Hz}$, tendo como referência o "mal do transporte"; a dependência no tempo aplicada para se estimar os efeitos sobre a saúde utiliza o conceito de VDV [Vibration rose 
value], que, segundo GRIFFIN (1990a), define uma dependência temporal simples para todas as durações até as 24 horas.

Na Diretiva da União Européia sobre Agentes Fisicos (COUNCIL OF EUROPEAN UNION 1994), a grandeza utilizada é a aceleração equivalente ponderada correspondente para 8 horas, ou $A(8)$, a qual é calculada segundo a soma vetorial (raiz quadrada da soma dos quadrados) dos valores $1,4 a^{2} w x, 1,4 a^{2} w y, a^{2} w z$, que são as aceleraçōes quadráticas médias ponderadas em freqüência registradas ao longo dos eixos ortogonais $x, y e$ $z$, como indicado pela norma ISO-2631-1 (1985). A diretiva permite que sejam desprezados componentes axiais inferiores a $60 \%$ da componente axial dominante.

A proposta de diretiva prescreve os seguintes valores:

> Nivel de limiar - $\mathbf{A}(8)=0,25 \mathrm{~m} / \mathrm{s}^{2}$, para o qual deve tender a atuação da diretiva;

> Nivel de ação - $A(8)=0,5 \mathrm{~m} / \mathrm{s}^{2}$, a partir do qual devem ser tomadas ações de redução de risco;

> Nivel limite $-\mathbf{A}(8)=0,7 \mathrm{~m} / \mathrm{s}^{2}$, cuja superação é vedada e deve ser prevenida;

Disco Relevante $-\mathrm{A}(8)=1,25 \mathrm{~m} / \mathrm{s}^{2}$, classificada como fonte de risco grave e sua notificação é compulsória à autoridade.

A superação do limite de ação prevê a determinação das seguintes medidas de tutela: informação dos trabalhadores que poderiam ser expostos a tal nivel; formação para a aplicação de medidas de tutela em conformidade com a diretiva; dados sobre vibração produzida pelo equipamento de trabalho que poderia provocar uma exposição durante o período de referência de $8 \mathrm{~h}$; programa de organização técnica e/ou de trabalho com as medidas destinadas a reduzir a exposição e vigilância com exames de rotina. 
Na Diretiva européia sobre máquinas (EUROPEAN AGENCY FOR SAFETY AND HEALTH AT WORK 1998) há uma referência genérica, mas importante, sobre a exposição à vibração, que abrange tanto a do tipo localizada como a de corpo inteiro. Em seu parágrafo 1.5 .9 há a seguinte declaração: "A máquina deve ser projetada e construída de tal modo que os riscos resultantes das vibrações por ela produzidas sejam reduzidos ao nivel mais baixo, levando em conta o progresso técnico e a disponibilidade de meios para reduzi-lo, em particular na fonte." 


\subsection{Aspectos sobre a avaliação audiológica:}

Na população de motoristas analisada neste estudo transversal foi registrada uma taxa de prevalência de PAIR de $35 \%$, sendo que no grupo classificado como exposto, a taxa de prevalência encontrada foi de $46 \%$, enquanto que no de referência de $24 \%$. É justo salientar que a maior parte dos casos de PAIR ou de traçado sugestivo de, se inseriu na classificação de grau um, considerada perda leve.

A comparação com outros estudos que abordaram as repercussões do ruído à audição de motoristas torna-se difícil, sobretudo tratando-se de pesquisas internacionais, uma vez que há uma diversidade de classificações de perda auditiva induzida por ruído em uso.

No levantamento bibliográfico deste trabalho foram encontradas informações bastante divergentes.

Uma prevalência considerada excessivamente elevada de $89 \%$ foi documentada em pesquisa conduzida por PATWARDHAN e col. (1991), os quais não empregaram o mesmo critério de classificação adotado neste trabalho

Por sua vez AHUMADA e col. (1991), investigando as condições de trabalho de motoristas da Cidade do México, registraram uma taxa de prevalência de PAIR de $17 \%$.

Com a pesquisa empreendida por CORDEIRO e col. (1994), há a possibilidade de se fazer uma comparação ilustrativa, uma vez que foi empregado o mesmo critério de classificação de perda auditiva. Deve ser somente ressaltado que a população do estudo também compreendia além dos motoristas, os cobradores do ônibus. A taxa de prevalência de PAIR encontrada foi de $45,2 \%$. 
Do mesmo modo há a possibilidade de cotejar os resultados encontrados nesta pesquisa com o trabalho conduzido por MARQUES (1998), que adotando igual critério de classificação, o de MERLUZZI e col. (1979), encontrou uma taxa de prevalência de curvas audiométricas sugestivas de PAIR de $55,4 \%$.

A despeito da facilidade de aplicação deste critério proposto por MERLUZZI e col. (1979), classificado como de análise visual, LÓBO e COSTA (1997) tecem criticas bastante pertinentes sobre os seus limites. Conforme os autores, os critérios fundamentados sobre classificações visuais podem superestimar alteraçōes de limiar pouco expressivas quando há uma modificação de grau ou ainda, há a possibilidade de subestimar alterações verdadeiramente importantes, contudo permanecendo no mesmo grau.

De todo modo, analisando o critério construído por MERLUZZI e col. (1979) através de parecer definido pelo NIOSH (1998), ele pode ser classificado como aceitável, pois é capaz de identificar prontamente um trabalhador com alteração de limiar na maioria das freqüências mais importantes, bem como de identificar um número relativamente alto de casos de PAIR. 


\subsection{Discussões finais:}

A rigor, este trabalho de pesquisa observacional não demonstrou existir associaçăo entre exposição à vibraçăo de corpo inteiro e perda auditiva induzida por ruído. Também năo se constatou associação da exposiçăo combinada à vibração e ao ruído sobre a audiçăo dos motoristas.

No primeiro modelo apresentado nos resultados, estabelecido através do procedimento de regressão logística, considerado o mais ajustado, trés variáveis apresentaram uma associaçăo estatisticamente significante para PAIR: idade $(p<0,05)$, nivel de imissão de ruído $(p<0,05)$ e histórico de diabetes $(p<0,05)$.

A variável que definia os grupos de exposição, fundamentada no tempo de trabalho na empresa, perdeu sua significáncia, e em razăo do critério adotado, foi excluída do modelo multivariado. Teve o mesmo comportamento, a variável correspondente à dose de exposiçăo à vibraçăo de corpo inteiro, demonstrando năo ser significante no modelo final ajustado.

Desse modo foi encontrada associaçăo entre as très variáveis explanatórias significantes descritas acima. A presença da variável correspondente à idade não surpreende, uma vez que ela é considerada significante para o desencadeamento da PAIR. Também é julgada com naturalidade a participação da variável correspondente ao nivel de imissão de ruido $\left(E_{A}\right)$, pois é reconhecida epidemiologicamente como causa de PAIR (PHANEUF R e HÉTU R 1990; MORIOKA I e col. 1997; HUMES 1984).

A associaçăo entre histórico de diabetes e PAIR, apontada neste estudo, foi também destacada em pesquisa desenvolvida por ISHII e col. (1992), cujos resultados evidenciaram as mesmas três variáveis destacadas 
por esta pesquisa. Assim, estes achados indicam que um motorista com histórico de diabetes apresenta uma maior probabilidade de PAIR, comparando-se com aquele isento de histórico, como pôde ser observado nos resultados do primeiro modelo.

Cabe discutir a inserção dos outros dois modelos, nos quais a variáveı referente à dose de vibração está presente.

No segundo modelo, tratando a variável dose de vibração (DOSE) como contínua, verificou-se, por meio do procedimento progressivo de inclusão de variáveis, que quando inserida ela apresenta significância, uma vez que $p<0,20$. No entanto, no modelo final sua significancia se debilita, revelando que pouco contribui para o modelo final. As outras variáveis deste modelo são as mesmas incluídas no modelo anterior: idade $(p<0,05)$, nivel de imissão de ruído $(p<0,10)$ e diabetes $(p<0,10)$. As interações testadas entre idade, dose de vibração, nivel de imissão de ruído não geraram resultados de interesse.

A inclusão deste modelo se justifica pois ficou demonstrada uma sugestão de associação da variável dose de vibração com a ocorrência de PAIR.

Já no terceiro e último modelo, com a exclusão dos motoristas com tempo de empresa superior ou igual a 15 anos, resultando em uma população de 131 motoristas, foram constatados achados interessantes. As quatro variáveis, idade, nivel de imissão de ruido, dose de vibração e histórico de diabetes foram classificadas como significantes, Nas três primeiras, o valor de $p$ foi inferior a 0,05 , enquanto para diabetes, esteve abaixo de 0,10. Estes resultados atingidos com esta exclusão podem ser explicados pela ocorrência de um viés de seleção chamado de "viés do sobrevivente", que acomete estudos de prevalência. Isto significa que no estrato de motoristas com tempo de empresa superior a 15 anos seria 
composto por aqueles que resistiram às condiçōes de trabalho de condução de ônibus na cidade de São Paulo. Contudo deve ser assinalado, que ainda resta uma contradição importante nos resultados, pois no estrato do nivel de imissão de ruído superior a 90,7 dB(A), o valor da Razão de Chances, inferior à unidade, indicou proteção. Neste caso, ainda persistiria o viés do sobrevivente para este estrato.

Nos três modelos discutidos, sendo o primeiro o que apresentou uma significância estatística importante, o tempo de empresa não foi considerado na modelagem, uma vez que apresentava uma correlação bastante intensa com a variável referente à dose de vibração. Logo, não foi possivel estimar os efeitos independentes entre tempo de empresa e dose de vibração, em razão do apresentado. Com efeito, a fórmula para o cálculo da dose de vibração encerra em seu bojo, o tempo de empresa.

Diante destes últimos resultados, é bastante pertinente a apreciação de outros vieses comuns aos estudos transversais, a partir da leitura das obras de CHECKOWAY e col. (1989) e de KELSEY e col. (1986).

De acordo com a literatura consultada, as duas principais limitações para estudos seccionais referem-se à associação temporal da exposição e doença e à medição da prevalência e não incidência.

O primeiro viès, que se reporta à fragilidade de evidência para causalidade, porque não se pode assegurar que a exposição precedeu a doença, possivelmente não exerce grande influência neste estudo, na medida em que se buscou recuperar 0 histórico de exposição dos motoristas. De fato, há limitações na recuperação destes dados, já que se tratou de uma estimativa, partindo do pressuposto que os niveis de vibração e de ruido permaneceram relativamente estáveis no tempo. 
O segundo viés de mais acentuada importância, que acomete estudos transversais, associado à medição preferencial da prevalência do que a incidência, também teve a seu poder reduzido neste estudo, por ser o agravo estudado, a PAIR, persistente, ou seja, irreversivel e não é fatal.

No entanto, o viés que exerceu uma forte influência neste estudo foi o da seleção, ou do sobrevivente que atingiu os dois últimos modelos apresentados. BERNARD e FINE (2001) discutem com profundidade esta questão em uma monografia substanciosa produzida pelo NIOSH que se dedicou a analisar os estudos epidemiológicos sobre os fatores de risco responsáveis pelo desenvolvimento de distúrbios osteomusculares relacionados ao trabalho. A proeminência deste viés na pesquisa ancora-se na inclusão de somente os trabalhadores na ativa, não compreendendo motoristas aposentados, os que migraram para outros empregos e os afastados ou inativos por outras razões.

Outro tipo de viés que merece ser adicionado aos elencados acima reporta-se ao da informação, já que a estimativa da exposição ao ruido e à vibração de corpo inteiro baseou-se em informações advindas do questionário aplicados aos motoristas.

A despeito de não ter sido constatada a associação entre exposição à vibração de corpo inteiro e ao ruido no desencadeamento da PAIR, os outros modelos apresentados sugerem esta associação. Em virtude disto, julga-se procedente a condução de estudos posteriores, abordando exposições combinadas, que trabalhem sobre a hipótese de associação. Sugestōes provenientes da literatura consultada, recomendam a seleção de populações com exposições bem definidas em relação aos dois fatores, ou seja, vibração com pouco ruido, a mesma vibração com mais ruido, mas não ao nivel de risco e uma exposição mais elevada ao ruido mas sem presença da vibração (LAWTON e ROBINSON 1989). Um estudo que use como método a exploração de gradientes de niveis de exposição ao ruído e à 
vibração de corpo inteiro consiste em outro norteamento para estudos complementares (HUMES, 1984).

Futuras pesquisas sobre o tema devem tentar superar os limites expostos, provocados notadamente pelos vieses de seleção, o que desempenhou maior força, e de informação. Para contornar o primeiro viés seria conveniente que a população do estudo não fosse constituída somente por motoristas na ativa, como mencionado anteriormente. Entretanto esta alternativa, classificada como ideal, esbarra em questões práticas. CHECKOWAY e col. (1989) sugerem a opção mais viável de incluir todos os trabalhadores da empresa na ativa.

A constituição da população nesta pesquisa foi estruturada e influenciada pelos ditames das circunstâncias e das possibilidades existentes em um serviço de saúde, em determinada realidade. Oportuno frisar o argumento lúcido de ROTHMAN (1986), que na determinação do tamanho da população, há outras variáveis que não cabem em uma equação matemática.

O viés correspondente à informação poderia ser contornado por meio de obtenção de registros consistentes sobre o histórico do motorista na empresa, contendo informaçōes sobre avaliaçōes periódicas da exposição à $\mathrm{VCl}$ e ao ruído. Contudo, esta é uma situação ainda bastante distante da nossa realidade do mundo do trabalho.

A busca por um grupo de referência que esteja somente exposto a niveis de ruido similares aos dos motoristas e não à $\mathrm{VCl}$ representa ainda uma estratégia que não deve ser desprezada. 


\section{CONCLUSÃO}

Os niveis de exposição ao ruido encontrados, correspondentes a uma jornada de oito horas, não são de muito relevo, pois são inferiores ao critério definido de $85 \mathrm{~dB}(\mathrm{~A})$ para uma jornada diária de $8 \mathrm{~h}$.

No tocante ao segundo grupo de modelo de ônibus, com motor na seção traseira, estimou-se que não existe nem mesmo a possibilidade de superar o nivel de ação de $82 \mathrm{~dB}(\mathrm{~A})$. O maior risco de PAIR foi identificado para os motoristas que operam os ônibus com motor na seção dianteira.

A comparação das médias dos niveis equivalentes ponderados na escala $\left(L_{\text {Aeq }}\right)$ entre os dois grupos de veículos demonstrou que, do ponto de vista de exposição ao ruído, o uso de veículos com motor localizado na seção traseira é uma opção racional, uma vez que apresenta um valor significativamente inferior ao veículo com motor dianteiro, visando assim a valorização da prevenção da PAIR.

A taxa de prevalència de PAIR, ou de traçados audiométricos sugestivos de PAIR, na população estudada, foi de $35 \%$. Para o grupo definido como exposto, a prevalència foi de $46 \%$ e para o grupo de referência, de $24 \%$. A diferença entre as duas taxas é estatisticamente significante $(p<0,001)$

Os dados obtidos, tanto resultantes da avaliação ambiental como da audiológica, apontam para a necessidade de implantação de um programa de conservação auditiva.

No tocante à exposição à vibração de corpo inteiro, os valores das somatórias vetoriais de aceleração, para todos os modelos de ónibus utilizados pela empresa, superaram os limites de exposição para uma jornada de $8 \mathrm{~h}$ preconizados pela ISO-2631 (1985). Assinala-se ainda qL a os 
valores registrados podem ser classificados como elevados, comparando-os com outros exemplos de avaliação de outros veículos, sabidamente mais importantes do ponto de vista da vibraçăo, encontrados na literatura.

Medidas de prevenção, que objetivem a proteção dos motoristas, devem ser implantadas, como a seleção de veículos dotados de suspensão mais adequada do chassi, bem como para o assento, manutençăo sistemática e apropriada das partes dos veículos relevantes e uma reestruturaçăo da característica do pavimento das ruas, que no caso envolveria outros personagens, como o poder público municipal.

A aplicação da regressão logistica, cuja finalidade foi a de avaliar simultaneamente os fatores de risco para PAIR, identificou, por meio do modelo mais ajustado, três variáveis com associação significante, com $p<$ 0,05: idade, nível de imissăo de ruído e histórico de diabetes.

Esta pesquisa não-experimental ou observacional demonstrou que a variável correspondente à dose de vibração não apresentou significáncia. Em outras palavras, não ficou evidenciada a influência da exposição à VCl na ocorrência de PAIR, nem interação com a exposiçăo ao ruído, capaz de gerar uma mudança na magnitude do efeito analisado. A variável relacionada aos grupos de exposiçăo inicialmente construidos também apresentou significância desprezível.

Dois outros modelos foram explorados pela regressão logística, por sugerirem associaçăo significante da variável referente à exposiçăo à vibração de corpo inteiro. No segundo modelo, trabalhando a variável atinente à dose de $\mathrm{VCl}$ como contínua e mantendo categóricas as variáveis idade e nivel de imissão sonora, mas alterando os pontos de corte, constatou-se que a primeira variável contribuiu pouco para o modelo final. Já no terceiro modelo selecionado para a discussão, com a exclusão dos motoristas com tempo de empresa acumulado superior ou igual a 15 anos, a 
variável dose de vibração revelou uma associação significante, juntamente com as variáveis idade, nivel de imissão de ruido e histórico de diabetes.

Neste último modelo foi constatado um paradoxo, uma vez que o estrato da variável nivel de imissão de ruído, $E_{A}$ superior ou igual a 90,8 $\mathrm{dB}(\mathrm{A})$ aparece como proteção. Tal incoerência deve-se provavelmente a um viés de seleção, denominado viés do sobrevivente, comum em estudos de prevalência. Deve ser lembrado que somente os motoristas na ativa participaram deste estudo.

Interações foram testadas nos processos de modelagem, porém foram gerados resultados marginais.

Efeitos à saúde produzidos por exposiçōes combinadas entre vibração de corpo inteiro e ruído têm sido investigadas sobretudo em estudos experimentais, cujo efeito analisado tem sido a mudança temporária de limiar (MTL). Esta pesquisa, ao contrário, teve a peculiaridade de ser nãoexperimental ou observacional e analisar, como efeito, a mudança permanente de limiar (MPL), representada pela PAIR. A despeito de não constatar importância na associação da vibração com a ocorrência de PAIR, outros modelos apresentados encorajam o empreendimento de estudos posteriores, adotando metodologias alternativas e que permitam superar os limites aqui apresentados e discutidos.

Nesta perspectiva, é essencial persistir nesta exploração para subsidiar no deslindamento da complexidade de riscos aos quais estão expostos os motoristas de ônibus urbano de uma grande cidade, com o fim de contribuir na busca de dignidade em uma realidade de trabalho tão penosa. 


\section{REFERÊNCIAS BIBLIOGRÁFICAS}

1. Ahumada $T$, Ramirez FL. Health status of urban passenger transportation conductors in Mexico City. Bol Ofic Sanit. Panam 1991; 111(4): 324332.

2. American Conference of Governmental Industrial Hygienists Threshold limit values for chemical substances and physical agents and biological exposure indices. ACGIH. Cincinnati, OH; 1995-1996.

3. American National Standard Institute. ANSI S3.6: Specifications for Audiometers. New York; 1969.

4. Barone JA, Peters MJ, Garabrant DH, Bernstein L, Krebsbach R. Smoking as a risk factor in noise-induced hearing loss. J Occup Med 1987; 29(9):741-45.

5. Behar A, Plener R. Noise exposure - sampling strategy and risk asessment. Am Ind Hyg Assoc J 1984; 45(2): 105-109.

6. Belkic K, Savic C, Theorell T, Rakic L, Ercegovac D, Djordjevic M. Mechanisms of cardiac risk among profesional drivers. Scand J Work Environ Health 1994; 20:73-86.

7. Benedetto G, Chiatella A, Lovisolo D, Maringelli M, Merluzzi F, Spagnolo $R$ Rumore e vibrazioni in ambiente di lavoro - manuale di prevenzione. Torino: Italgrafica; 1986.

8. Bernard BP, Fine LJ Editors. Musculoskeletal disorders and workplace factors: a critical review of epidemiologic evidence for work-related musculoskeletal disorders of the neck, upper extremity, and low back. [monograph on line]. Cincinnati: National Institute for Occupational and Health; 1997. Available from <URL:http://www.cdc.gov/niosh/pdfs/97141. pdf>. [2001 Jun 20].

9. Bodi J, Balbo JT. Modelos para priorização de serviços de manutenção de pavimentos urbanos. In: Anais da 31. Reunião Anual de Pavimentação; 1998 out 20-30; São Paulo: Associação Brasileira de Pavimentação; 1998, v 2, p. 794-814 
10. Boileau PE, Scory $H$. Les lombalgies chez les conducteurs de débusqueuses: étude des vibrations appliquées au corps entier dans les chantiers forestiers du Québec. Arch Mal Prof 1988; 49(5): 305-314.

11. Bongers PM, Boshuizen HC, Hilshof CT, Koemeester AP. Back disorders in crane operators exposed to whole-body vibration. Int Arch Occup Environ Health 1988a; 60:129-137.

12. Bongers PM, Boshuizen HC, Hulshof CTJ, Koemeester AP. Long-term sickness absence due to back disorders in crane operators exposed to whole-body vibration.Int Arch. Occup Environ Health 1988b; 61:59-64.

13. Boshuizen HC, Bongers PM, Hulshof CTJ. Back disorders and occupational exposure to whole-body vibration. Int J Ind Ergonomics 1990a; 6: 55-59.

14. Boshuizen HC, Bongers PM, Hulshof CTJ. Self-reported back pain in tractor drivers exposed to whole-body vibration. Int Arch Occup Environ Health_ 1990b; 62: 109-115.

15. Boulanger $P$, Donati $P$, Galmiche JP. L'environment vibratoire au poste de conduite des camions. Cah Notes Doc 1992; 146:35-42.

16. Bovenzi M, Betta A. Low-back disorders in agricultural tractor drivers exposed to whole-body vibration and postural stress. Appl ergonomics 1994; 25(4): 231-241.

17. Bovenzi M, Zadini A. Self-reported low back symptoms in urban bus drivers exposed to whole-body vibration. Spine1992; 17(6): 1048-1059.

18. Bovenzi M. Effetti acuti delle vibrazioni trasmesse a tutto il corpo. In: Convegno Nazionale - Rumore e Vibrazioni: valutazione, prevenzione, bonifica. 20-21 novembre - Bologna. 22-24 novembre Modena; 1990. pp 49-67.

19. Brendstrup T, Biering-Sørensen F. Effect of fork-lift truck driving on lowback trouble. Scand J Work Environ Health 1987; 13:445-452.

20. British Standard Institution. BS 6841: Measurement and evaluation of human exposure to whole-body mechanical vibration and repeated shock. London; 1987. 
21. Britto, R. Motorista de ônibus - atuação profissional.. In: Anais do 14. Congresso Nacional de Prevenção de Acidentes do Trabalho; 1975, Rio de janeiro, Brasil. São Paulo, Ed. Artes e Texto; 1975. p. 1076-109.

22. Brunn 10, Campbell JS, Hutzel RL. Evaluation of occupational exposures: a proposed sampling method. Am Ind Hyg Assoc J. 1986; 47(4):229-35.

23. Burdorf A, Sorock G. Positive and negative evidence of risks factors for back disorders. Scand J Work Environ Health 1997; 23: 243-256.

24. Burdorf $A$, Swuste $P$. The effect os seat suspention on exposure to wholebody vibration of professional drivers. Ann Occup Hyg 1993; 37(1): 4555.

25. Burton AK, Sandover J. Back pain in Grand Prix drivers: a "found" experiment. 1987; Appl Ergonomics, 18:3-8.

26. Buschinelli JT, Moro G. Avaliação epidemiológica de sintomatologia gástrica e lombalgias em expostos a vibrações de baixa freqüência (corpo inteiro). Rev Bras Saúde Ocup 1985; 51(13):37-9.

27. Calvino I. Palomar. São Paulo: Companhia das letras; 1994.

28. Campana $\mathrm{Cl}$. Contribuição para o estudo de alguns dos riscos a que está submetida uma classe de motoristas profissionais. Ribeirão Preto, 1973. [Tese de Doutorado - Faculdade de Farmácia e Odontologia].

29. Carrère S, Evans GW, Palsane MN, Rivas M. Job strain and occupational stress among urban public transit operators. J Occup Psychol 1991; 64:305-16.

30. Center for Disease Control \& Prevention, World Health Organization. Epi Info 6: A word processing, database and statistics program for public health. [programa de computador]. Atlanta, Geneva. CDCMHO; 1997.

31. Chaudron B, Knab A, Bortolameolli C, Dussausoy P, Lemer M. Le conducteur receveur d’autobus en milieu urbain région parisienne. Cah Med Interprof 1997; 4:459-72

32. Checkoway $H$, Pearce N, Crawford-Brown D. Research methods in occupational epidemioloav. New York. Oxford Universitv Press. 1989. 
33. Cluff $\mathrm{GL}$. Is the five $\mathrm{dB}$ doubling rule na accurate basis for noise limits? Occup health Safety $1984 ; 4: 45-61$.

34. Cocheo V, Valsecchi M, Peretti A, Coato F. Chariots de manutention pollution chimique, bruit et vibrations. Cah Notes Doc 1984; 115:159168.

35. Comité Européen de Normalisation. CEN report - CEN/TC 231 WI 27. Mechanical Vibration - Guide to the health effects of vibration on the human body, 1996.

36. Comunidade Econômica Européia. Council Directive 86/188/EEC of 12 May 1986 on the protection of workers related to exposure to noise at work, Official Journal $n^{\circ} \mathrm{L} 137$ of 24.05.1986, p. 28-37; 1986. Available from $<$ http://europa eu.int/eurlex/en/lif/dat/1986/en_386L0188.html>.[2001 Fev 20]

37. Comunidade Econômica Européia. Council Directive 86/188/EEC of 12 May 1986 on the protection of workers related to exopsure to noise at work. Official Journal $n .{ }^{\circ} \mathrm{L} 137$ of 24.05.1986, p. 28-37; 1986. Available from <http:/leurope.eu.int/eurlex/en/lif/dat/1986/en_386L0188.html> [2001 Jun 12].

38. Conselho Nacional de Saúde. Resolução N. ${ }^{\circ} 196$, de 10 de Outubro de 1996: Regulamenta pesquisas envolvendo seres humanos.

39. Cordeiro R Lima-Filho EC, Nascimento LCR. Associação da perda auditiva induzida por ruido com o tempo acumulado de trabalho entre motoristas e cobradores. Cad. Saúde Públi 1994; 10(2): 210-221.

40. Council of the European Union (1994) Amended proposal for a council directive on the minimum health and safety requrements regarding the exposure of workers to the risks arising from physical agents - individual directive in relation to Article 16 of the Directive 89/391/EEC. Off J Eur Communities 94/C 230 03:C 230/3-29.

41. Cowan JP. Handbook of environmental acoustics. New York: Van Nostrand Reinhold; 1994. 
42. Crépeau G. Noise of transportation travelers. In: May DN, editor. Handbook of noise assessment. New York: Van Nostrand Reinhold Environmental Engineering Series; 1978. P. 140-69.

43. Cruickshanks KJ, Klein R, Klein BE, Wiley TL, Nondahl DM, Tweed TS. Cigarette smoking and hearing loss: the epidemiology of hearing loss study. JAMA 1998; 279(21):1715-1719.

44. Crutchfield CD, Sparks CST. Effects of noise and vibration on farm workers. Occup med: state art rev 1991; 6(3): 355-369.

45. Damongeot A, Kusy A. Pertinence de l'echantillonnage "en aveugle"pour l'estimation des niveaux sonores en entreprises. Cah Notes Doc 1990; 139(2): 347-61.

46. Danière $P$, Boulanger, Donati $P$, Galmiche JP. Environnement acoustique et vibratoire aux postes de conduite des chariots élévateurs; Cah Notes Doc 1992; 148: 345-358.

47. Donati $P$, Boulanger $P$, Galmiche JP. Confort vibratoire dans les vehicules industriels et les engins de chantier. Trav Sécurité 1993; 92:150-58.

48. Duffy CA, McGoldrick AE. Stress and the bus driver in the UK transport industry. Work and Stress 1990; 4(1):17-27.

49. Dupuis $\mathrm{H}$, Zerlett $\mathrm{G}$. Whole-body vibration and disorders of the spine_Int Arch Environ Health 1987; 59: 323-336.

50. European Agency for Safety and Health at Work. Council Directive $86 / 188 / E E C$ of 12 May 1986 on the protection of workers related to exposure to noise at work, Official Journal $n^{\circ} L 137$ of 24.05.1986, $p$. 28.

51. European Agency for Safety And Health at Work. Machines, products and Apparatus. 1.2. Machines Directive - Directive 98/37/EC of the European Parliament and of the Council of 22 June 1998 on the approximation of the laws of the Member States relating to machinery, Official Journal $L$ 207 , 23 Jul 1998 p. 0001-0046; 1998, Available from $<$ http://europe osha.eu int/legislation/directives/b1.php3>. [2001 Jan 11] 
52. Evans GW, Carrère S. Traffic congestion, perceived controt, and psychophysiological stress among bus drivers. J Appl Paychol 1991; 76(5):658-63.

53. Evans GW, Working on the hot seat. Accid Anal and Prev 1994; 26(2): 181-93.

54. Fairley TE. Predicting the discomfort caused by tractor vibration. Ergonomics 1995; 38(10): 2091-2106.

55. Fernandes JC. Avaliaçăo dos niveis de ruido em tratores agricolas e seus efeitos sobre o operador. Botucatu, 1991. TTese de Doutorado Faculdade de Ciências Agronómicas da UNESP].

56. Fonseca JC, Nicótera FN, Gronchi CC, Pastorello NA, Alves LC. Avaliaçăo da exposiçăo ao ruido dos motoristas e cobradores de Onibus urbanos de Săo Paulo. São Paulo; 1993. (Fundacentro).

57. Fundacentro. Norma para avaliaçăo de exposiçăo ocupacional ao ruido, NHO-01. São Paulo, 1999.

58. Futatsuka M, Maeda S, Inaoka T, Nagano M, Shono M, Miyakita T. Whole-body vibration and health effects in the agricultural machinery drivers. Ind Health 1998; 36:123-32.

59. Gerges SNY. Ruido: Fundamentos e controle. Florianópolis: S.N.Y. Gerges; 1992.

60. Griffin MJ. Handbook of human vibration. London: Academic Press; $1990 a$.

61. Griffin MJ. Measurement and evaluation of whole-body vibration at work. Int J Ind Ergonomics 1990b; 6: 45-54.

62. Griffin MJ. Predicting the hazards of whole-body vibration considerations of a standard. Ind Health 1998; 36:83-91.

63. Griffin MJ. The evaluation of vehicle vibration and seats. Appl Ergonomics 1978; 9:15-21.

64. Hamernik RP, Ahroon WA, Davis RI. Noise and vibration interactions: effects on hearing. J Acoust Soc Am 1989; 86(6):2129-2137. 
65. Hamernik RP, Henderson D, Coling D, Salvi R. Influence of vibration on asymptotic threshold shift produced by ompulse noise. Audiol 1981; 20:259-69.

66. Hedlund $U$. Raynaud's phenomenon of fingers and toes of miners exposed to local and whole-body vibration and cold. Int Arch. Occup Environ Health 1989; 61: 457-461.

67. Helmkamp JC, Talbott EO, Marsh GM. Whole-body vibration - a critical review. Am Ind Hyg Assoc J 1984; 45(3):162-167.

68. Hosmer DW, Lemeshow S. Applied logistic Regression. New York, John Wiley \& Sons, 1989.

69. HSE - Health \& Safety Executive. In the driving seat [Leaflet on line].1996; Available from:http://uww.open.gov.uk/hse/pubns/indg242.htm [1999 Feb 09]

70. Hulshof C, Van Zanten V. Whole-body vibration and low-back pain. Int Arch Occup Environ Health 1987; 59: 205-220.

71. Humes LE. Noise-induced hearing loss as influenced by other agents and by some physical caracteristics of the individual. J Acoust Soc Am 1984; 76(5): 1318-1329.

72. International Electrotechnical Commission. IEC 804: Integrating sound level meters. Geneva; 1985.

73. International Labour Organisation. C153 Hours of work and rest periods (road transport) convention, 1979. [Convention on line]. Geneva: International Labour Organisation; 1979. Available from $<$ URL:http://www.ilolex.ch> [2001 Mar 10].

74. International Organisation for Standardization. ISO-2631-1: Mechanical vibration and shock - Evaluation of human exposure to whole-body vibration - Part 1: General requirements. Geneva; 1985.

75. International Organisation for Standardization. ISO-2631-1: Mechanical vibration and shock - Evaluation of human exposure to whole-body vibration - Part 1: General requirements. Geneva; 1997. 
76. International Organisation for Standardization. 1SO-389: Acoustic standard reference zero for the calibration of pure tone audiometers. Geneva; 1975.

77. International Organization for Standardization. ISO-1999: Acoustics Determination of occupational noise exposure and estimation of noise-induced hearing impairment. Geneva; 1990.

78. Ishii EK, Talbott EO, Findlay RC, D'Antonio JÁ, Kuller LH. Is NIDDM a risk factor for noise-induced hearing loss in na occupationally noise exposed cohort? Sci Total Environ 1992; 127: 155-65.

79. Jackson RA, Behar A. Noise exposure - sample size and confidence limit calculation. Am Ind Hyg Assoc J 1985; 46(7): 387-90.

80. Jauhiainen $T$, Kohonen A, Tarkkanen J, Kaimio M. The effect of wholebody vibration on the cochlea. Laryngos 1969; 79:1950-55.

81. Johanning $E$, Wilder DG, Landrigan PJ, Pope M. Whole-body vibration exposure in subway cars and review of adverse health effects. $J$ Occup Medicine 1991a; 33(5): 605-612.

82. Johanning $E$. Back disorders and health problems among subway train operators exposed to whole-body vibration. Scand J Work Environ Health 1991b; 17: 414-419.

83. Kaimio $M$, Jauhiainen $T$, Kohonen $A$, Tarkkanen J. Whole - body infrasonic vibration effects on the cochlea. Environ Res 1970 1970; 42529.

84. Kelsey J, Hardy RJ. Driving of motor vehicles as a risk factor for acute herniated lumbar intervertebral disc. Am J Epidemiol 1975; 102(1): 6373.

85. Kelsey JL, Thompson WD, Evans AS. Methods in observational epidemiology. New York: Oxford University Press; 1986

86. Kirby RH, Coates GD, Mikulka PJ, Winne PS, Cempsey TK, Leatherwood JD. Effect of whole-body vibration in combined axes and with noise on subjective evaluation of ride quality. Am Ind Hyg Assoc J 1977; 38(3):125-133. 
87. Kleinbaum DG, Kupper LL, Morgenstern H. Epidemiologic research principles and quantitative methods. New York: John Wiley \& Sons, Inc.; 1982.

88. Köhl U. Les dangers encourus par les conducteurs de tracteurs - une enquête dans le canton de Vaud. Arch Malad Prof Méd Trav Séc Sociale 1975 ; 36(3): 145-162.

89. Kompier MAJ. Bus drivers: occupational stress and stress prevention. Geneva; 1996. (ILO - working paper CONDI/TMP.2)

90. Kühlmann TM. Coping with occupational stress among urban bus and tram drivers. J Occup Psychol 1990; 63:89-96.

91. Landström $U$, Kjellberg A, Lundström R. Combined effects of exposure to noise and whole-body vibration in dumpers, helicopters and railway engines. J low frequency noise vib 1993; 12(3): 75-85.

92. Lawton BW, Robinson DW. The effects upon hearing of noise in combination with other agents: a critical review of the literature. Southampton; 1989. (The Institute of Sound and Vibration Research University of Southampton - HSE Contract Research Report N. ${ }^{\circ}$ 14/1989).

93. Leidel NA, Busch KA, Lynch JR. Occupational exposure sampling strategy manual. Cincinnati, 1977. (National Institute for Occupational Safety and Health - Publication n. ${ }^{\circ} 77-173$ ).

94. Lewis $\mathrm{CH}$, Griffin MJ. A comparison of evaluations and assessments obtained using alternative standards for predicting the hazards of wholebody vibration and repeated shocks. J Sound Vibration 1998; 215(4):915-26.

95. Lôbo R, da Costa EA. Classificação das perdas auditivas induzidas por riido. In: Nudelmann AA et al., organizadores. PAIR -. Perda auditiva induzida por ruido. Porto Alegre: Bagaggem Comunicação; 1997. p. 209-21.

96. Malchaire J, Piette A. Relation between vibration levels and perceptive and appreciative judgements of overhead crane operators. Ann Occup Hyg. $1991 ; 35(6): 613-618$. 
97. Manninen O, Ekblom A. Single and joint actions of noise and sinusoidal whole-body vibration on TTS2 values and low frequency upright posture sway in men. Int Arch Occup Environ Health 1984; 54: 1-17.

98. Manninen $O$. Changes in hearing, cardiovascular functions, haemodynamics, upright body sway, urinary catecholamines and their correlates after prolonged successive exposures to complex environmental conditions. Int Arch Occup Environ Health 1988; 60: 249-272.

99. Manninen $O$. Further studies on changes in subjective stressfulness under various combinations of noise, vibration, temperature and work tasks. Arch Complex Environ Studies 1990; 2(2):31-39.

100. Manninen O. Simultaneous effects of sinusoidal whle-body vibration and broadband noise on $T T S_{2}$ 's and R-wave amplitudes in men at two different dry bulb temperatures. Int Arch. Occup Environ Health 1983a; 51: $289-297$.

101. Manninnen $O$. Studies of combined effects of sinusoidal whole-body vibrations and noise of varying bandwidths and intensities on $\pi S_{2}$ in men. Int Arch Occup Environ Health 1983b; 51: 273-288.

102. Marques SR. Os efeitos do ruído em motoristas de ônibus urbano no município de São Paulo. São Paulo; 1998. [Dissertação de Mestrado - Faculdade de Fonoaudiologia da PUC-SP].

103. Merluzzi F, Parigi G, Gornacchia L, Terrana, T. Metodologia di esecuzione del controllo dell'udito dei lavoratori esposti a rumore. Nuovo Arch Ital Otol 1979; 7(4):695-712.

104. Morata TC, Dunn DE, Kretschmer LW, Lemasters GK, Keith RW. Effects of occupational exposure to organic solvents and noise on hearing. Scand J Work Environ Health 1993; 19: 245-54,

105. Morioka I, MiYashita K, Takeda S. Noise-induced hearing loss in working environment and its background. J Occup Health 1997; 39:5-17. 106. Moura C, Cardoso MRA. Urban noise measurements in the city of São Paulo, Brazil: an important problem of public health. In: NOPHER 2001 An International Symposium on Noise Pollution \& Health - 
Programme \& Abstract Book; 2001 Abril 6-8; Cambridge, UK. London: University College London; 2001. p. 73.

107. MULTLR. A microcomputer program for multiple regression by conditional and unconditional maximum likelihood methods. Am J Epidemiol 1989; 129: 439-44.

108. National Institute for Occupational Safety and Health. Criteria for a Recommended Standard - Occupational Noise Exposure - Revised Criteria. Cincinnati (OH); 1998. (DHHS-NIOSH Publication No. 98-126) 109. National Institute for Working Life - Technical Risk Factors - Wholebody vibration database Available from <URL:http://umetech.niwl.se/VibrationWBVHome.html>. [2001 Jan 07].

110. NF S 31-084 - Acoustique. Méthode de mesurage des niveaux sonores en milieu de travail en vue de l'évaluation du niveau quotidienne des travailleurs. Paris - La Défense, AFNOR, avril 1985.

111. Okada $A$, Myake $H$, Yamamura $K$, Minami $M$. Temporary hearing loss induced by noise and vibration. J Acoust Soc Am 1971; 51(4):1240-48.

112. Ozkaya N, Goldsheyder D, Willems B. Effect of subway car design on vibration exposure. Int $\mathbf{J}$ Ind Ergonomics 1997; 19:377-85.

113. Ozkaya N, Goldsheyder D, Willems B.. Effect of operator seat design on vibration exposure. Am Ind Hyg Assoc J 1996; 57:837-842,.

114. Palmer KT, Griffin MJ, Bendall H, Pannett B, Coggon D. Prevalence and pattern of occupational exposure to whole-body vibration in Great Britain: findings from a national survey. Occup Environ Med 2000a; 57:229-36.

115. Patwardhan MS, Kolate MM, More TA. To assess effect of noise on hearing ability of bus drivers by audiometry. Indian J Physiol Pharmacol. 1991; 35(1): 35-38.

116. Pearson JD. Morrell CH, Gordon-Salant S, Brant LJ, Metter EJ, Klein $\mathrm{LL}$, Fozard JL. Gender differences in a longitudinal study of ageassociated hearing loss. J Acoust Soc Am 1995; 97(2): 1196-1205. 
117. Pelmear P. Noise and vibration. In: McDonald, C. Epidemiology of work related diseases. London: BMJ Publishing Group; 1995. p. 185205.

118. Phaneuf R, Hétu R. An epidemiological perspective of the causes of hearing loss among industrial workers. J. Otolaryngology 1990; 19:3140 .

119. Piette A, Malchaire J. Exposition aux vibrations dans les ponts roulants. Cah Notes Doc 1992; 149: 497-504.

120. Ragland DR, Winkleby MA, Schwalbe J, Holman BL, Morse L, Syme SL, Fisher JM. Prevalence of hypertension in bus drivers. Int J Epidemiol 1987; 16(2):208-14.

121. Robin P. Trator agricola e vibrações. Rev Bras Saúde Ocup 1987; 59(15): 44-50.

122. Rosengren A, Anderson $K$, Wilhelmsen $L$. Risl of coronary heart disease in middle-aged male bus and tram drivers compared to men in other occupations; a prospective study. Int J Epidemiol 1991; 20(1):8287

123. Rothman KJ. Modern epidemiology. Boston/Toronto: Little, Brown and company; 1986.

124. Santana VS, Barberino Jl. Exposição ocupacional ao ruido e hipertensão arterial. Rev Saúde Pública 1995; 29(6):478-87.

125. Santos Júnior EA. Mendes R. Estudo das condições de trabalho e saúde de motoristas de ônibus urbanos de Belo Horizonte - MG. Rev Bras Saúde Ocup 1999; 25(95/96): 131-42.

126. Sato L. Abordagem do trabalho penoso: estudo de caso de motoristas de ônibus urbano. São Paulo, 1991. [Dissertação de Mestrado - Pontificia Universidade Católica de São Paulo].

127. Seidel H, Harazin B, Pavlas K, Sroka C, Richter J, Blüthner R, Erdmann U, Grzesik J, Hinz B, Rothe R. Isolated and combined effects of prolonged exposures to noise and whole-body vibration on hearing, vision and strain. Int Arch Occup Environ Health. 1988; 61:95-106. 
128. Seidel $H$, Heide $R$. Long-term effects of whole-body vibration: a critical survey of the literature. Int Arch Occup Environ Health 1986; 58: 1-26.

129. Seidel H. Selected Health risks caused by long-term, whole-body vibration. Am J Ind Med 1993; 23:589-604.

130. Seshagiri B. Occupational noise exposure of operators of heavy trucks. Am Ind Hyg Assoc J 1998; 29:205-213.

131. Sherwood N, Griffin MJ. Evidence of impaired learning during wholebody vibration. J Sound Vibration 1992; 152(2): 219-225.

132. Silva AA, da Costa EA. Avaliação da surdez ocupacional. Rev Ass Med Brasil 1998; 44(1):65-8.

133. Simonin, C. Médecine du travail. $2^{\text {me }}$ ed. Paris: Librairie Maloine; 1956.

134. Sulkowski WJ, Kowalska S, Lipowczan A. Hearing loss in weavers and drop-forge hammermen: comparative study on the effects of steady-state and impulse noise. In: Proceedings of the International Congress on Noise as a Public Health Problem; 1983; Milan (IT). Centro Ricerche e Studi Amplifon; 1983. P. 171-84.

135. Van Den Heever DJ, Roets FJ. Noise exposure of truck drivers: a comparative study. Am Ind Hyg Assoc J 1996; 57:564-566.

136. Walsh K, Vatnes $N$, Osmond $C$, Styles R, Coggon D. Occupational Causes Of low-back pain. Scand J Work Environ Health 1989; 15:5459.

137. Wasseman DE, Wilder DG, Pope MH, Magnusson M, Aleksiev AR, Wasserman JF. Whole-body vibration exposure and occupational workhardening. [editorial] J Occup Environ Med 1997; 39(5):403-7.

138. Wikström B-O, Kjellberg A, Landström U. Health effects of long-term occupational exposure to whole-body vibration; a review. Int $\mathbf{J}$ Ind Ergonomics 1994; 14: 273-292.

139. Yiming Z. Shuzheng Z, Selvin S, Spear RC. A dose response relation for noise induced hypertension. Br J Ind Medicine 1991; 48: 179-184. 
140. Yokoyama T, Osako S, Yamamaoto K. Temporary threshold shifts produced by exposure to vibration, noise, and vibration-plus-noise. Acta Otolaryng 1974; 78:207-212. 


\section{PROJETO: EXPOSIÇÃO COMBINADA ENTRE RUÍDO E VIBRAÇÃO DE CORPO-TODO}

DATA: 12000

ID:

NOME:

IDADE: anos Data de nascimento 1

Há quanto tempo você trabalha como motorista? anos Tempo de empresa como motorista

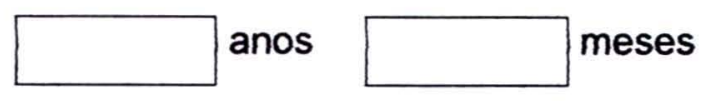

1. IMPRESSÃO SOBRE A PRÓPRIA AUDIÇÃO:
Direito 1. boa
Esquerdo
1. boa
2. regular
2. regular
3. ruim
3. ruim
4. não sabe
4. não sabe

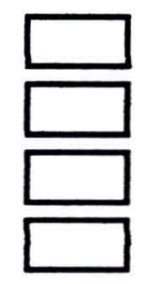

Tempo: considerar o pior ouvido) meses (somente para as alternativas "regular" e "ruim";

2. ANTECEDENTES PESSOAIS

2.1 INFECÇÃO OU DOR NA ORELHA: 1. sim

2. não

3. não sabe

2.2 SE SIM, QUAL A FREQUÊNCIA DESSES EPISÓDIOS?

\begin{tabular}{|c|c|c|c|}
\hline $\begin{array}{l}2.3 \text { DOENÇAS } \\
\text { sarampo }\end{array}$ & 1. $\operatorname{sim}$ & 2. näo & 3. não sabe \\
\hline caxumba & 1. $\operatorname{sim}$ & 2. não & 3. não sabe \\
\hline meningite & 1. $\operatorname{sim}$ & 2. não & 3. não sabe \\
\hline prob. cardiovasc. & 1. $\operatorname{sim}$ & 2. não & 3. não sabe \\
\hline outros & 1. $\operatorname{sim}$ & 2. não & 3. não sabe \\
\hline
\end{tabular}

Obs:

2.4 HIPERTENSÃO:

Tem recebido tratamento para pressão alta ?

1. $\operatorname{sim}$

2. não

\subsection{DIABETES}

Tem recebido tratamento para diabetes?

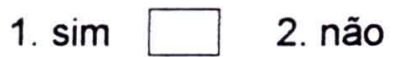


2.6 CIRURGIA DE ORELHA 1. não

2. sim, bilateral

3. $\operatorname{sim}, O D$

4. sim, $O E$

5 , sim, não sabe referir o lado

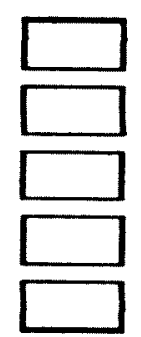

Tempo Meses Obs.:

3. TRAUMA CRANIANO 1. sim

2. não

3. não sabe

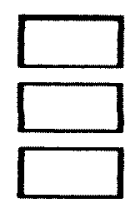

Tempo Meses Obs.:

4 TRAUMA ACÚSTICO
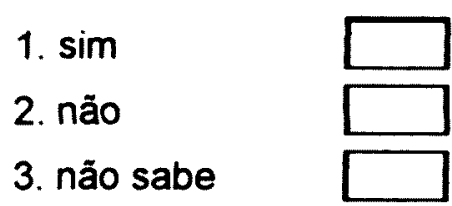

Tempo Meses Obs:

$\begin{array}{ll}5 \text { ANTECEDENTES AUDIOLOGICOS } & \text { 1. sim } \\ \text { FAMILIARES SIGNIFICATIVOS } & \text { 2. não } \\ & \text { 3. não sabe }\end{array}$

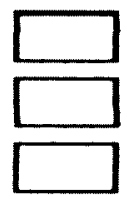

6 ZUMBIDO
1. $\operatorname{sim}$
2. não

Tempo Meses Obs:

6.1 LOCALIZAÇÃO 1. OD

2. $O E$

3. bilateral

4. não sabe

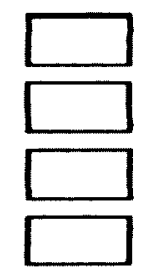

7 TABAGISMO
1. Fumante
2. Não fumante
3. Ex-fumante

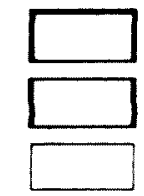


8. Tem tomado qualquer medicamento, pelo menos três vezes ao dia, por mais de duas semanas, o qual você acha que afetou a sua audição ou causou sons de campainha em seus ouvidos?

1. $\operatorname{Sim}$

2. Não

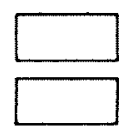

9. SERVIÇO MILITAR

1. $\operatorname{sim}$

2. não

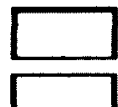

10. DADOS OCUPACIONAIS

Que tipo de ônibus você dirige ou dirigiu em seu atual emprego?

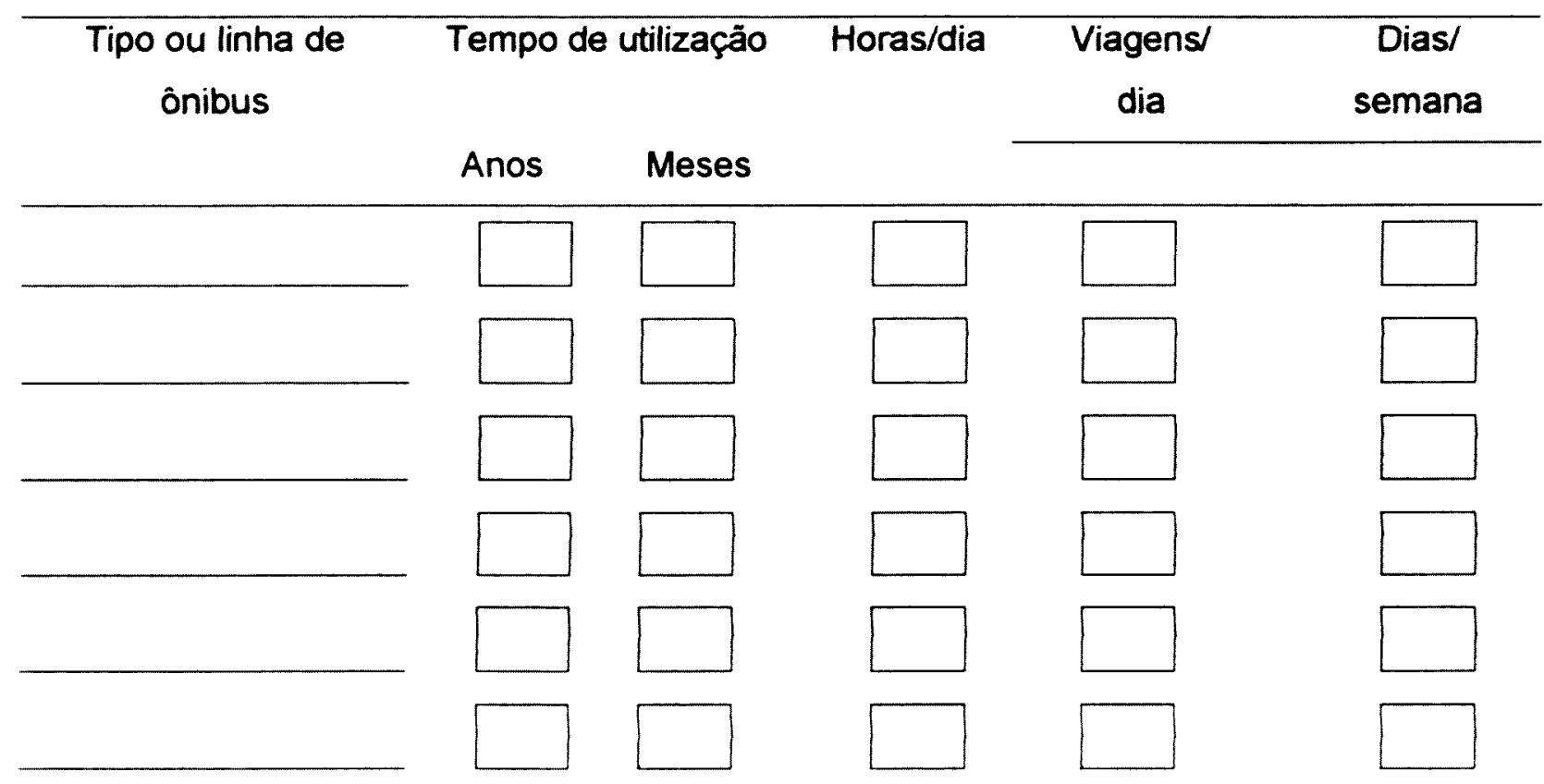

11. EXPOSIÇÃO ANTERIOR Ȧ VIBRAÇÃO DE CORPO-TODO:

1. Sem histórico

2. Com histórico

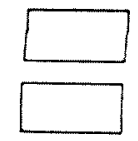


Se a resposta for negativa , salte para a questão $n^{\circ} 12$

12. EXPOSIÇÃO ANTERIOR A RUIDOO OCUPACIONAL:

1. Sem histórico

2. Com histórico

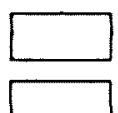

Empresa Função Tempo (meses) Ruido $>_{,}=,<$

Fonoaudióloga responsável: 
Lista de simbolos:

\begin{tabular}{|c|c|}
\hline$a_{\text {eq }}$ & Aceleração equivalente $\left(\mathrm{m} / \mathrm{s}^{2}\right)$ \\
\hline$a_{w t}$ & Somatória vetorial ponderada das acelerações $\left(\mathrm{m} / \mathrm{s}^{2}\right)$ \\
\hline$a_{x w}$ & Aceleração ponderada na direção ortogonal $x\left(\mathrm{~m} / \mathrm{s}^{2}\right)$ \\
\hline$a_{y w}$ & Aceleração ponderada na direçăo ortogonal y $\left(\mathrm{m} / \mathrm{s}^{2}\right)$ \\
\hline$a_{z w}$ & Aceleraçáo ponderada na direçăo ortogonal $z\left(\mathrm{~m} / \mathrm{s}^{2}\right)$ \\
\hline$E_{a}$ & Nivel de imissão sonora $[\mathrm{dB}(\mathrm{A})]$ \\
\hline $\mathrm{L}_{\text {Aeq }}$ & Nivel equivalente ponderado na escala $A[d B(A)]$ \\
\hline$L_{E P, w}$ & Nivel de exposição semanal $[\mathrm{dB}(\mathrm{A})]$ \\
\hline Lex & Nivel de exposiçăo [dB(A)] \\
\hline $\mathrm{T}$ & Tempo de exposição \\
\hline$T_{0}$ & Tempo de referência \\
\hline
\end{tabular}

\section{Lista de abreviaturas:}

ACGIH American Conference of Governmental Industrial Hygienists AFNOR Association Française de Normalisation

ANSI American National Standard Institute

BS British Standard

CEN Comité Européen de Normalisation

CEREST-SP Centro de Referência em Saúde do trabalhador do Estado de São Paulo

ISO International Organization for Standardization

MPL Mudança permanente de limiar

MTL Mudança temporária de limiar

MTL2 Mudança temporária de limiar após 2 min

NA Nivel de audição

$\mathrm{NIOSH} \quad$ National Institute for Occupational Safety and Health

PAIR Perda auditiva induzida pelo ruido

r.m.s. Root-mean-square

SEAT Seat effective amplitude transmissibility

$\mathrm{VCl}$ Vibração de corpo inteiro

VDV Vibration dose value 
Limiares auditivos, em dB, segundo freqüência, do grupo com tempo de exposição superior ou igual a 5 anos - "Grupo Exposto":

\begin{tabular}{|c|c|c|c|c|c|c|c|c|c|c|c|c|c|c|c|c|}
\hline \multirow{3}{*}{ ID } & \multicolumn{16}{|c|}{ Freqüência em Hz } \\
\hline & \multicolumn{8}{|c|}{ Orelha direita } & \multicolumn{8}{|c|}{ Orelha esquerda } \\
\hline & 250 & 500 & 1000 & 2000 & 3000 & 4000 & 6000 & 8000 & 250 & 500 & 1000 & 2000 & 3000 & 4000 & 6000 & 8000 \\
\hline 1 & 25 & 15 & 15 & 25 & 15 & 25 & 15 & 10 & 25 & 20 & 15 & 20 & 35 & 45 & 35 & 15 \\
\hline 2 & 5 & 0 & 5 & 5 & 10 & 20 & 0 & 0 & 5 & 0 & 0 & 5 & 15 & 15 & 20 & 5 \\
\hline 3 & 25 & 25 & 5 & 0 & 0 & 0 & 65 & 40 & 20 & 15 & 5 & 0 & 0 & 0 & 55 & 25 \\
\hline 4 & 25 & 20 & 15 & 20 & 25 & 25 & 25 & 5 & 25 & 25 & 20 & 30 & 35 & 35 & 45 & 15 \\
\hline 5 & 15 & 15 & 5 & 0 & 10 & 20 & 20 & 25 & 10 & 5 & 0 & 0 & 0 & 10 & 10 & 5 \\
\hline 6 & 5 & 0 & 0 & 0 & 5 & 10 & 15 & 10 & 0 & 0 & 5 & 0 & 10 & 5 & 20 & 5 \\
\hline 7 & 15 & 15 & 25 & 25 & 25 & 25 & 35 & 50 & 15 & 20 & 25 & 20 & 25 & 45 & 50 & 50 \\
\hline 8 & 5 & 15 & 25 & 10 & 5 & 15 & 20 & 15 & 0 & 10 & 20 & 15 & 5 & 15 & 25 & 25 \\
\hline 9 & 10 & 5 & 10 & 15 & 0 & 0 & 20 & 25 & 10 & 5 & 10 & 0 & 0 & 10 & 15 & 15 \\
\hline 10 & 15 & 20 & 15 & 10 & 15 & 20 & 30 & 25 & 15 & 20 & 20 & 15 & 15 & 20 & 25 & 20 \\
\hline 11 & 10 & 0 & 5 & 0 & 0 & 20 & 10 & 0 & 5 & 0 & 5 & 0 & 0 & 10 & 0 & 5 \\
\hline 12 & 15 & 10 & 5 & 0 & 20 & 25 & 5 & 0 & 10 & 5 & 0 & 0 & 0 & 25 & 0 & 0 \\
\hline 13 & 15 & 15 & 0 & 0 & 0 & 0 & 15 & 15 & 0 & 0 & 0 & 0 & 0 & 0 & 0 & 10 \\
\hline 14 & 5 & 10 & 5 & 10 & 0 & 20 & 25 & 15 & 10 & 10 & 5 & 10 & 10 & 20 & 25 & 20 \\
\hline 15 & 5 & 5 & 15 & 15 & 20 & 25 & 35 & 30 & 10 & 5 & 5 & 0 & 20 & 25 & 10 & 20 \\
\hline 16 & 5 & 5 & 0 & 15 & 45 & 40 & 15 & 25 & 5 & 5 & 5 & 20 & 50 & 50 & 50 & 45 \\
\hline 17 & 0 & 0 & 0 & 0 & 0 & 15 & 0 & 20 & 0 & 5 & 0 & 0 & 0 & 5 & 0 & 15 \\
\hline 18 & 10 & 5 & 0 & 0 & 0 & 0 & 0 & 0 & 10 & 10 & 0 & 0 & 0 & 0 & 0 & 0 \\
\hline 19 & 10 & 15 & 10 & 10 & 15 & 10 & 5 & 5 & 10 & 10 & 0 & 15 & 20 & 30 & 15 & 15 \\
\hline 20 & 15 & 15 & 10 & 15 & 10 & 15 & 20 & 20 & 10 & 10 & 5 & 5 & 15 & 15 & 25 & 15 \\
\hline 21 & 15 & 10 & 10 & 15 & 45 & 40 & 25 & 25 & 10 & 10 & 15 & 25 & 50 & 55 & 50 & 35 \\
\hline 22 & 5 & 5 & 5 & 0 & 0 & 0 & 5 & 10 & 0 & 0 & 0 & 0 & 10 & 10 & 0 & 0 \\
\hline
\end{tabular}


$\pi$

Freqüência em Hz

\begin{tabular}{|c|c|c|c|c|c|c|c|c|c|c|c|c|c|c|c|c|}
\hline \multirow{3}{*}{ ID } & \multicolumn{16}{|c|}{ Freqüëncia em Hz } \\
\hline & \multicolumn{8}{|c|}{ Orelha direita } & \multicolumn{8}{|c|}{ Orelha esquerda } \\
\hline & 250 & 500 & 1000 & 2000 & 3000 & 4000 & 6000 & 8000 & 250 & 500 & 1000 & 2000 & 3000 & 4000 & 6000 & 8000 \\
\hline 23 & 20 & 10 & 10 & 10 & 25 & 35 & 35 & 15 & 15 & 5 & 10 & 10 & 15 & 35 & 15 & 10 \\
\hline 24 & 15 & 15 & 15 & 5 & 0 & 20 & 20 & 25 & 15 & 10 & 10 & 5 & 0 & 10 & 15 & 5 \\
\hline 25 & 15 & 5 & 0 & 15 & 25 & 25 & 25 & 5 & 15 & 5 & 0 & 10 & 25 & 45 & 45 & 15 \\
\hline 26 & 5 & 5 & 10 & 15 & 10 & 5 & 10 & 20 & 5 & 5 & 10 & 20 & 25 & 20 & 35 & 10 \\
\hline 27 & 15 & 10 & 5 & 0 & 0 & 0 & 25 & 0 & 15 & 10 & 10 & 0 & 10 & 10 & 0 & 0 \\
\hline 28 & 10 & 15 & 25 & 15 & 25 & 40 & 35 & 35 & 15 & 10 & 15 & 10 & 10 & 35 & 35 & 30 \\
\hline 29 & 5 & 10 & 5 & 0 & 0 & 0 & 0 & 10 & 10 & 5 & 0 & 10 & 10 & 0 & 15 & 10 \\
\hline 30 & 10 & 5 & 5 & 5 & 15 & 50 & 40 & 40 & 5 & 5 & 5 & 0 & 30 & 45 & 35 & 45 \\
\hline 31 & 15 & 10 & 5 & 5 & 5 & 25 & 25 & 20 & 10 & 5 & 0 & 0 & 0 & 0 & 0 & 5 \\
\hline 32 & 10 & 10 & 5 & 10 & 20 & 15 & 25 & 20 & 5 & 5 & 5 & 10 & 10 & 10 & 0 & 10 \\
\hline 33 & 5 & 10 & 15 & 0 & 0 & 15 & 5 & 10 & 5 & 10 & 15 & 0 & 0 & 15 & 25 & 10 \\
\hline 34 & 15 & 10 & 25 & 35 & 40 & 45 & 30 & 5 & 10 & 20 & 30 & 35 & 35 & 30 & 15 & 15 \\
\hline 35 & 10 & 5 & 5 & 0 & 0 & 0 & 0 & 10 & 5 & 5 & 0 & 0 & 0 & 0 & 15 & 5 \\
\hline 36 & 5 & 10 & 10 & 0 & 0 & 0 & 25 & 15 & 10 & 10 & 5 & 5 & 15 & 15 & 10 & 5 \\
\hline 37 & 5 & 5 & 5 & 0 & 10 & 15 & 0 & 5 & 5 & 10 & 5 & 5 & 10 & 10 & 0 & 10 \\
\hline 38 & 10 & 5 & 0 & 10 & 10 & 15 & 25 & 10 & 10 & 5 & 10 & 10 & 15 & 20 & 30 & 40 \\
\hline 39 & 20 & 20 & 5 & 10 & 10 & 20 & 40 & 20 & 15 & 15 & 0 & 0 & 15 & 20 & 25 & 15 \\
\hline 40 & 10 & 20 & 15 & 20 & 10 & 0 & 25 & 0 & 10 & 15 & 15 & 20 & 0 & 10 & 15 & 0 \\
\hline 41 & 15 & 15 & 5 & 10 & 40 & 30 & 25 & 15 & 10 & 10 & 5 & 20 & 55 & 75 & 35 & 30 \\
\hline 42 & 5 & 5 & 10 & 10 & 0 & 0 & 0 & 20 & 5 & 5 & 10 & 0 & 0 & 10 & 10 & 5 \\
\hline 43 & 10 & 10 & 10 & 5 & 0 & 0 & 30 & 0 & 15 & 20 & 20 & 10 & 10 & 15 & 25 & 30 \\
\hline 44 & 10 & 5 & 0 & 0 & 10 & 0 & 0 & 10 & 5 & 10 & 0 & 0 & 0 & 0 & 10 & 10 \\
\hline 45 & 15 & 10 & 5 & 0 & 5 & 15 & 10 & 10 & 10 & 5 & 0 & 0 & 10 & 20 & 20 & 15 \\
\hline 46 & 5 & 5 & 10 & 5 & 10 & 30 & 35 & 5 & 5 & 5 & 10 & 15 & 35 & 55 & 35 & 20 \\
\hline 47 & 5 & 5 & 0 & 0 & 0 & 0 & 0 & 15 & 10 & 10 & 5 & 10 & 5 & 0 & 5 & 5 \\
\hline 48 & 15 & 20 & 20 & 15 & 0 & 5 & 10 & 20 & 15 & 20 & 20 & 15 & 0 & 15 & 10 & 25 \\
\hline 49 & 15 & 20 & 25 & 25 & 15 & 20 & 25 & 15 & 25 & 20 & 25 & 20 & 5 & 15 & 35 & 15 \\
\hline
\end{tabular}


Freqüência em $\mathrm{Hz}$

\begin{tabular}{|c|c|c|c|c|c|c|c|c|c|c|c|c|c|c|c|c|}
\hline \multirow{3}{*}{ ID } & \multicolumn{16}{|c|}{ Freqüência em Hz } \\
\hline & \multicolumn{8}{|c|}{ Orelha direita } & \multicolumn{8}{|c|}{ Orelha esquerda } \\
\hline & 250 & 500 & 1000 & 2000 & 3000 & 4000 & 6000 & 8000 & 250 & 500 & 1000 & 2000 & 3000 & 4000 & 6000 & 8000 \\
\hline 50 & 5 & 10 & 5 & 5 & 0 & 30 & 15 & 15 & 5 & 10 & 5 & 5 & 35 & 25 & 25 & 5 \\
\hline 51 & 0 & 0 & 0 & 0 & 0 & 0 & 0 & 0 & 0 & 0 & 0 & 0 & 0 & 0 & 25 & 15 \\
\hline 52 & 10 & 20 & 25 & 25 & 30 & 35 & 25 & 25 & 15 & 20 & 25 & 20 & 25 & 40 & 35 & 25 \\
\hline 53 & 0 & 5 & 0 & 0 & 0 & 0 & 0 & 5 & 5 & 5 & 0 & 0 & 0 & 10 & 0 & 10 \\
\hline 54 & 5 & 10 & 10 & 15 & 0 & 0 & 0 & 0 & 5 & 5 & 10 & 10 & 10 & 20 & 25 & 5 \\
\hline 55 & 15 & 10 & 15 & 10 & 15 & 15 & 35 & 25 & 15 & 15 & 15 & 25 & 30 & 75 & 65 & 40 \\
\hline 56 & 20 & 15 & 10 & 15 & 25 & 40 & 40 & 20 & 10 & 5 & 15 & 10 & 30 & 40 & 35 & 20 \\
\hline 57 & 5 & 0 & 0 & 0 & 0 & 0 & 10 & 5 & 0 & 0 & 0 & 0 & 5 & 15 & 20 & 15 \\
\hline 58 & 5 & 15 & 15 & 10 & 10 & 25 & 20 & 25 & 10 & 15 & 15 & 15 & 20 & 35 & 30 & 15 \\
\hline 59 & 0 & 0 & 0 & 0 & 15 & 0 & 0 & 10 & 0 & 5 & 0 & 0 & 25 & 20 & 30 & 55 \\
\hline 60 & 5 & 5 & 5 & 0 & 0 & 0 & 0 & 0 & 5 & 5 & 5 & 0 & 0 & 5 & 0 & 0 \\
\hline 61 & 20 & 10 & 0 & 0 & 0 & 15 & 35 & 5 & 10 & 0 & 5 & 0 & 0 & 15 & 55 & 0 \\
\hline 62 & 5 & 5 & 0 & 0 & 0 & 5 & 35 & 25 & 10 & 5 & 0 & 0 & 10 & 25 & 45 & 35 \\
\hline 63 & 10 & 10 & 10 & 5 & 15 & 25 & 25 & 10 & 5 & 5 & 5 & 0 & 0 & 0 & 25 & 15 \\
\hline 64 & 5 & 5 & 5 & 15 & 25 & 25 & 30 & 25 & 10 & 10 & 10 & 25 & 25 & 25 & 30 & 25 \\
\hline 65 & 5 & 0 & 15 & 0 & 0 & 20 & 20 & 5 & 0 & 0 & 0 & 10 & 35 & 35 & 40 & 5 \\
\hline 66 & 10 & 5 & 5 & 5 & 0 & 0 & 0 & 5 & 5 & 5 & 5 & 5 & 0 & 0 & 0 & 0 \\
\hline 67 & 20 & 20 & 15 & 5 & 10 & 10 & 15 & 20 & 15 & 20 & 10 & 5 & 15 & 10 & 20 & 20 \\
\hline
\end{tabular}




\begin{tabular}{|c|c|c|c|c|c|c|c|c|c|c|c|c|c|c|c|c|}
\hline \multirow{3}{*}{ ID } & \multicolumn{16}{|c|}{ Freqüência em Hz } \\
\hline & \multicolumn{8}{|c|}{ Orelha direita } & \multicolumn{8}{|c|}{ Orelha esquerda } \\
\hline & 250 & 500 & 1000 & 2000 & 3000 & 4000 & 6000 & 8000 & 250 & 500 & 1000 & 2000 & 3000 & 4000 & 6000 & 8000 \\
\hline 1 & 15 & 10 & 0 & 10 & 15 & 30 & 0 & 10 & 0 & 0 & 0 & 0 & 20 & 35 & 0 & 5 \\
\hline 2 & 5 & 5 & 0 & 0 & 5 & 15 & 15 & 0 & 10 & 5 & 0 & 10 & 15 & 25 & 20 & 15 \\
\hline 3 & 15 & 15 & 10 & 15 & 40 & 45 & 40 & 50 & 20 & 10 & 15 & 15 & 25 & 35 & 5 & 15 \\
\hline 4 & 5 & 0 & 5 & 0 & 0 & 0 & 0 & 10 & 0 & 5 & 0 & 0 & 0 & 5 & 0 & 5 \\
\hline 5 & 5 & 15 & 5 & 20 & 10 & 0 & 20 & 10 & 10 & 15 & 5 & 10 & 0 & 0 & 25 & 15 \\
\hline 6 & 5 & 15 & 5 & 0 & 15 & 25 & 10 & 10 & 10 & 10 & 10 & 5 & 20 & 10 & 20 & 15 \\
\hline 7 & 10 & 5 & 10 & 0 & 0 & 0 & 0 & 0 & 5 & 5 & 5 & 5 & 0 & 55 & 100 & 75 \\
\hline 8 & 5 & 10 & 15 & 15 & 10 & 0 & 35 & 15 & 5 & 10 & 15 & 10 & 5 & 15 & 25 & 5 \\
\hline 9 & 15 & 10 & 5 & 0 & 0 & 0 & 5 & 5 & 10 & 5 & 0 & 0 & 0 & 0 & 25 & 10 \\
\hline 10 & 0 & 5 & 0 & 0 & 10 & 15 & 20 & 0 & 0 & 0 & 0 & 0 & 0 & 20 & 10 & 5 \\
\hline 11 & 0 & 5 & 5 & 0 & 20 & 25 & 20 & 5 & 5 & 5 & 5 & 0 & 0 & 25 & 20 & 15 \\
\hline 12 & 5 & 5 & 5 & 5 & 0 & 0 & 0 & 5 & 15 & 10 & 0 & 0 & 0 & 0 & 0 & 5 \\
\hline 13 & 5 & 5 & 0 & 5 & 0 & 0 & 5 & 5 & 5 & 5 & 5 & 5 & 0 & 0 & 20 & 15 \\
\hline 14 & 5 & 5 & 0 & 10 & 5 & 0 & 0 & 10 & 5 & 5 & 0 & 0 & 15 & 10 & 25 & 15 \\
\hline 15 & 0 & 0 & 0 & 0 & 0 & 0 & 0 & 10 & 15 & 0 & 0 & 0 & 5 & 15 & 20 & 5 \\
\hline 16 & 5 & 0 & 5 & 5 & 0 & 35 & 25 & 25 & 5 & 0 & 0 & 0 & 5 & 15 & 20 & 25 \\
\hline 17 & 15 & 10 & 10 & 5 & 0 & 30 & 25 & 15 & 15 & 15 & 5 & 5 & 10 & 15 & 30 & 15 \\
\hline 18 & 10 & 10 & 10 & 0 & 0 & 0 & 0 & 0 & 10 & 5 & 5 & 0 & 0 & 0 & 0 & 0 \\
\hline 19 & 5 & 5 & 0 & 0 & 0 & 0 & 0 & 0 & 5 & 10 & 0 & 0 & 0 & 0 & 0 & 0 \\
\hline 20 & 0 & 5 & 5 & 5 & 10 & 30 & 0 & 10 & 5 & 5 & 10 & 0 & 5 & 10 & 20 & 10 \\
\hline 21 & 10 & 5 & 25 & 20 & 15 & 15 & 5 & 25 & 5 & 5 & 5 & 25 & 25 & 25 & 25 & 25 \\
\hline 22 & 0 & 0 & 0 & 0 & 15 & 20 & 0 & 5 & 0 & 0 & 0 & 0 & 0 & 0 & 0 & $\begin{array}{c}20 \\
0\end{array}$ \\
\hline 23 & 5 & 15 & 15 & 15 & 20 & 25 & 25 & 10 & 5 & 10 & 10 & 15 & 35 & 40 & 30 & 15 \\
\hline 24 & 10 & 15 & 20 & 15 & 15 & 35 & 20 & 10 & 10 & 20 & 15 & 15 & 20 & 35 & 25 & 15 \\
\hline
\end{tabular}


$\frac{0}{4}$

\begin{tabular}{|c|c|c|c|c|c|c|c|c|c|c|c|c|c|c|c|c|}
\hline \multirow{3}{*}{ ID } & \multicolumn{16}{|c|}{ Freqüência em Hz } \\
\hline & \multicolumn{8}{|c|}{ Orelha direita } & \multicolumn{8}{|c|}{ Orelha esquerda } \\
\hline & 250 & 500 & 1000 & 2000 & 3000 & 4000 & 6000 & 8000 & 250 & 500 & 1000 & 2000 & 3000 & 4000 & 6000 & 8000 \\
\hline 25 & 15 & 15 & 5 & 0 & 0 & 15 & 5 & 15 & 5 & 5 & 0 & 0 & 5 & 15 & 15 & 15 \\
\hline 26 & 10 & 10 & 10 & 5 & 35 & 25 & 0 & 10 & 5 & 5 & 0 & 0 & 20 & 20 & 5 & 10 \\
\hline 27 & 5 & 5 & 5 & 0 & 0 & 0 & 0 & 5 & 5 & 0 & 0 & 0 & 0 & 0 & 0 & 5 \\
\hline 28 & 10 & 5 & 5 & 10 & 0 & 0 & 0 & 10 & 5 & 0 & 5 & 0 & 0 & 0 & 10 & 0 \\
\hline 29 & 5 & 5 & 5 & 0 & 5 & 15 & 10 & 5 & 0 & 5 & 5 & 0 & 0 & 0 & 20 & 5 \\
\hline 30 & 10 & 15 & 10 & 0 & 15 & 10 & 0 & 0 & 5 & 10 & 5 & 0 & 0 & 0 & 0 & 0 \\
\hline 31 & 15 & 10 & 0 & 15 & 25 & 40 & 35 & 35 & 5 & 10 & 0 & 10 & 25 & 50 & 40 & 40 \\
\hline 32 & 25 & 15 & 5 & 0 & 0 & 0 & 25 & 20 & 20 & 20 & 10 & 0 & 20 & 15 & 10 & 25 \\
\hline 33 & 10 & 10 & 0 & 0 & 0 & 0 & 0 & 0 & 5 & 10 & 5 & 0 & 0 & 15 & 0 & 0 \\
\hline 34 & 15 & 15 & 15 & 20 & 20 & 5 & 25 & 5 & 25 & 15 & 10 & 25 & 30 & 35 & 20 & 10 \\
\hline 35 & 5 & 10 & 15 & 15 & 0 & 15 & 15 & 20 & 10 & 15 & 15 & 10 & 0 & 15 & 0 & 5 \\
\hline 36 & 10 & & & 20 & 30 & 40 & 30 & 35 & 5 & 5 & 10 & 15 & 20 & 20 & 25 & 15 \\
\hline 37 & 5 & 10 & 15 & 10 & 0 & 0 & 0 & 0 & 5 & 10 & 10 & 10 & 0 & 0 & 5 & 5 \\
\hline 38 & 0 & 5 & 0 & 10 & 0 & 0 & 0 & 10 & 0 & 5 & 0 & 0 & 0 & 0 & 0 & 5 \\
\hline 39 & 10 & 10 & 5 & 10 & 5 & 5 & 0 & 5 & 5 & 5 & 10 & 5 & 0 & 0 & 0 & 5 \\
\hline 40 & 0 & 5 & 0 & 10 & 10 & 0 & 0 & 0 & 0 & 0 & 0 & 15 & 20 & 20 & 0 & 5 \\
\hline 41 & 5 & 0 & 5 & 0 & 10 & 25 & 30 & 35 & 0 & 0 & 0 & 0 & 0 & 0 & 35 & 20 \\
\hline 42 & 10 & 10 & 15 & 20 & 20 & 20 & 25 & 25 & 15 & 10 & 10 & 20 & 15 & 25 & 40 & 30 \\
\hline 43 & 5 & 10 & 5 & 0 & 0 & 0 & 0 & 0 & 0 & 5 & 0 & 0 & 0 & 0 & 0 & 10 \\
\hline 44 & 10 & 5 & 5 & 5 & 0 & 0 & 0 & 5 & 10 & 5 & 0 & 5 & 15 & 15 & 10 & 10 \\
\hline 45 & 5 & 5 & 5 & 5 & 0 & 0 & 5 & 5 & 5 & 0 & 0 & 5 & 0 & 0 & 0 & 10 \\
\hline 46 & 0 & 5 & 5 & 0 & 0 & 0 & 10 & 10 & 0 & 0 & 0 & 0 & 0 & 0 & 0 & 5 \\
\hline 47 & 5 & 10 & 5 & 15 & 20 & 20 & 25 & 25 & 25 & 25 & 15 & 15 & 25 & 40 & 15 & 15 \\
\hline 48 & 0 & 10 & 5 & 5 & 15 & 20 & 0 & 0 & 0 & 0 & 0 & 0 & 10 & 10 & 15 & 0 \\
\hline 49 & 10 & 15 & 10 & 10 & 10 & 20 & 5 & 0 & 15 & 15 & 5 & 0 & 5 & 25 & 5 & 0 \\
\hline 50 & 10 & 15 & 10 & 5 & 5 & 0 & 0 & 5 & 10 & 15 & 10 & 0 & 5 & 0 & 10 & 5 \\
\hline 51 & 10 & 15 & 10 & 10 & 15 & 15 & 15 & 15 & 10 & 10 & 5 & 10 & 10 & 15 & 15 & 10 \\
\hline
\end{tabular}


$\frac{1}{4}$

Freqüência em Hz

\begin{tabular}{|c|c|c|c|c|c|c|c|c|c|c|c|c|c|c|c|c|}
\hline \multirow{3}{*}{ ID } & \\
\hline & & & & \multicolumn{4}{|c|}{ Orelha direita } & & \multicolumn{8}{|c|}{ Orelha esquerda } \\
\hline & 250 & 500 & 1000 & 2000 & 3000 & 4000 & 6000 & 8000 & 250 & 500 & 1000 & 2000 & 3000 & 4000 & 6000 & 8000 \\
\hline 52 & 0 & 5 & 0 & 0 & 0 & 0 & 0 & 0 & 0 & 5 & 0 & 0 & 0 & 0 & 0 & 0 \\
\hline 53 & 10 & 5 & 5 & 0 & 0 & 0 & 20 & 10 & 15 & 5 & 5 & 0 & 0 & 0 & 5 & 0 \\
\hline 54 & 10 & 5 & 5 & 0 & 5 & 10 & 25 & 20 & 10 & 5 & 5 & 0 & 0 & 25 & 15 & 15 \\
\hline 55 & 10 & 10 & 15 & 15 & 0 & 0 & 20 & 5 & 15 & 10 & 15 & 10 & 5 & 0 & 15 & 0 \\
\hline 56 & 20 & 15 & 0 & 0 & 0 & 0 & 0 & 0 & 10 & 0 & 0 & 0 & 0 & 10 & 0 & 0 \\
\hline 57 & 10 & 5 & 5 & 0 & 0 & 0 & 15 & 0 & 5 & 5 & 0 & 0 & 10 & 10 & 15 & 15 \\
\hline 58 & 5 & 10 & 0 & 0 & 0 & 0 & 10 & 15 & 0 & 5 & 0 & 0 & 0 & 0 & 40 & 5 \\
\hline 59 & 10 & 5 & 0 & 15 & 15 & 5 & 0 & 10 & 15 & 5 & 0 & 15 & 10 & 0 & 15 & 10 \\
\hline 60 & 0 & 0 & 5 & 0 & 0 & 15 & 0 & 0 & 0 & 5 & 0 & 0 & 10 & 20 & 10 & 5 \\
\hline 61 & 0 & 0 & 5 & 10 & 10 & 15 & 0 & 0 & 0 & 0 & 0 & 0 & 5 & 0 & 0 & 0 \\
\hline 62 & 5 & 5 & 0 & 0 & 0 & 0 & 25 & 0 & 0 & 0 & 0 & 0 & 20 & 20 & 15 & 20 \\
\hline 63 & 10 & 20 & 25 & 15 & 15 & 15 & 25 & 15 & 10 & 20 & 20 & 15 & 15 & 10 & 0 & 20 \\
\hline 64 & 10 & 10 & 5 & 0 & 0 & 0 & 0 & 5 & 5 & 10 & 5 & 0 & 0 & 0 & 0 & 0 \\
\hline 65 & 10 & 5 & 0 & 0 & 20 & 45 & 25 & 25 & 10 & 5 & 5 & 10 & 50 & 50 & 50 & 35 \\
\hline 66 & 15 & 10 & 0 & 0 & 20 & 20 & 25 & 25 & 20 & 15 & 5 & 5 & 25 & 25 & 15 & 25 \\
\hline 67 & 0 & 5 & 10 & 0 & 0 & 0 & 0 & 0 & 0 & 0 & 15 & 0 & 0 & 0 & 0 & 5 \\
\hline 68 & 15 & 5 & 10 & 0 & 5 & 0 & 0 & 15 & 5 & 5 & 0 & 0 & 0 & 0 & 0 & 10 \\
\hline 69 & 15 & 10 & 5 & 0 & 0 & 0 & 0 & 10 & 10 & 10 & 0 & 0 & 0 & 15 & 0 & 0 \\
\hline 70 & 10 & 5 & 5 & 5 & 0 & 0 & 0 & 0 & 0 & 0 & 0 & 0 & 0 & 0 & 0 & 0 \\
\hline 71 & 5 & 5 & 5 & 5 & 5 & 5 & 5 & 5 & 5 & 5 & 5 & 0 & 0 & 10 & 0 & 0 \\
\hline 72 & 5 & 0 & 0 & 0 & 0 & 20 & 20 & 5 & 5 & 0 & 0 & 0 & 0 & 15 & 15 & 5 \\
\hline 73 & 25 & 25 & 25 & 10 & 0 & 15 & 0 & 0 & 15 & 25 & 20 & 10 & 0 & 15 & 15 & 15 \\
\hline 74 & 5 & 5 & 0 & 0 & 0 & 0 & 15 & 5 & 5 & 5 & 5 & 0 & 0 & 0 & 20 & 5 \\
\hline
\end{tabular}

